Universidad Politécnica de Valencia

Departamento de Producción Vegetal

\title{
El tiempo de permanencia del fruto en el árbol y su relación con la floración en los cítricos.
}

Tesis Doctoral

Amparo Martínez Fuentes

Director

Prof. Manuel Agustí Fonfría

Valencia, junio 2010 

D. Manuel Agustí Fonfría, Dr. Ingeniero Agrónomo, Catedrático de Universidad del Departamento de Producción Vegetal de la Universidad Politécnica de Valencia

\section{Expone:}

Que la presente Tesis Doctoral 'El papel regulador del fruto en la floración de los cítricos', realizada por la Ingeniera Agrónoma Amparo Martínez Fuentes para optar al grado de Doctora, se ha llevado a cabo bajo mi dirección en el Departamento de Producción Vegetal de la Universidad Politécnica de Valencia, y por la presente

\section{Autoriza:}

La presentación de la memoria adjunta a los efectos académicos oportunos.

En Valencia, 10 de junio de 2010 

A mis padres

A Rafa 



\section{Agradecimientos}

A mi profesor, maestro y amigo Manolo Agustí, con quien empecé y descubrí esta 'carrera científica' y con el que he aprendido lo que significan las palabras esfuerzo, dedicación, entrega, compromiso, rigor, estudio, exigencia... entre otras como amistad, ilusión, ayuda desinteresada, imaginación, comprensión, confianza... y además, a hacer las cosas de un único modo posible, BIEN. Sin él, éste y muchos otros trabajos no se hubiesen completado.

A mis compañeros y amigos de esta 'carrera científica', Carmina y Carlos, sin los que no sería igual el día a día en nuestro laboratorio. A Carmina, por transmitirme en muchas ocasiones la tranquilidad necesaria y las palabras justas de apoyo y confianza. A Carlos, por su ayuda incondicional y su atención continua a cualquier cambio laboral y personal, por su 'xispa' oportuna y divertida que hace nuestro día a día más agradable.

Al resto de compañeros, con los que comparto cada día experiencias e ilusiones, como Vicent, siempre dispuesto a colaborar, sin poner excusas ni problemas. También, a todos los que han pasado por nuestro laboratorio, de éste y del otro lado del océano, y han dejado, cada uno a su manera, alguna huella. En especial a Giuli, por estar siempre pendiente de posibles avances y logros, y enviarme toda su energía a pesar de la distancia.

A esas personas, relacionadas o no con el mundo científico, que sin saberlo, me han ayudado e ilusionado con mi trabajo, me han transmitido ganas de completarlo y de superar las diferentes y difíciles etapas con las que me he encontrado.

A los propietarios y técnicos de las fincas agrícolas donde me han permitido realizar los experimentos de este trabajo.

A mi maravillosa familia, en especial a mis padres y hermanos, siempre a mi lado mostrándome su cariño, confianza y apoyo incondicional en todo lo que hago. Porque podemos compartir momentos malos y sin embargo, quedarnos sólo con los buenos. Por haberme permitido con su esfuerzo y dedicación mi desarrollo como persona, por darme la oportunidad de elegir.

A Rafa, por estar siempre a mi lado y hacer que los momentos que vivimos cada día sean especiales. Por compartir nuestras vidas y la que hemos creado juntos. Por todo lo que nos queda. 

Índice 



\section{Resúmenes}

Resumen

Abstract

1. Aspectos generales del fenómeno de alternancia en los frutales

2. Causas de la alternancia

3. La alternancia de cosechas en los cítricos 30

- $\quad$ Descripción del cultivo

- La alternancia de cosechas en los cítricos

- $\quad$ Técnicas de control de la floración

- Inhibición de la floración

- $\quad$ El estrés hídrico $\quad 38$

- Otras técnicas 38
4. Hipótesis y objetivos

3. Determinaciones analíticas 
1. Capítulo 1. Interrelaciones floración-fructificación en los cítricos. Estudio del 55 comportamiento alternante.

2. Capítulo 2. Efecto del tiempo de permanencia del fruto en el árbol sobre la floración siguiente.

3. Capítulo 3. Efecto del aislamiento parcial del fruto sobre la floración. Microrayado de la corteza del pedúnculo.

4. Capítulo 4. Estudio de la aplicación de inhibidores de la síntesis de giberelinas sobre la floración 
Resúmenes 

En esta Tesis Doctoral se estudia el comportamiento alternante de los cítricos, naranjo dulce, mandarino Clementino e híbridos, y la influencia del fruto en el mismo.

La hipótesis de trabajo es que en los cítricos el fruto inhibe la floración a través de la síntesis y exportación de giberelinas a las yemas que se hallan bajo su influencia impidiendo su brotación y alterando su diferenciación.

Nuestros resultados eliminando frutos en diferentes estados de su desarrollo indican que el fruto comienza a ejercer su acción a partir de momentos próximos a completar su desarrollo (estado 78 de la escala $\mathrm{BBCH}$ ). Desde ese momento y hasta que lo completa e inicia el cambio de color (estado 79 de la escala $\mathrm{BBCH}$; principios de noviembre), la floración del naranjo dulce cv.'Valencia' pasa de 43 flores/100 nudos a 6.9 flores/100 nudos. $Y$ desde el inicio del cambio de color hasta su completa maduración la reducción adicional observada no alcanzó la significación estadística (2.9 flores/100 nudos). Experimentos con el tangor 'Nadorcott' en los que se retrasó la época de recolección de árboles con diferente intensidad de cosecha demuestran una reducción significativa de la floración, pero el hecho de que la interacción también alcanzara la significación estadística indica que el efecto está mediado por el número de frutos.

Esta reducción de la floración resultó ser aproximadamente paralela a una reducción de la brotación, pero el número de órganos por brote (número de hojas y/o flores) no fue alterado en ningún caso, lo que indica un efecto directo del fruto sobre la yema impidiéndole brotar. El fruto, por tanto, no altera el número de flores por yema sino el número de yemas que brotan.

La modificación en el contenido en azúcares solubles y almidón derivada de la eliminación de los frutos no presenta relación convincente con los cambios en la floración. Solamente un desajuste en el metabolismo del nitrógeno provocado por la presencia del fruto se ha relacionado significativamente con la intensidad de floración.

La evolución de la concentración de las giberelinas $\mathrm{GA}_{1}$ y $\mathrm{GA}_{4}$ en la corteza del tallo que soporta el fruto en los naranjos navel indica una exportación de éstas desde el fruto que se relaciona con su acción inhibidora. En coherencia con ello, la aplicación de $\mathrm{GA}_{3}$ a partir del estado 78-BBCH inhibe significativamente la floración, y la de paclobutrazol o prohexadione$\mathrm{Ca}$, inhibidores de la síntesis de giberelinas, la promueve en todas las especies y cultivares estudiados, si bien en este caso el fruto anula la acción.

La similitud temporal y de acción de la presencia del fruto, de concentraciones elevadas de giberelinas endógenas en el floema próximo a las yemas, y de la aplicación exógena de $\mathrm{GA}_{3}$, demuestra la participación de estos fitorreguladores en la acción inhibidora del fruto sobre la floración. 

This Thesis studies alternate bearing behavior of Citrus, sweet orange, Clementine mandarin and hybrids, and the influence of fruit in the process.

The hypothesis is that, in Citrus, the fruit inhibits flowering through the synthesis of gibberellins and their transport to the buds, preventing them to sprout and altering apex differentiation into flower.

Fruit exerted its inhibitory effect from the time it was close to reaching its maximum weight, namely $80 \%$ of its final size (BBCH stage 78 ). From then until the fruit completes the growth and colour break starts (BBCH stage 79; early November) flowering intensity is reduced by 6 times, from 43 flowers $/ 100$ nodes to 6.9 flowers $/ 100$ nodes. From then to bud sprouting (April) flowering intensity does not reduce significantly (2.9 flowers/100nodes). Experiments with tangor "Nadorcott" trees with similar crop load and differing in the harvesting date showed significant reduction of flowering, but since date of harvest and crop load interactions becomes statistically significant reveals that the effect is mediated by the number of fruits per tree.

The reduction in flowering paralleled the reduction in bud sprouting. This reduction was due to a decrease in the number of generative sprouted buds, whereas mixed-typed shoots were largely independent of the time of fruit removal, and vegetative shoots increased in frequency. The number of leaves and/or flowers per sprouted shoot was not significantly modified by fruit load. Fruit, however, did not alter the number of flowers per bud but rather the number of buds that eventually sprout.

Neither soluble sugar content nor the accumulation of reserve carbohydrates seems to fulfil an inductive function, but our results show evidence that sprouting and/or flower formation may require a threshold level of carbohydrates as an energy source. Only some kind of imbalance in nitrogen metabolism was observed in trees tending to flower scarcely.

Changes in $\mathrm{GA}_{1}$ and $\mathrm{GA}_{4}$ gibberellins' concentration in the bark tissue of the shoot feeding the fruit in navel sweet orange indicate transport from the fruit to the bud, explaining its flowering inhibition effect. Further, $\mathrm{GA}_{3}$ applied from $\mathrm{BBCH}$ stage 78 to whole maturation inhibits flowering significantly, and paclobutrazol and prohexadione-Ca, two inhibitor of the gibberellins synthesis, applied at the same dates promote it in all species and cultivar studied, although the fruit avoids the action of these inhibitors.

Accordingly, fruit presence effect, high endogenous gibberellins concentrations in the bark tissues next to buds, and $\mathrm{GA}_{3}$ exogenously applied, coincide in time and way of action, what demonstrates gibberellins participate in the inhibitory effect of fruit on flowering. 

En esta Tesi Doctoral s'avalua el comportament alternant, al llarg de diversos cicles successius de cultiu, del taronger dolç cv. 'Salustiana', del tangor 'Nadorcott' i del mandariner Clementino cv. 'Hernandina'.

La hipòtesi de treball és que en els cítrics el fruit inhibix la floració a través de la síntesi i exportació de giberelinas als rovells que es troben davall la seua influència impedint la seua brotació i alterant la seua diferenciació.

Els nostres resultats eliminant fruits en diferents estats del seu desenrotllament indiquen que el fruit comença a exercir la seua acció a partir de moments pròxims a completar el seu desenrotllament (estat 78 de l'escala BBCH). Des d'eixe moment i fins que ho completa i inicia el canvi de color (estat 79 de l'escala BBCH; principis de novembre), la floració del taronger dolç cv. 'València' passa de 43 flors/100 nucs a 6.9 flors/100 nucs. I des de l'inici del canvi de color fins a la seua completa maduració la reducció addicional observada no va aconseguir la significació estadística (2.9 flors/100 nucs). Experiments amb el tangor 'Nadorcott' en els que es va retardar l'època de recollecció d'arbres amb diferent intensitat de collita demostren una reducció significativa de la floració, però el fet que la interacció també aconseguira la significació estadística indica que l'efecte està mediat pel nombre de fruits.

Esta reducció de la floració va resultar ser aproximadament paral·lela a una reducció de la brotació, però el nombre d'òrgans per brot (nombre de fulls i/o flors) no va ser alterat en cap cas, la qual cosa indica un efecte directe del fruit sobre el rovell impedint-li brollar. El fruit, per tant, no altera el nombre de flors per rovell sinó el nombre de rovells que brollen.

La modificació en el contingut en sucres solubles i midó derivada de l'eliminació dels fruits no presenta relació convincent amb els canvis en la floració. Només un desajust en el metabolisme del nitrogen provocat per la presència del fruit s'ha relacionat significativament amb la intensitat de floració.

L'evolució de la concentració de les giberelinas $\mathrm{GA}_{1}$ i $\mathrm{GA}_{4}$ en la corfa de la tija que suporta el fruit indica una exportació d'estes des del fruit que es relaciona amb la seua acció inhibidora. En coherència amb això, l'aplicació de $\mathrm{GA}_{3}$ a partir de l'estat 78-BBCH inhibix significativament la floració, i la de paclobutrazol o prohexadione-Ca, inhibidors de la síntesi de giberelinas, la promou, si bé en este últim cas el fruit anul·la l'acció.

La similitud temporal i d'acció de la presència del fruit, de concentracions elevades de giberelinas endògenes en el floema pròxim als rovells, i de l'aplicació exògena de $\mathrm{GA}_{3}$, demostra la participació d'estos fitoreguladors en l'acció inhibidora del fruit sobre la floració. 

Introducción 



\section{Introducción}

\section{Aspectos generales del fenómeno de la alternancia en los frutales}

La alternancia de cosechas supone un serio problema en el cultivo de numerosas especies frutales. Se trata de un fenómeno ampliamente extendido y que afecta tanto a plantas caducifolias como perennifolias (Davies 1957; Singh 1971).

El comportamiento alternante de un árbol supone una producción irregular a lo largo de los ciclos productivos. Cosechas muy abundantes son seguidas de cosechas escasas y viceversa. Los años de cosechas elevadas, se denominan 'años on' y los de cosechas escasas 'años off. Se trata de un aspecto desfavorable en ambos casos. Cuando las producciones son escasas, los frutos son de tamaño excesivo y baja calidad comercial, mientras que cuando las producciones son elevadas el excesivo número de frutos que llega a desarrollarse no alcanza un tamaño adecuado comercialmente. Las ramas individuales llegan a comportarse, también, como entidades autónomas en relación a la alternancia. Un estudio detallado de este último aspecto en cultivares alternantes de Prunus domestica se llevó a cabo por Couranjou (1978) demostrándose que la autonomía se incrementaba con el tamaño de la rama.

El término 'comportamiento bianual' puede utilizarse en el mismo sentido que 'comportamiento alternante' pero, la alternancia de cosechas no implica estrictamente un modelo bianual regular, uno, dos o más años on pueden ser seguidos por uno o varios años off.

El comportamiento alternante puede iniciarse de dos modos distintos. El primero aparece de forma gradual y está relacionado con el incremento progresivo de la producción durante los primeros años de producción de la planta. El segundo surge como consecuencia de alguna situación de estrés ambiental. Este es más frecuente que el anterior y aparece de forma generalizada en toda una zona de cultivo. Este caso incluye el efecto de las heladas primaverales en árboles caducifolios o de un estrés hídrico durante el cuajado en zonas templadas; la intensidad del comportamiento alternante que se desarrolla depende de la severidad de las condiciones ambientales que se den, ya sean favorables o desfavorables para el proceso de floración o cuajado (Lavee, 1996).

En las especies con comportamiento alternante las flores no se forman en las ramas en las que se desarrollaron frutos en el ciclo anterior (Plummer et al. 1989; Nielsen y Dennis 1998; Dennis y Nielsen, 1999), por lo que tras un año de producción intensa se limita el número de puntos potenciales para el desarrollo de flores. 
La alternancia de cosechas es un fenómeno común en todas las especies frutales, si bien la intensidad con que la sufren es variable con ellas. De entre las especies de mayor valor frutícola, las que están sujetas a un comportamiento alternante más intenso se muestran en la siguiente tabla. En ella se indica también las fuentes bibliográficas más importantes al respecto para una más completa información.

\begin{tabular}{|c|c|c|c|}
\hline Familia & Especie & Nombre común & Fuente \\
\hline \multirow[t]{2}{*}{ Anacardiaceae } & Magnifera indica & Mango & Singh 1971 \\
\hline & Pistacia vera & Pistacho & Crane y Nelson 1971 \\
\hline Corylaceae & Corylus avellana & avellano & Gardner 1966 \\
\hline Ericaceae & Vaccinium macrocarpon & Arándano & Eaton 1978 \\
\hline Euphorbiaceae & Aleurites fordii & Tung & Potter et al., 1947 \\
\hline \multirow[t]{2}{*}{ Juglandaceae } & Carya illinoensis & Nuez pecán & Worley 1971 \\
\hline & Juglans ssp. & nuez & \\
\hline Lauraceae & Persea americana & Aguacate & Chandler 1950 \\
\hline Oleaceae & Olea europae & Olivo & Morettini 1950 \\
\hline \multirow[t]{4}{*}{ Rosaceae } & Malus sylvestris & Manzano & Jonkers 1979 \\
\hline & Pyrus communis & Peral & Jonkers 1979 \\
\hline & Prunus domestica & Ciruelo & Couranjou 1970 \\
\hline & Prunus armeniaca & Melocotonero & Fisher 1951 \\
\hline Rubiaceae & Coffea arabica & Café & Chandler 1950 \\
\hline \multirow[t]{4}{*}{ Rutaceae } & Citrus sinensis & Naranjo & West y Barnard 1935 \\
\hline & Citrus reticulata & Mandarino & Jones et al., 1975 \\
\hline & Hibridos & Tangor Murcott & Stewart et al., 1968 \\
\hline & Citrus unshiu & Satsuma & Iwasaki et al., 1962 \\
\hline \multirow[t]{2}{*}{ Sapindaceae } & Litchi sinensis & Litchi & Chandler 1950 \\
\hline & Euphoria longana & Longan & Olszack 1986 \\
\hline Arecaceae & Phoenix dactylifera & Palmera & Pillary et al., 2005 \\
\hline
\end{tabular}




\begin{tabular}{|llll|}
\hline Myrtaceae & Psidium cattleianum & Guayava fresa & Normand y Habib \\
& & 2001 & \\
\hline Ebenaceae & Diospyrus kaki & caqui & Ojima 1985 \\
\hline Proteaceae & Macadamia integrifolia & Macadamia & Thompson 1993 \\
& & & \\
\hline
\end{tabular}

Entre cultivares de una misma especie se aprecian diferencias notables en cuanto a su comportamiento alternante, como es el caso del manzano y el peral (Westwood, 1978; Jonkers, 1979). Éste puede variar de unas áreas a otras, así los cvs. 'Golden Delicious' y 'Yellow transparent' fueron considerados como alternantes por Westwood (1978) y como no alternantes por Jonkers (1979), y en Israel, Gur y colaboradores (1969) consideraron al cv.'Delicious' con un fuerte comportamiento 'biannual', pero con tendencia a disminuir con la distancia entre zonas de cultivo. En los cítricos, algunos cultivares de naranjo dulce, pomelo y limón no presentan comportamiento alternante. Otros, como el cv. 'Valencia', bajo ciertas condiciones ambientales, como climas extremos o semi-áridos, se comportan como alternantes (Moss et al. 1981). Cultivares de mandarina e híbridos, como 'Wilking', 'Kinnow', 'Murcott' y 'Michal', son, de forma general, intensamente alternantes.

Las diferencias en el comportamiento alternante de las especies frutales, dentro de un mismo cultivar, no se conocen bien. Algunos autores (Monselise y Goldschmidt, 1982) intentan explicar estas diferencias considerando la localización de las yemas de flor (ramos de mayo vs ramos mixtos o chifonas) o la necesidad de polinización cruzada, otros las atribuyen a diferentes respuestas ante situaciones de estrés climático, a la capacidad para compensar la baja formación de flores con un alto índice de cuajado, a la mejor eficiencia de auto-polinización...

En los frutales no cítricos raramente se considera el fenómeno de la alternancia directamente inducido por el patrón. Así, en el aguacate no se encontraron diferencias en el comportamiento alternante de cuatro cultivares cultivados sobre diferentes patrones (Ben-Yaakov et al., 1991). Sin embargo, la utilización de patrones enanizantes en el manzano redujo el comportamiento alternante de algunas variedades (Jonkers, 1979).

El efecto de la edad del árbol presenta resultados contradictorios, y generalmente no uniformes, dentro de un mismo cultivar, cuando se consideran diferentes zonas de cultivo. Ciertos cultivares de manzano presentan una alternancia más intensa en edades juveniles que cuando son adultos (Jonkers, 1979), a pesar de que generalmente, en esta especie la alternancia se acentúa con la edad, posiblemente por el incremento en la proporción de frutos desarrollados en ramos de mayo (Gur, 1976). En el mango, la alternancia también se incrementa con la edad (Singh y Khan, 
1940). Algunos cultivares de aguacate, como 'Anaheim' y 'Ettinger', presentan un comportamiento alternante creciente con la edad, mientras que otros intensamente alternantes, como 'Nabal' y 'Hass', no presentan diferencias a lo largo de los años (Ben-Yaakov et al., 1991). Los árboles de nuez pecán o pistachero no muestran alternancia hasta el décimo año (Sparks, 1975; Crane y Forde, 1976). En los cítricos, generalmente, la alternancia se considera como una señal de juvenilidad (Monselise y Goldschmidt, 1982).

\section{Causas de alternancia}

\section{Factores exógenos}

Las condiciones ambientales pueden iniciar el fenómeno de alternancia de cosechas; sin embargo, una vez iniciado, son los factores endógenos los que controlan el comportamiento cíclico entre años on y off. Ciertas situaciones de estrés ambiental, como las heladas, temperaturas excesivamente cálidas o una baja humedad ambiental, pueden iniciar el comportamiento alternante de los árboles.

En el manzano, las heladas primaverales, pueden iniciar los ciclos de alternancia en los cultivares sensibles al frío (Williams y Edgerton, 1974). La práctica anulación de la cosecha provocada por ellas favorece una floración intensa el año siguiente, aumentando la cosecha e iniciando este fenómeno.

Las bajas temperaturas también pueden actuar de forma indirecta, anticipando la caída de las hojas en otoño y alterando, de este modo, el contenido en reservas, almacenadas (Sparks, 1975) o afectando la actividad de los polinizadores y/o el propio proceso del cuajado (Moss et al.,1981). Dificultades similares con efecto de las altas temperaturas son las responsables de una cosecha final escasa en los cítricos, el aguacate y el mango (Moss, 1974; Gardner, 1966; Bhandwalkar y y Desai, 1995).

La baja humedad ambiental afecta la producción de diferentes cultivos ya que provoca una caída masiva de frutos en desarrollo. Es frecuente en el olivo (Morettini, 1950), cítricos (Agustí, 2003), y probablemente la mayoría de los frutales cultivados en climas templados y secos. En el aguacate, además, la baja humedad ambiental provoca una baja germinación del polen por deshidratación del estigma (Gardner, 1966). En la nuez pecán, se puede promover la caída de 
hojas y causar, indirectamente, una importante caída prematura de frutos (Davis y Sparks, 1974; Sparks, 1975).

Otros tipos de estrés, como la falta de disponibilidad de agua, la asfixia radicular, la salinidad, plagas o enfermedades... pueden provocar reducciones intensas de la cosecha y disparan el inicio de ciclos de alternancia.

\section{Factores endógenos.}

En el origen de la alternancia de cosechas se encuentran las hormonas vegetales. El papel de los reguladores del desarrollo en la reducción de la formación de yemas de flor después de un año on se ha estudiado para diferentes especies frutales.

Las citoquininas son necesarias para el desarrollo de los órganos reproductivos. En experimentos realizados con segmentos de tallo Mullins y Rajasekaran (1981) demostraron que los primordios vegetativos son sumideros más potentes de citoquininas que los primordios florales, y que una limitación en la disponibilidad de citoquininas significaría una reducción en el desarrollo de yemas reproductivas. Aún más, descensos en los niveles de citoquininas causan la caída de racimos (Mullins 1980). La importancia de este tipo de hormonas fue demostrada, además, mediante aplicaciones exógenas a tallos sin raíces. Otros autores, sin embargo, no han encontrado este efecto de las citoquininas sobre la formación de yemas reproductivas de olivo (Badr y Hartman 1972).

El ácido abscísico puede reducir la intensidad de floración mediante la reducción del desarrollo de inflorescencias sin hojas en los cítricos (Davenport 1990), aunque no se ha encontrado una relación directa entre el contenido endógeno de ácido abscísico y algunas de las condiciones inductoras de la floración, como el estrés hídrico y las bajas temperaturas (Southwick y Davenport 1986). Sin embargo, los frutos cítricos contienen gran cantidad de ácido abscísico (Tanaka et al. 2004; Harris y Dugger 1986) y, las yemas de árboles on, es decir, los que van a florecer poco, contienen mayor cantidad de ácido abscísico que las de los árboles off (Jones et al. 1976), implicando a ésta fitohormona en el proceso de alternancia.

A pesar de esto, el que aplicaciones tempranas de ácido abscísico no retrasen la brotación y sólo prolonguen la dormición de las yemas cuando se realizan inmediatamente antes de la brotación natural, es decir, cuando el efecto inhibidor del fruto sobre la floración ya se ha completado, impide atribuir a esta sustancia un papel regulador de la floración (García-Luis et al. 1986). 
Niveles más elevados de ácido indolacético se encontraron en hojas de mandarino durante el año off (Epstein, 1981). Sin embargo, Verreynne y Lovatt (2009) encontraron niveles más elevados de ácido indolacético en las yemas de árboles de mandarino 'Pixie' en año on, que en las yemas de árboles en año off. Asimismo, se consiguió incrementar la floración en plantones de pomelo mediante la aplicación de un inhibidor del transporte de auxinas, el TIBA (Kessler, 1959). Todo ello sugiere que el ácido indolacético puede influir en el proceso de floración directa o indirectamente, aunque su efecto concreto todavía es incierto (Okuda, 2000).

En el manzano, las auxinas producidas en las semillas se desplazan desde éstas a las inflorescencias (Luckwill, 1957; Grochowska, 1968). Este movimiento es más intenso en un cultivar bianual o alternante de manzano, como el 'Laxton Superb', que en otros de comportamiento regular, como el 'Cox Orange Pippin' (Hoad, 1978). Además, se han observado niveles más bajos de auxinas en los brotes en los que se diferencian flores durante el año off que en los que no las diferencian (Grochowska, 1964).

En la mayoría de frutales caducifolios, el inicio del desarrollo del fruto coincide con el periodo de inducción floral, observándose una relación directa e inversa entre los frutos en desarrollo y las flores formadas (Lavee, 1996; Bubán y Faust, 1982). Por otro lado, si la polinización es intensa, los frutos contienen un gran número de semillas. En el manzano (Bubán y Faust, 1982) y en el pistachero (Crane et al., 1973) se ha demostrado el papel de éstas en la inhibición de la producción de yemas reproductivas. Además, la presencia de semillas, generalmente, mejora la persistencia del fruto en el árbol, evitando su caída, lo que se debe a un incremento en la producción de reguladores del desarrollo y, con ello, a una más intensa actividad sumidero de los frutos (Monselise y Goldschmidt, 1982). Este efecto de las semillas fue demostrado en cultivares de fecundación libre y partenocárpicos de manzano (Chan y Cain, 1967) y de peral (Huet, 1972), en los que se observaban diferencias en las formación de yemas reproductivas.

De entre todas las hormonas vegetales, las giberelinas son las más influyentes sobre el proceso de floración (Pharis y King, 1985; Okuda, 2000) ya que: (1) la aplicación de ácido giberélico reduce la floración, especialmente las inflorescencias sin hojas (Monselise y Halevy, 1964; Davenport, 1983; Guardiola et al., 1977), (2) la actividad de las giberelinas se correlaciona positivamente con el efecto del fruto sobre la floración siguiente (Goren y Goldschmidt, 1970; Erner et al., 1976; García-Luis et al., 1986) y (3) existe actividad de las giberelinas en los tejidos vasculares de los brotes alternantes (Saidha et al., 1983).

La aplicación exógena de ácido giberelico reduce la floración en frutales perennifolios y caducifolios (Kachru et al., 1971; Monselise y Halevy, 1964; Gonzalez-Rossia et al., 2006; 2007), si bien, el momento óptimo de aplicación varía con la especie. En el olivo, las aplicaciones de ácido 
giberélico en verano u otoño reducen la floración, mientras que en la vid el momento adecuado de aplicación es en primavera (Lavee et al., 1981). En ciruelos (Gonzalez-Rossia et al., 2006), melocotoneros (Gonzalez-Rossia et al., 2007) y manzanos (Looney et al., 1985) las aplicaciones al inicio del verano reducen significativamente la formación de yemas de flor.

Las giberelinas producidas en las semillas (Luckwill 1974; Hoad 1978) y traslocadas hacia el resto de la planta actúan como inhibidoras del desarrollo de flores. De hecho, aplicaciones exógenas de inhibidores de las citoquininas como chlormequat o daminozide incrementaron el desarrollo de yemas de flor en cítricos (Monselise y Halevy 1964; Nir et al. 1972) y en el manzano (Luckwill 1970, 1974). Al igual que ocurre con las auxinas, se difunden desde el fruto, en mayor cuantía, en los cultivares alternantes de manzano que en los cultivares de comportamiento regular (Hoad 1978; Ebert y Bangerth 1981; Callejas y Bangerth, 1997).

La importancia de la presencia de hojas para el desarrollo de yemas reproductivas se ha demostrado en diferentes especies frutales como el mango (Reece et al. 1949), el manzano (Harley et al. 1932), el olivo (Hackett y Hartmann 1964), el níspero (Fatta del Bosco 1961) y los cítricos (Ayalon y Monselise 1960) y puede entenderse desde el punto de vista hormonal y nutricional.

El esfuerzo energético que un árbol realiza para completar su actividad productiva durante un ciclo de producción, supone un agotamiento de las reservas en carbohidratos (Goldschmidt y Golomb, 1982) y elementos minerales (Golomb y Golsdchmidt, 1981). En pistacheros en año off se acumulan cantidades superiores de nitrógeno, fósforo y potasio que durante el año on (Rosencrace et al. 1998).

El rayado de ramas incrementa el desarrollo de yemas de flor en diferentes especies frutales, como el aguacate (Lahav et al., 1971), el olivo (Lavee et al., 1983; Ben-Tal y Lavee, 1984, 1985), el níspero (Reig et al., en preparación) y los cítricos (Agustí et al. 1992). Esta técnica provoca la interrupción del transporte floemático, incrementando la disponibilidad de carbohidratos (Wallerstein et al., 1973; 1974) y modificando el balance hormonal en las yemas (Wallerstein et al., 1978). A pesar de ello, en el olivo (Stutte y Martin 1986), pistachero (Crane et al. 1976), melocotonero (Reig et al. 2006) y cítricos (García-Luis et al., 1995) los carbohidratos no son un factor determinante en la inducción floral. En estos últimos, se ha señalado la necesidad de un nivel umbral mínimo para que la diferenciación de flores tenga lugar (García-Luis et al., 1995; Goldschmidt, 1999). 


\section{La alternancia de cosechas en los cítricos}

\section{Descripción del cultivo}

Los cítricos, como otras especies leñosas, son plantas policárpicas que experimentan ciclos continuos de floración y fructificación (Spiegel-Roy y Goldschmidt, 1996). Estas especies mantienen un cierto balance entre el crecimiento vegetativo y el reproductivo, de modo que cada año sólo transforman un porcentaje de los meristemos en flores, mientras el resto continúan el crecimiento vegetativo para asegurar el futuro de la planta (Goldschmidt y Monselise, 1970).

En climas subtropicales, los cítricos presentan de una a tres brotaciones al año. De ellas, es la brotación de primavera la que proporciona flores útiles, mientras que las brotaciones de verano y otoño, dan brotes vegetativos, de modo que generan nuevos puntos de brotación (nudos) para la siguiente estación (Krajewski y Rabe, 1995; Gravina, 1999).

La brotación de primavera se presenta sobre ramas desarrolladas el año anterior (Agustí y Almela, 1991) siendo la brotación más joven, esto es, la del otoño anterior, la que aporta mayor número de flores, seguida de la de verano y esta, a su vez, de la de la primavera anterior, y así sucesivamente, de tal modo que sólo ocasionalmente existe desarrollo de yemas adventicias o latentes de mayor edad.

La distribución de la floración en tipos de brotes es idéntica para todas las especies y variedades de agrios cultivados, pero presentan diferencias cuantitativas. En el naranjo dulce el $50 \%$, aproximadamente, está constituido por brotes mixtos, el $25 \%$ por ramos de flor; las flores solitarias y los brotes vegetativos se encuentran en una proporción de un 10\%, aproximadamente, cada uno, y el $5 \%$ restante corresponde a brotes campaneros (Guardiola et al., 1977). En el mandarino Clementino e híbridos, son las flores solitarias los brotes más abundantes (50\%), seguidos de los brotes campaneros $(20 \%)$, el resto de los brotes se reparten por partes iguales (10\%). El mandarino Satsuma solo tienen brotes uniflorales, con hojas (35\%) o sin hojas $(25 \%)$ y vegetativos (40\%) (Agustí, 2003).

En los cítricos, el número de flores formadas depende de factores endógenos (genéticos y hormonales) y exógenos (temperatura y fotoperiodo). De acuerdo con los conocimientos actuales, todas las yemas de un árbol tienen la información suficiente para brotar y florecer; si no lo hacen es por la existencia de factores inhibidores que impiden su desarrollo como flores (Goldschmidt et al., 1997; Martínez-Fuentes et al., 2004). 
Tres factores independientes, al menos, controlan la formación de las flores en cítricos (García-Luís y Guardiola, 2000): a) un cambio en la sensibilidad de las yemas a las señales medioambientales; b) la acción inhibidora del fruto, probablemente a través de un mecanismo hormonal (GAs?) pero independientemente de los niveles de carbohidratos en las hojas, y que tiene lugar antes del periodo inductivo; y c) los carbohidratos, cuyo posible papel en la floración es el de fuente de energía para la brotación y la iniciación floral.

Estos factores han sido estudiados tratando de explicar el desarrollo del proceso floracional, dividido en dos etapas bien definidas: inducción floral y diferenciación. Se entiende por inducción floral el proceso a través del cual las yemas vegetativas son promovidas a florecer (Davenport 1990). En condiciones subtropicales, la floración ocurre principalmente durante la primavera, después de que las bajas temperaturas del invierno causen la inactividad de la yema mientras la inducen a florecer (Reuther et al., 1973), y el grado de inducción se ha mostrado proporcional a la severidad y a la duración del factor inductivo (Southwick y Davenport, 1986). Una vez inducidas las yemas, su liberación del estrés por un aumento de las temperaturas primaverales desencadena el inicio del crecimiento reproductivo (Cassin et al., 1969). La diferenciación floral es la transición morfológica y anatómica de los meristemos vegetativos a meristemos florales (Davenport, 1990). Durante este proceso, las altas temperaturas acortan el periodo de desarrollo y adelantan la fecha de antesis (Valiente y Albrigo, 2000).

En general, la acumulación de horas frío aumenta la brotación y el número de flores por nudo (Poerwanto y Inoue, 1990), de modo que con el aumento de la acumulación de frío aumenta el número de las yemas que cambian de vegetativas a reproductivas (Moss, 1969).

El estrés hídrico también se ha mostrado como factor inductor de la floración. La biosíntesis de citoquininas principalmente se realiza en órganos en crecimiento, como las raíces, de modo que aquellas condiciones que promuevan la inactividad radicular reducirán la síntesis hormonal que tiene lugar en las raíces y el transporte de dichas hormonas a la copa. Esto explica la necesidad de bajas temperaturas en climas templados para que se produzca la floración (Goldschmidt et al., 1985) y de periodos de sequía en las regiones con climas tropicales.

La floración en los cítricos, podría estar inducida por la longitud de los días cortos del invierno. Sin embargo, éstos por sí mismos son insuficientes para inducir la floración. Así, se ha comprobado que plantas que crecen a altas temperaturas sólo producen brotes vegetativos, con independencia de la longitud del día, mientras que plantas cultivadas a baja temperatura florecen tanto en condiciones de día corto como de día largo (Reuther, 1973). Moss (1969) ya demostró que para bajas temperaturas $\left(15^{\circ} \mathrm{C}\right.$ día $/ 5^{\circ} \mathrm{C}$ noche) la floración del naranjo dulce es independiente del fotoperiodo. 
Por otro lado, el estudio de la expresión de genes relacionados con el proceso de floración aporta información adicional. El análisis genético de Arabidopsis demuestra que los genes CONSTANS (CO) Y FLOWERING LOCUS T (FT) están involucrados en la inducción de la floración por el fotoperíodo (Koorneef et al., 1991). Otro factor importante en el control de la floración es la exposición a bajas temperaturas durante cierto tiempo. Sin exposición a una temperatura baja el FLOWERING LOCUS C (FLC) reprime la floración actuando sobre los activadores de la floración (Michels et al., 2005). Por el contrario, la expresión del FLC se reduce por la exposición a una baja temperatura, y, consecuentemente, se induce la expresión de genes activadores de la floración (Henderson y Dean, 2004; Amasino, 2005).

En el naranjo dulce, Pillitteri et al. (2004) encontraron que la acumulación de transcritos de CsTFL, un homólogo del TERMINAL FLOWER 1 (TFL1) en los cítricos, se correlacionaba positivamente con la juvenilidad y negativamente con la expresión de los homólogos de LEAFY (LFY) y APETALA (AP1) en este género. En los citranges (híbridos de $C$. sinensis $\times$ Poncirus trifoliata) la expresión constitutiva de los genes LFY o AP1 de Arabidopsis, redujo notablemente el periodo de juvenilidad (Peña et al., 2001). Endo y colaboradores (2005), obtuvieron un Poncirus trifoliata transgénico, en el cual un homólogo del FT, CiFT1, derivado del mandarino Satsuma, fue expresado constitutivamente. La planta transformada mostró una floración extraordinariamente precoz. Estos resultados indican que FT, LFY y AP1, son genes promotores clave de la floración en Arabidopsis, y podrían regular la transición de la fase juvenil a la adulta en los cítricos. Más recientemente Nishikawa et al. (2007) mostraron que la expresión del homologo del FT en los cítricos, $\mathrm{Ci} \mathrm{FT}$, presentaba un incremento estacional durante el periodo de inducción floral y también era inducido por un tratamiento artificial con baja temperatura $\left(15^{\circ} \mathrm{C}\right)$, que, a su vez, promovía la floración. Además, se observó que la expresión de TFL1, LFY y AP1, no mostraron ninguna correlación con la inducción floral, tanto en el campo como en condiciones de baja temperatura artificial. En la actualidad no se han identificado ningún gen que regule de manera específica la alternancia de cosechas (Goldschmidt, 2005).

Sagee y Lovatt (1991) estudiando el contenido en poliaminas del naranjo 'Washington' navel observaron que las flores apicales de las inflorescencias presentaban mayores concentraciones de $\mathrm{NH}_{3}-\mathrm{NH}_{4}{ }^{+}$, arginina, putrescina y espermidina, y que su concentración se reducía paralelamente al desarrollo de la flor hasta la caída de pétalos. Del mismo modo, el contenido en $\mathrm{NH}_{3}-\mathrm{NH}_{4}{ }^{+}$de las flores disminuyó durante las 4 semanas previas a la antesis paralelamente a su disminución foliar. Estos resultados permitieron establecer que las hojas y las flores sufren cambios conjuntos en el metabolismo del nitrógeno durante el proceso de ontogenia de la flor. Asimismo, durante el proceso de biosíntesis de novo de arginina y de putrescina sus niveles cambiaban paralelamente con los contenidos florales de $\mathrm{NH}_{3}-\mathrm{NH}_{4}{ }^{+}$, lo que sugiere que estos compuestos se encuentran 
metabólicamente ligados. Finalmente, el estímulo floracional logrado con el estrés térmico en el naranjo dulce 'Washington navel' y con el estrés hídrico en el limón 'Lisbon' fue proporcional la acumulación de ión amonio en las hojas (Lovatt et al., 1988a). Alteraciones en la reducción de $\mathrm{NH}_{3}$ $\mathrm{NH}_{4}{ }^{+}$y su relación con la floración se han demostrado no solo en los cítricos (Monselise et al., 1981), sino también en el melocotonero como respuesta a la presencia del fruto (Reig et al., 2006). Es más, en el melocotonero, la concentración $\mathrm{NH}_{3}-\mathrm{NH}_{4}{ }^{+}$aumentó con la acumulación de horas frío en la corteza de segmentos de tallo con yemas cultivados in vitro (Gonzalez-Rossia et al., 2008).

En resumen, el amonio es precursor de la biosíntesis de novo de arginina, aminoácido precursor, a su vez, de las poliaminas en su ruta de síntesis y las poliaminas han demostrado ser compuestos promotores de la floración (Lovatt et al., 1988a, 1988b), tanto en etapas de inducción (Ali y Lovatt 1995), como de ontogenia floracional (Sagee y Lovatt, 1991). Aplicaciones exógenas del aminoácido arginina y de las poliaminas espermina, espermidina y putrescina, en época de inducción floral al mandarino Clementino cv. 'Hernandina' a una concentración de $100 \mathrm{mg} \mathrm{l}^{-1}$, no provocó, sin embargo, ninguna respuesta en la floración (Arias, 1999).

Por el contrario, aplicaciones de ácido giberélico entre mediados de septiembre y hasta el momento de la brotación, inhiben la floración del naranjo dulce y de los mandarinos Satsuma y Clementino (Monselise y Halevy, 1964; Guardiola et al., 1977; 1982). Estas aplicaciones exógenas de giberelinas disminuyen los niveles de floración mediante la modificación del balance hormonal endógeno, como lo demuestra la aplicación de paclobutrazol, un inhibidor de la síntesis de giberelinas, aumentando la floración (Martínez-Fuentes et al. 2004).

Un aspecto de interés se presenta al eliminar los frutos y realizar aplicaciones de ácido giberélico. En estos casos se ha observado una intensidad de floración similar a la encontrada en los árboles con fruto, lo que demuestra que las giberelinas exógenas pueden sustituir el efecto inhibitorio del fruto (Goldschmidt y Monselise, 1972). Las giberelinas, por tanto, son parte del mecanismo de control de la floración de los cítricos (Goldschmidt y Monselise, 1970; Guardiola et al., 1982).

El fruto inhibe la formación de flores, de modo que la intensidad de la floración se halla inversamente relacionada con el número de frutos de la cosecha anterior (Becerra y Guardiola, 1984; Rivas et al., 2004) y se reduce si se retrasa la recolección (Agustí y Almela 1984; García-Luís et al., 1986). Se ha sugerido que la presencia del fruto podría reducir la sensibilidad de las yemas a las condiciones inductivas, o incrementar la exigencia en condiciones inductivas de la floración (Albrigo y Saúco, 2004). Por otra parte, el contenido en giberelinas es mayor en las hojas de brotes con frutos que en hojas de brotes sin frutos (Koshita et al., 1999). 
Estudios realizados en mandarino Satsuma han demostrado una correlación positiva entre la intensidad de brotación y la de floración. En términos absolutos la distribución de la brotación afectó principalmente a los brotes florales, mientras que los brotes vegetativos se mantenían prácticamente constantes en su número (García-Luís et al., 1986).

El efecto inhibitorio de los frutos sobre la brotación y sobre el desarrollo vegetativo y reproductivo parece estar relacionado con cambios hormonales y por competencia por carbohidratos (Goldschmidt et al., 1985; Valiente y Albrigo, 2004). Giberelinas y carbohidratos actúan, por tanto, como factores reguladores independientes de la floración (Erner, 1988).

Este efecto depresivo de la presencia del fruto sobre la floración puede llegar a afectar la cosecha siguiente. En estos casos, la floración al año siguiente de una cosecha elevada puede ser prácticamente nula. Ante la ausencia de frutos que ello comporta, y dado el papel de éste en el control de la floración, la floración siguiente aumenta sensiblemente iniciándose lo que se denomina alternancia de cosechas.

\section{La alternancia de cosechas en los cítricos.}

Diferentes grados de alternancia pueden encontrarse en las especies de cítricos. De forma general, los cultivares sin semillas de naranjo dulce, pomelo y limón (excepto el mandarino 'Satsuma') tienen un comportamiento regular. Algunos de éstos, sin embargo, pueden alternar en cierto modo, cuando se desarrollan en determinadas condiciones de cultivo, como son los casos del naranjo dulce cv. 'Valencia' cultivado en California o en zonas frías de Australia (Jones et al. 1976), el cv. 'Shamouti' en zonas semi-áridas y suelos pesados de Israel (Goren y Monselise, 1969), el cv. 'Washington navel' (Goren y Monselise, 1971) o el pomelo 'Marsh' recolectado con retraso en Cuba (Betancourt et al., 2008)

La alternancia es un fenómeno común en algunas mandarinas. Se trata de híbridos de Citrus reticulata con Citrus sinensis (tangors) o Citrus paradisi (tangelos), que normalmente tienen semillas. En muchos casos la alternancia puede llegar a ser tan intensa que se alcance el colapso de los árboles después de cosechas extremadamente abundantes (Monselise y Goldschmidt, 1982).

La capacidad de evitar la caída masiva de frutos durante el cuajado y de producir cosechas moderadas y regulares, a lo largo de los años, parece una característica determinante de los cultivares no-alternantes. Sin embargo, en los cítricos, la presencia de semillas parece incrementar 
el comportamiento alternante. De hecho, muchos cultivares alternantes de cítricos, como son 'Wilking', 'Dancy', 'Murcott' o 'Michal', contienen semillas.

En los cítricos, el patrón empleado puede condicionar el comportamiento alternante del cultivar incrementando o reduciendo du intensidad. La intensa alternancia de cosechas de los mandarinos en la zona del Mediterráneo puede deberse al empleo del naranjo dulce como patrón en esta área (Davies y Albrigo, 1994). En experimentos realizados en Australia con naranjo dulce cv. 'Valencia' sobre diferentes patrones, se observaron diferencias notables en la alternancia de su producción en los seis años del experimento (El-Zeftawi y Thornton, 1975).

\section{Técnicas de control de la floración en los cítricos.}

\section{Inhibición de la floración.}

\section{Aplicación de fitorreguladores.}

Desde que Monselise y Halevy (1964) redujeron la floración en el naranjo dulce cv. 'Shamouti' mediante la aplicación de ácido giberélico, se han obtenido resultados similares en casi todas las especies y cultivares de cítricos (Harty y Van Standen, 1988a), tales como el naranjo dulce 'Washington Navel (Moss, 1970), 'Valencia' (Moss y Bellamy, 1973), 'Navelate' (Guardiola et al., 1977), mandarino 'Satsuma' (Iwahori, 1978, Iwahori y Oohata, 1981; Guardiola et al. 1982; García Luis et al. 1986), mandarino Clementino (Deidda y Agabbio, 1978), tangor 'Temple' (Monselise et al. 1981), calamondin (Lenz y Karnatz, 1975) y lima Tahiti (Davenport, 1983). En el limonero, el ácido giberélico inhibe también la floración inducida tras un período de sequía (Nir et al., 1972).

La respuesta siempre va acompañada de una redistribución de la brotación, aumentando la proporción de brotes florales con hojas y reduciéndose la de los brotes florales sin hojas. En los casos de reducción intensa de la floración, los brotes vegetativos también sufren cambios, produciéndose un aumento de los mismos (Agustí, 2003).

La respuesta a estos tratamientos depende críticamente de la época de aplicación. Si bien la época de sensibilidad de los agrios a esta sustancia es muy amplia, existen dos épocas de máxima eficacia bien definidas (Guardiola et al., 1982): durante el reposo invernal, de finales de noviembre a principios de diciembre, un tratamiento con ácido giberélico, a una

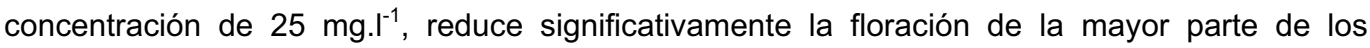
cultivares ensayados; y al inicio de la brotación, cuando los brotes aún no han superado los 1-3 
$\mathrm{mm}$ de longitud, tratamientos con $10 \mathrm{mg}^{.} \mathrm{I}^{-1}$ de ácido giberélico reducen la floración con la misma intensidad que los efectuados durante el reposo invernal, aunque el periodo de sensibilidad en este caso en más corto.

Además del ácido giberélico, las $\mathrm{GA}_{7}$ (Goldschmidt y Monselise, 1972) y la $\mathrm{GA}_{4}$ (Goldschmidt y Monselise, 1972; Tamim et al., 1996), también provocan la inhibición de la floración en los cítricos.

La aplicación de auxinas, como reguladoras del proceso de floración, fue explicado por Zeevart (1978). La aplicación de 2,4-D a una dosis de $12 \mathrm{mg.l}^{-1}$ entre mediados de noviembre y mediados de diciembre en árboles de naranjo dulce cv. 'Navelate' reduce la floración aproximadamente en un 30\% (Guardiola et al,. 1977).

El papel de las citoquininas en la regulación de la floración en cítricos ha recibido una escasa atención, a pesar de la correlación entre los bajos niveles endógenos de las citoquininas y la apertura de yemas (Davenport, 1990; El-Otmani et al., 1995).

Agustí y Almela (1991) revisaron los tratamientos más eficaces y las condiciones de aplicación para inhibir la floración en los cítricos.

\section{Estímulo de la floración.}

\section{Aplicación de retardadores del crecimiento.}

Diferentes retardadores del desarrollo se han utilizado para promover la floración de variedades alternantes de cítricos. La producción de flores se incrementa con un aumento en la concentración de compuestos del triazol, inhibidores de la síntesis de giberelinas (Delgado et al., 1986a, 1986b; Harty y van Staden, 1988b). Monselise (1979) considera la eficacia de los antagonistas de la síntesis de giberelinas solamente antes de que éstas hayan sido sintetizadas y no cuando están presentes en cantidades elevadas.

En pomelo se obtuvieron incrementos de la floración con aplicaciones foliares de 500 ppm de ácido triiodobenzoico (TIBA) (Kessler et al., 1959). Aplicaciones de 2-cloroetiltrimetilamonio (CCC; Cycocel) a concentraciones de 1000 ppm, y de ácido N-dimetilaminosuccinámico (Alar, BNine), a concentraciones de 2500 ppm, aumentaron la floración del limonero 'Eureka'; el Alar también provocó el estimulo de la floración del naranjo dulce, aunque de modo no consistente (Monselise y Goren 1984). Más efectivo que los anteriores fue el benzotiazol-2-oxiacetato (BTOA). Estos resultados fueron confirmados por diversos autores (Monselise et al., 1966; Nir et al., 1972; Salomon, 1988; Lenz y Karnatz, 1975). 
La aplicación de paclobutrazol [(2RS, 3RS)-1-(4-chlorophenyl)-4,4-dimethyl-2-(1,2,4-triazol-lyl) penta-3-ol], un inhibidor de la síntesis de giberelinas, entre 2.5 y $10 \mathrm{~g} /$ árbol, al suelo (Delgado et al. 1986a; 1986b) y vía foliar, entre 25 y 100 ppm (Harty y van Staden 1988b), aumenta la floración en el naranjo dulce, el mandarino y el limonero. Otros autores, sin embargo, otros autores (Iwahori 1986; Agustí et al. 1991) no encontraron respuesta a las aplicaciones foliares de paclobutrazol.

\section{El rayado de ramas}

El rayado de ramas es una técnica eficaz para estimular la floración; la respuesta depende de la época de ejecución. Los mejores efectos se consiguen cuando se realiza a finales del otoño o principios de invierno (Cohen, 1981). Sin embargo, Agustí et al. (1992) observaron que la respuesta óptima se obtiene con rayados efectuados en verano. El efecto es independiente de la edad de la rama que se raya; el rayado del tronco (Cutting y Lyne, 1993) o de ramas más pequeñas (Goldschmidt et al., 1985) provocan resultados similares.

El rayado de ramas da lugar a la acumulación de carbohidratos en la zona superior del corte (Cohen, 1981) y por tanto, a un reparto más ventajoso de carbohidratos (Wallerstein et al., 1974; 1978). Pero la posibilidad de que el rayado ejerza su acción a través de un mecanismo hormonal ha sido también señalada. La variaciones en el transporte (Monselise, 1979) y acumulación de auxinas (Dann et al., 1985), giberelinas (Wallerstein et al., 1973; Cutting y Lyne, 1993) y citoquininas (Cutting y Lyne, 1993) tras el rayado invita a pensar en un control hormonal del efecto provocado por éste, aunque su mecanismo todavía se desconoce.

Un aspecto de interés es el efecto combinado del rayado y la presencia del fruto en la floración de los árboles de mandarino 'Murcott' con elevada cosecha (Goldschmidt et al., 1985). A pesar del efecto del rayado promoviendo la floración, la presencia del fruto consigue anular su acción. Así, el rayado provocó un acumulación de carbohidratos en las hojas y brotes situados por encima de la zona de incisión en los árboles off, pero en los árboles on la elevada demanda de carbohidratos por parte de los frutos en desarrollo evitó la acumulación (Goldschmidt et al., 2003). Si esta es la razón por la cual los frutos anulan el efecto del rayado, se desconoce.

Además del efecto del rayado de ramas sobre la disponibilidad de carbohidratos, algunos autores (Rivas et al., 2007) han considerado su efecto sobre la actividad fotosintética en árboles de mandarino, observando que debe existir un control hormonal por parte del fruto, ya que aplicaciones con ácido giberélico incrementan la tasa fotosintética mediante la promoción de la 
actividad Rubisco (Yuan y Xu, 2001). Aún más, concentraciones mayores de GA1 se encontraron en frutitos en desarrollo de árboles rayados (Talón et al., 2000).

El estrés hídrico.

Trabajos realizados por Lovatt et al. (1988a) en limonero 'Frost Lisbon' demostraron el efecto conocido del estrés hídrico en el incremento de la floración (verdelli), de forma que un estrés moderado (-2 MPa durante 50 días o -3 MPa durante 20 días seguido de -2 MPa durante 40 días) y su rotura posterior aumentó significativamente el número de flores por árbol.

\section{Otras técnicas.}

Se han intentado diversas técnicas para promover la floración de los cítricos, como la aplicación de urea, buscando un incremento de la concentración foliar del ion $\mathrm{NH} 4+$, de acuerdo con los experimentos de Lovatt et al. (1988), pero la respuesta nunca fue reproducida.

El aclareo químico de frutos resulta, aparentemente, el mejor método de control de la floración (Goldschmindt y Golomb, 1982). Para ello, se han utilizado aplicaciones ácido 2-cloroetilfosfónico (CEPA, Ethephon o Ethrel) o de ácido naftalenacético (ANA), que se han mostrado eficaces cuando se aplican en los primeros estados de desarrollo del fruto (Galliani et al. 1975; Monselise et al., 1981; Hield, 1969, Moss et al., 1977), pero tampoco resuelven el problema.

La anticipación de la época de recolección puede ser un método útil para el control de la alternancia de cosechas (Moss et al., 1977). La inhibición que el fruto ejerce sobre la floración aumenta gradualmente con el tiempo de modo que recolecciones tempranas pueden provocar un aumento del número de brotes de flor (García-Luis et al., 1986). Tampoco con ello se consigue promover la floración de las yemas.

La eficacia de la poda en el control de la floración depende de la época y su severidad. Ha sido empleada en pomelos (Fucik, 1977) y en naranjo dulce (Moss et al., 1977) pero sin ningún resultado convincente.

El hecho de que ningún tratamiento se haya mostrado eficaz en la inducción de un meristemo a la diferenciación de flores es porque se desconoce el proceso de la floración. La posibilidad de que éste no fuera un proceso inductivo sino inhibitorio se explora en este estudio. 


\section{Hipótesis y Objetivos}

En la presente Tesis Doctoral se plantea la siguiente hipótesis de trabajo:

En los cítricos, el fruto inhibe la floración a través de la síntesis y exportación de giberelinas a las yemas que se hallan bajo su influencia impidiendo su brotación y alterando su diferenciación.

Para su estudio se plantean los siguientes objetivos:

1. Determinar el efecto del tiempo de permanencia del fruto en la planta sobre la brotación y floración siguientes. Definir la época a partir de la cual el fruto ejerce su acción inhibidora sobre la floración.

2. Establecer la influencia del fruto sobre el contenido foliar en carbohidratos y fracciones nitrogenadas, y su relación con la floración.

3. Estudiar el aislamiento del fruto y el transporte de giberelinas desde éste sobre la brotación y diferenciación de las yemas adyacentes.

4. Estudiar la eficacia del paclobutrazol y la prohexadione-Ca como promotores de la floración. 

Materiales y métodos 



\section{Materiales y métodos.}

1. Material vegetal

Los experimentos se realizaron en plantaciones comerciales de naranjo dulce [Citrus sinensis (L.) Osb.], cvs. 'Salustiana', 'Washington navel', 'Navelate y 'Valencia', mandarino Clementino (Citrus clementina Hort. ex Tanaka), cvs.'Marisol', 'Orogrande' y 'Hernandina', y el híbrido 'Nadorcott'. Todas ellas disponían de condiciones normales de riego localizado, fertilización y cultivo.

Los naranjos dulces eran árboles adultos de entre 12 y 20 años de edad, injertados sobre citrange Carrizo [Poncirus trifoliata $x$ Citrus sinensis], con un marco de plantación de entre $5 \times 6$ y 7 × 6 m, y localizados en Cartaya (Huelva, 37:30:04 N; 7:16:22 W). Además se utilizó una parcela de naranjo dulce cv. 'Valencia', localizado en Lliria (Valencia, 39:37:29 N; 0:35:41 W), con suelo arenoso-franco y franco-arcilloso, respectivamente.

Los mandarinos eran, también, árboles adultos, de 7-8 años de edad, injertados sobre citrange Carrizo, con un marco de plantación de entre $4 \times 5$ y 4 ×6 m, localizados en la Vall d'Uixò (Castellón, 40:14:29 N; 0:08:48 W) (cv. 'Marisol', cv. 'Orogrande'), Godelleta (Valencia, 39:25:30 N; 0:41:09W) y Ribarroja (Valencia 39:33:00 N; 0:34:00 W) (cv. 'Hernandina' en los dos últimos casos), con un suelo franco-arcilloso en todos los casos.

Los árboles del híbrido 'Nadorcott' se encontraban en Cartaya (Huelva, 37:30:04 N; 7:16:22 W) y Gibraleón (Huelva, 37:21:46 N; 06:56:59 W), en suelo arenoso-franco, eran de 10 años de edad y estaban injertados sobre citrange Carrizo, con un marco de plantación de 6 x 4 m.

2. Experimentos.

Capítulo 1. Interrelaciones floración-fructificación en los cítricos. Estudio del comportamiento alternante.

Se seleccionaron 10 árboles de naranjo dulce cv.'Salustiana' con intensidad creciente de floración. De cada uno de ellos se seleccionaron 4 ramas orientadas según los cuatro puntos cardinales. De cada una de ellas se evaluó, durante 4 años consecutivos, el número total de nudos, el número de brotes por nudo y el número de flores y hojas por brote. A partir de estos valores se determinó el número de nudos brotados y el número flores, y también se determinó el número de frutos producidos, expresando estos resultados por 100 nudos para compensar las diferencias de 
tamaño de las ramas seleccionadas. Los brotes se clasificaron de acuerdo con Guardiola et al. (1977). En el momento de la recolección se determinó el diámetro medio del fruto y la cosecha $(\mathrm{kg})$ de cada árbol.

Capítulo 2. Efecto del tiempo de permanencia del fruto en el árbol sobre la floración siguiente.

En las plantaciones de naranjo dulce cv. 'Valencia', se seleccionaron 70 árboles de cosecha aparentemente similar y de cada uno de ellos se seleccionaron 4 ramas con un número de frutos prácticamente idéntico. Desde el inicio de la caída fisiológica de frutos hasta la recolección, se fueron eliminando periódicamente la totalidad de los frutos de las ramas seleccionadas de 5 árboles, de las que en la primavera siguiente se evaluó la brotación, floración y cosecha del modo descrito anteriormente. Las fechas en las que se eliminaron los frutos fueron las siguientes:

- Junio: inicio de la caída fisiológica de los frutos. Estado 72 de la escala fenológica BBCH (Agustí et al., 1997).

- Julio: fin de la caída fisiológica de los frutos. Estado 74 de la escala BBCH.

- Septiembre: plena fase de desarrollo lineal del fruto. Estado 78 de la escala BBCH

- Noviembre: cuando el fruto alcanzó el $90 \%$ de su tamaño final. Estado 79 de la escala $\mathrm{BBCH}$.

- Diciembre: cuando el fruto alcanzó su tamaño definitivo e iniciaba el cambio de color. Estado 80 de la escala fenológica $\mathrm{BBCH}$

- Enero: en el momento del cambio de color del fruto. Estado 81 de la escala BBCH

- Abril: en el momento de la maduración fisiológica del fruto, cuando está apto para su recolección y consumo e inicia su senescencia. Estado 89 de la escala $\mathrm{BBCH}$

En los estados fenológicos 78, 81 y 89 de la escala $\mathrm{BBCH}$ se tomaron muestras de hojas para análisis de carbohidratos y de fracciones nitrogenadas de las ramas a las que se les había eliminado el fruto en el estado $72(\mathrm{BBCH})$ y de las que se eliminaría el fruto en el estado 89 $(\mathrm{BBCH})$. 
Un experimento basado en la aplicación, a finales de septiembre, de $\mathrm{GA}_{3}$ a diferentes dosis $\left(0,10,20,30,40\right.$ y $\left.50 \mathrm{mg} \mathrm{I}^{-1}\right)$ se realizó en el naranjo dulce cv. 'navelate' con el fin de evaluar el efecto de la aplicación en etapas próximas al completo desarrollo del fruto sobre la floración y brotación siguientes. Para ello se seleccionaron unos 50 árboles en los que se realizaron los diferentes tratamientos y en los que se evaluó la brotación y cosecha como se ha descrito anteriormente.

En el tangor 'Nadorcott' se diseñaron experimentos para determinar la influencia de la época de la recolección comercial sobre la intensidad de floración de la primavera siguiente. El primer experimento consistió en el fraccionamiento de la cosecha. Un grupo de 60 árboles de cosecha similar, se dividió en 4 grupos de 15 árboles, recolectándose 3 de ellos en su totalidad (3/3) o parcialmente ( $2 / 3$ y 1/3) el 21 de febrero, completándose el 7 de abril, y dejando un cuarto grupo de 15 árboles para recolectar totalmente en la última fecha. El segundo estaba formado por 45 árboles seleccionados por la cuantía de su cosecha y agrupados en lotes de 15 según los tres intervalos siguientes: 1) $100-150 \mathrm{Kg}_{\text {árbol }}{ }^{-1}$; 2) 150-200 $\mathrm{Kg}_{\text {árbol }}{ }^{-1}$ y 3) $>200 \mathrm{Kg}^{2}$ árbol ${ }^{-1}$; la recolección de 5 árboles de cada intervalo de cosecha se llevó a cabo en tres fechas separadas un mes, aproximadamente, 23 de febrero, 21 de marzo y 10 de abril.

De todos los árboles se evaluó la brotación y la floración durante la primavera siguiente del modo descrito en el apartado anterior.

Capítulo 3. Efecto del aislamiento parcial del fruto sobre la floración. Micro-rayado de la corteza del pedúnculo.

De árboles de naranjo dulce 'Valencia', 'Navelate' y 'Washington navel', se seleccionaron 120-200 frutos, según el cultivar, situados en brotes campaneros que contuvieran, al menos, 5 nudos. A la mitad de ellos se les rayó el pedúnculo, eliminado un anillo de 2-3 $\mathrm{mm}$ de anchura de corteza con un bisturí, dejando la otra mitad como controles sin rayar. En el cv. 'Valencia, el experimento se llevó a cabo en 3 años consecutivos rayando los pedúnculos en el momento señalado en la bibliografía como de inducción floral (finales de noviembre). En este mismo cultivar (año II) y en el cv. 'Navelate' se ensayaron, un solo año, diferentes épocas de rayado, desde mediados de julio hasta finales de enero.

De todos los brotes marcados se evaluó la brotación y la floración durante la primavera siguiente, del modo descrito en el capítulo 1, y la longitud media de los nuevos brotes, así como el tamaño medio del fruto y su coloración mediante un colorímetro Minolta (CR-300) (Japón). 
Cuarenta días después de efectuado el rayado (finales de noviembre, estado fenológico 79 de la escala $\mathrm{BBCH}$ ), se tomaron muestras de la corteza de 60 brotes de las zonas apical (zona próxima al fruto) y basal del rayado para análisis de carbohidratos.

En el naranjo dulce cv. 'Washington navel', se tomaron muestras de flavedo y de brotes en tres fechas a lo largo de la maduración del fruto del mismo modo descrito anteriormente, para el análisis de giberelinas.

Capítulo 4. Estudio de la aplicación de inhibidores de la síntesis de giberelinas sobre la floración.

Los experimentos para modificar la intensidad de floración se llevaron a cabo en árboles de cosecha uniforme de naranjo dulce cvs. 'Salustiana' y 'Navelate', mandarino Clementino cvs. 'Marisol' y 'Orogrande', y el tangor 'Nadorcott'. En el mandarino Clementino cv. 'Hernandina' los árboles se clasificaron como árboles de escasa cosecha (árboles off) y de cosecha elevada (árboles on).

El ácido giberélico $\left(\mathrm{GA}_{3}\right)$ se aplicó vía foliar a las concentraciones de $0,10,20,30,40$ y 50 $\mathrm{mg} \mathrm{l}^{-1}$. El paclobutrazol (PBZ) se aplicó vía foliar, a una concentración de $2000 \mathrm{mg} \mathrm{l}^{-1}$, localizado a las hojas, yema o rama, a una concentración de $2500 \mathrm{mg} \mathrm{l}^{-1}$ y al suelo, a razón de 1 ó $2 \mathrm{~g} \mathrm{planta}^{-1}$. La prohexadione-Ca se aplicó vía foliar a una concentración de $200 \mathrm{mg} \mathrm{l}^{-1}$. Dejando siempre controles sin tratar.

Las aplicaciones se realizaron con un tanque de pulverización, a una presión de trabajo de $30 \mathrm{~atm}$, con un consumo medio de $10 \mathrm{l}$ por árbol, procurando mojarlo en su totalidad hasta el goteo. En todos los casos se añadió un agente tensoactivo no iónico, a la dosis recomendada por el fabricante. Las aplicaciones localizadas a las hojas y a las ramas se llevaron a cabo mojándolas con un pulverizador manual; las yemas se mojaron depositando sobre ellas una gota de la solución con una pipeta $\left(10 \mu l . y e m a^{-1}\right)$. Las aplicaciones al suelo se llevaron a cabo depositando la solución directamente al área de goteo de los emisores de riego.

En todos los casos, se evaluó la brotación y floración siguientes del modo descrito anteriormente.

En el reposo vegetativo (noviembre y enero) y al inicio de la brotación (marzo) se tomaron muestras de brotes de otoño y raíz, para análisis de carbohidratos. En los brotes de otoño, las 
hojas y los tallos se analizaron por separado. Al menos 10 brotes por árbol y $200 \mathrm{~g}$ de raíz se tomaron por muestra.

\section{Determinaciones analíticas.}

\subsection{Carbohidratos}

Partiendo de $100 \mathrm{mg}$ de tejido vegetal previamente liofilizado y molido, se procedió a su extracción. A dicha muestra se añadió $1 \mathrm{ml}$ de etanol al $80 \%$ y $100 \mu \mathrm{l}$ de una solución de $60 \mathrm{mg} \mathrm{ml}^{-1}$ de fucosa (Sigma Química). La fucosa es un compuesto hidrocarbonado que no existe en los tejidos vegetales, por tanto sirve como estándar interno para corregir las posibles pérdidas de azúcares durante el proceso de extracción y purificación.

Tras homogeneizar la muestra, se calentó en un baño termostatizado a $85^{\circ} \mathrm{C}$ durante 5 minutos. El homogeneizado obtenido se centrifugó durante 10 minutos a $12.000 \mathrm{rpm}$ y el sobrenante se recogió en un tubo eppendorf. La extracción se repitió dos veces más. El sobrenadante resultante fue evaporado en condiciones de vacío en un Speed-Vac (Savant ${ }^{\circledR}$, Holbrook, NY) a $40^{\circ} \mathrm{C}$, hasta obtener un volumen de $0.5 \mathrm{ml}$.

El extracto vegetal se purificó filtrándolo a través dos columnas de intercambio, una aniónica y otra catiónica. La primera, resina catiónica Dowex 50WX8-100 (Acros Organics), se disolvió en ácido clorhídrico $2 \mathrm{~N}$, y la segunda, resina aniónica Dowex $1 \times 4, \mathrm{Cl}^{-}$(Sigma-Aldrich), en carbonato sódico $1 \mathrm{M}$, antes de su utilización, la resinas fueron llevadas a un $\mathrm{pH}$ entre 4.5-5 (Mehouachi et al., 1995) y 7.5-8 respectivamente, mediante sucesivos lavados con agua milliQ.

La muestra, además se hizo pasar por un filtro de nylon de $0.45 \mu \mathrm{m}$ y un cartucho tipo C18. La muestra purificada se evaporó en el Speed-Vac hasta obtener un residuo sólido de azúcares.

El residuo sólido de azúcares, resultante de la extracción y purificación de la muestra vegetal, se disolvió en $60 \mu \mathrm{l}$ de una disolución de acetonitrilo y agua miliQ (60-40\%). Para determinar los azúcares existentes en la solución, se inyectaron $20 \mu \mathrm{l}$ de esta solución en un HPLC (High Performance Liquid Cromatography) Thermo Spectra System ${ }^{\circledR}$ (California, USA), equipado con un refractrómetro diferencial R150, una bomba de vacío P2000 y un sistema de procesamiento de datos Chrom Quest para Windows $\mathrm{NT}^{\circledR}$. Se utilizó una columna APS-2 Hypersil, $250 \times 4.6 \mathrm{~mm}$, adaptada a una precolumna. Se empleó como disolvente una mezcla de acetonitrilo y agua miliQ (80:20), a un flujo de $1 \mathrm{ml} \mathrm{min}^{-1}$. 
Los azúcares fructosa, glucosa y sacarosa se identificaron por su momento de retención, y se cuantificaron por las áreas de sus picos en relación a una curva de calibración elaborada con concentraciones conocidas de cada azúcar. Se utilizó un factor de corrección, dependiente de la recuperación de fucosa, y los resultados se expresaron en g de azúcar por $100 \mathrm{~g}$ de materia seca.

Para la determinación de almidón, el residuo sólido obtenido después de la extracción de azúcares con etanol, se diluyó con agua miliQ hasta un volumen de $6 \mathrm{ml}$.

El material se esterilizó en autoclave (P-Selecta ${ }^{\circledR}$ Presoclave 30 , Barcelona, España) durante $2 \mathrm{~h}$ a $130^{\circ} \mathrm{C}$ y a una presión entre 1.2 y 1.5 bares.

Los tubos autoclavados se centrifugaron a $4500 \mathrm{rpm}$ en una centrífuga P Selecta ${ }^{\circledR}$ Meditronic BL (Barcelona, España) y se enrasó el volumen de agua de cada tubo hasta aproximadamente $2 \mathrm{ml}$.

Posteriormente se añadieron $0.2 \mathrm{ml}$ de una solución de fucosa de concentración $30 \mathrm{mg} \mathrm{ml}^{-1}$, $0.5 \mathrm{ml}$ de una solución tampón de acetato sódico a pH 4.5 (40\% ácido acético $0.2 \mathrm{M}$ y $60 \%$ acetato sódico $0.2 \mathrm{M}$ ) y $1 \mathrm{ml}$ de solución de enzima amiloglucosidasa de Rhizopus mold (Sigma Química, St. Louis, Missouri, USA) de concentración $60 \mathrm{mg} \mathrm{ml}^{-1}$.

Se dejó actuar el enzima durante $2 \mathrm{~h}$ en un baño a $55^{\circ} \mathrm{C}$, para hidrolizar el almidón a glucosa, agitando de vez en cuando con el agitador del baño. Pasado este tiempo, se centrifugó durante $30 \mathrm{~min}$ a $4500 \mathrm{rpm}$ para recoger el sobrenadante en tubos de vidrio Pirex-18.

Se evaporó el agua en un rotovapor Speed Vac (Savant ${ }^{\circledR}$ Holbrook, NY) hasta sequedad. A continuación se le añadió $1 \mathrm{ml}$ de agua MilliQ a cada tubo, y finalmente, se centrifugaron durante 20 minutos a 12000 rpm en una centrífuga P-Selecta Meditronic-BL (Barcelona, España).

Posteriormente se filtró el conjunto con un cartucho C-18 y con uno de nylon de $0.45 \mu \mathrm{m}$. Se inyectaron $20 \mu \mathrm{l}$ de esta solución en el HPLC, cuyas características se detallaron en apartado anterior, para cuantificar la glucosa liberada.

Los resultados se expresaron en mg de glucosa liberada por g de materia seca.

\subsection{Fracciones nitrogenadas.}

Nitrógeno proteico y amoniacal $\left(\mathrm{N}-\mathrm{NH}_{4}{ }^{+}\right)$.

Para la extracción de las fracciones de nitrógeno proteico y nitrógeno amoniacal se utilizó en la metodología propuesta por Maquieira et al. (1984). Partiendo de una muestra de tejido 
vegetal previamente liofilizado y molido, se consigue separar el nitrógeno proteico (insoluble) y no proteico (soluble) usando ácido tricloro acético, que precipita la fracción proteica.

Se pesaron $0.5 \mathrm{~g}$ de muestra, a la que se adicionaron $10 \mathrm{ml}$ de ácido tricloro acético frío al 5\% (TCA 5\%-T6399, Sigma-Aldrich, St. Louis, USA). La solución se mantuvo durante $15 \mathrm{~min}$ en agitación; a continuación se añadieron $30 \mathrm{ml}$ de TCA 5\% y se introdujo en nevera (temperatura aproximada de $4^{\circ} \mathrm{C}$ ) durante 15 minutos.

Después se procedió al filtrado por medio de un embudo con un papel de filtro (Schleicher y Shvell, de $\varnothing 90 \mathrm{~mm}$ ), recogiendo la parte soluble en un matraz. Se realizó un lavado del recipiente en que se encontraba la muestra, con $10 \mathrm{ml}$ de TCA al $5 \%$, pasándolo también a través del filtro, y luego se lavó el embudo tres veces con $10 \mathrm{ml}$ de TCA al 5\%. Después del último lavado se dejó escurrir el residuo durante $15 \mathrm{~min}$, aproximadamente.

El matraz se enrasó con agua destilada hasta $100 \mathrm{ml}$ y se almacenó en nevera a $4^{\circ} \mathrm{C}$. En esta solución se encuentra la fracción amoniacal soluble, que se analizará posteriormente con un analizador FIAstar 5000 Analyzer $^{\circledR}$ (Höaganäs, Sweden).

El residuo sólido procedente del filtrado, junto con su papel de filtro, se introdujo en un tubo de digestión Tecator $^{\circledR}$ (Foss, Höaganäs, Sweden). Al tubo se le adicionaron $3 \mathrm{~g}$ de una mezcla de tres catalizadores; sulfato potásico $\left(\mathrm{K}_{2} \mathrm{SO}_{4}\right)$, sulfato cúprico al $99 \%\left(\mathrm{CuSO}_{4}\right)$ y selenio (Se), en proporción 10:1:0.1, respectivamente; además se añadieron $10 \mathrm{ml}$ de peróxido de hidrógeno, al $35 \%$, y $10 \mathrm{ml}$ de ácido sulfúrico, al $96 \%$. El tubo Tecator se introdujo en el digestor a $450^{\circ} \mathrm{C}$ durante $30 \mathrm{~min}$. Posteriormente, y una vez enfriados los tubos, se le añadieron $50 \mathrm{ml}$ de agua destilada a cada tubo, tras lo cual se introdujeron en un destilador (Foss Kjeltec 2200 Auto Destillation, Höaganäs, Sweden), en corriente de vapor durante $4 \mathrm{~min}$, utilizando $\mathrm{NaOH}$, al $40 \%$, como alcalinizante, agua destilada y una solución de ácido bórico indicador (ácido bórico 2, rojo de metilo, verde de bromocresol). El destilado se valoró con ácido clorhídrico, $0.1 \mathrm{~N}$, factor 1 , la solución vira de color verde a morado-rojizo. Paralelamente se llevó a cabo un ensayo en blanco.

El porcentaje de nitrógeno proteico se calculó de acuerdo con la siguiente ecuación:

$\% \mathrm{NP}=\underline{\mathrm{ml} \mathrm{HCl} \times \text { factor } \times \mathrm{N} \text { del } \mathrm{HCl} \times 100 \times 14}$

$1000 \times$ Peso muestra $(\mathrm{g})$

El nitrógeno amoniacal se midió a partir del filtrado guardado en nevera, tomando alícuotas de $10 \mathrm{ml}$ y usando un equipo FIAstar 5000 Analyzer $^{\circledR}$ con un muestreador automático 5027 
Sampler. El equipo se dotó del cassette correspondiente para la determinación del ión amonio ( $\mathrm{N}$ $\mathrm{NH} 4^{+}$). Se siguió la metodología propuesta por Raigón et al. (1992) y Foss Tecator AB (2000).

El cassette de amonio contiene una membrana de difusión cuya finalidad es permitir el paso del amoníaco liberado de la muestra al alcalinizarse ésta con $\mathrm{NaOH} 0.5 \mathrm{M}$ (Reactivo 1). EI amoníaco es arrastrado y disuelto por el Reactivo 2, con el cuál reacciona, produciendo un cambio de color que se cuantifica por espectrofotometría a una longitud de onda de $590 \mathrm{~nm}$. Para la determinación del $\mathrm{N}-\mathrm{NH}_{4}{ }^{+}$son necesarios los siguientes reactivos:

Carrier: Agua miliQ.

Reactivos: $\mathrm{NaOH}$ 0.5M (Reactivo 1) y solución indicadora (Sulfanilamida; Reactivo 2). La solución indicadora se preparó diluyendo $10 \mathrm{ml}$ de la solución madre indicadora (Indicator Stock Solution) en $500 \mathrm{ml}$ de agua miliQ. La solución madre indicadora se preparó disolviendo $1 \mathrm{~g}$ de amonio indicador con $10 \mathrm{ml}$ de $\mathrm{NaOH} 0.01 \mathrm{M}$ y $10 \mathrm{ml}$ de etanol $95 \%$ y finalmente enrasando hasta $200 \mathrm{ml}$ con agua miliQ.

El equipo requiere realizar una calibración previa a cada análisis, para la cual se prepararon los siguientes patrones de calibración a distintas concentraciones en ppm: 0, 0.1, 0.3, 0.7, 1, 1.5, 2 y 4, a partir de la Standard Stock Solution $1000 \mathrm{mg} \mathrm{l}^{-1} \mathrm{NH}_{4}$ (SSS) y de la Interim Stock Solution $20 \mathrm{mg} / \mathrm{l} \mathrm{NH}$ (ISS). La SSS se preparó con $2.998 \mathrm{~g}$ de $\mathrm{NH}_{4} \mathrm{Cl}$ (cloruro de amonio, AM0273, Scharlau, Barcelona, España) diluidos hasta $1000 \mathrm{ml}$ con agua miliQ. La ISS se prepara diluyendo $10 \mathrm{ml}$ de la SSS hasta $500 \mathrm{ml}$ con agua miliQ. Posteriormente, se extraen las alícuotas a partir de la ISS para obtener los patrones de calibración.

Fracciones Nitrato y Nitrito $\left(\mathrm{N}^{-\mathrm{NO}_{3}}{ }^{-}\right.$y N-NO$\left.{ }_{2}{ }^{-}\right)$.

La extracción de las fracciones de nitrógeno nitrato y nitrito se basó en la metodología propuesta por Beljaars et al. (1994) y FOSS Tecator AB (2001). Se pesaron $0.5 \mathrm{~g}$ de muestra, previamente liofilizada y finamente molida, en un vaso de precipitados de $100 \mathrm{ml}$, al que posteriormente se le añadieron $50 \mathrm{ml}$ de agua miliQ. La suspensión se agitó durante $30 \mathrm{~min}$ en un agitador magnético múltiple RO5 IKA-WERKE (GMBH \& CO, Staufen, Germany) con un imán, al cabo de lo cual se filtró el conjunto mediante un embudo de plástico y papel de filtro (Schleicher y Shvell de $\varnothing 90 \mathrm{~mm}$ ). El filtrado se recogió en un matraz de vidrio aforado de $100 \mathrm{ml}$ del cual se tomó una alícuota de $10 \mathrm{ml}$ por muestra y se introdujo en un tubo de ensayo directamente en el muestreador automático 5027 Sampler del equipo FIAstar 5000 Analyzer $^{\circledR}$ equipado con el cassette correspondiente para la determinación del ión nitrato $\left(\mathrm{N}_{-}-\mathrm{NO}_{3}{ }^{-}\right)$y del ión nitrito $\left(\mathrm{N}-\mathrm{NO}_{2}{ }^{-}\right)$, siguiendo la metodología propuesta por Foss Tecator $\mathrm{AB}$ (2001). El cassette de $\mathrm{NO}_{3}^{-}$y $\mathrm{NO}_{2}^{-}$incluye una 
columna de reducción de Cadmio cuya finalidad es reducir todos los nitratos a nitritos, y una membrana de diálisis que sirve para purificar la muestra evitando el taponamiento y la pérdida de eficiencia de la columna de reducción. Los nitritos resultantes de la reducción reaccionan con la sulfanilamida (Reactivo 2 ) y el NED (ver más adelante) (Reactivo 3), generando una coloración rojo púrpura que se mide con un espectrofotómetro a una longitud de onda de $540 \mathrm{~nm}$. Para la determinación del $\mathrm{N}-\mathrm{NH}_{4}{ }^{+}$son necesarios los siguientes reactivos:

Carrier: Agua miliQ.

Reactivos: $\mathrm{NH}_{4} \mathrm{Cl}$ a pH 8.5 (Reactivo 1), Sulfanilamida (Reactivo 2) y NED (Reactivo 3). El reactivo 1 se preparó con $85 \mathrm{~g}$ de cloruro de amonio $\left(\mathrm{NH}_{4} \mathrm{Cl}\right.$, Scharlau AM0273, Barcelona, España), $500 \mathrm{ml}$ de agua miliQ y aproximadamente $12 \mathrm{ml}$ de hidróxido de amonio $\left(\mathrm{NH}_{4} \mathrm{OH}\right.$, Scharlau AM0250, Barcelona, España) hasta obtener un pH de 8.5. El reactivo 2 se preparó disolviendo $5 \mathrm{~g}$ de sulfanilamida con $250 \mathrm{ml}$ de agua miliQ, a los que se añadieron $25 \mathrm{ml} \mathrm{de} \mathrm{HCl}$, el conjunto se homogenizó y enrasó hasta $500 \mathrm{ml}$ con agua miliQ. El reactivo 3 , se obtuvo disolviendo $0.5 \mathrm{~g}$ de $\mathrm{N}$-(1-naphtyl)-ethylene diamine dihydrochloride (NED) en $250 \mathrm{ml}$ de agua miliQ y enrasando hasta $500 \mathrm{ml}$ posteriormente.

Para la correcta cuantificación del ión nitrato y antes de cada análisis, debe calibrarse dos veces, una preparando patrones a baja concentración y otra a alta concentración. Para éstas rectas se prepararon los siguientes patrones de calibración (ppm): 0, 0.10, 0.25, 0.50, 0.75, 1, y 1, 2.5, 5, $7.5,10,15,20$, a partir de la Standard Stock Solution $1000 \mathrm{mg} / \mathrm{l} \mathrm{NO}{ }_{3}^{-}$(SSS) y de la Interim Stock Solution $100 \mathrm{mg} / \mathrm{l} \mathrm{NO}{ }_{3}^{-}$(ISS). La SSS se preparó a partir de $1.663 \mathrm{~g}$ de $\mathrm{KNO}_{3}$ (Panreac, Barcelona, España) diluidos hasta $1000 \mathrm{ml}$ con agua miliQ. De esta se tomaron $10 \mathrm{ml}$ y se diluyeron hasta 500 $\mathrm{ml}$ con agua miliQ para la obtención de la solución ISS, a partir de la cual se tomaron diferentes alícuotas, en función de la concentración, para obtener los diferentes patrones de calibración

El contenido de nitrógeno total en las hojas se obtuvo sumando el nitrógeno proteico y el no proteico.

\subsection{Giberelinas $\left(\mathrm{GA}_{1}\right.$ y $\left.\mathrm{GA}_{4}\right)$}

La determinación de giberelinas se realizó por cromatografía líquida y espectrometría de masas (LC-MS/MS), siguiendo la metodología propuesta por Chiwocha et al. (2003), con modificaciones menores. A partir de $200 \mathrm{mg}$ de muestra liofilizada y molida con nitrógeno líquido, se realizó la extracción con $5 \mathrm{ml}$ de solución de extracción MeOH:H2O:HOAc (80:19:1, a pH 1-3). 
Se agregaron $100 \mathrm{ng}$ de estándares deuterados (2H2-GA1, 2H2-GA4), se agitaron en vortex, y se colocaron a $4^{\circ} \mathrm{C}$ por 12 horas. Posteriormente, se centrifugó a $290 \mathrm{~g}$ durante 10 minutos, separando el sobrenadante del pellet para la evaporación de la fase acuosa. Luego, mediante partición por dos veces con acetato de etilo (C4H8O2), acidificado con $\mathrm{HOAc}(1 \%)$, se reunió la fase orgánica para ser evaporada a sequedad. Se re-suspendió con metanol para su purificación con cartucho C18 (Sep-Pak, Waters-Millipore), la fracción con GAs, se llevó a sequedad en SpeedVac. La muestra se disolvió con $100 \mu \mathrm{L}$ de $\mathrm{MeOH}$ (100\%) para su identificación y cuantificación en LC-MS/MS. Se inyectaron $10 \mu \mathrm{l}$ en un cromatógrafo líquido (Alliance 2695, Waters Inc), provisto de una columna Restek C18 $(2.1 \times 100 \mathrm{~mm}, 5 \mu \mathrm{m})$, a $25^{\circ} \mathrm{C}$. Se utilizó un gradiente que comenzó (40\% MeOH: 60\% H2O:HOAc al $0.2 \%)$ a un flujo de $0.2 \mathrm{~mL}$ min-1. Las muestras se analizaron a través de un doble quadrupolo (Quatro Ultimatm Pt., Micromass, UK), utilizando la fuente de iones en modo negativo y un capilar de ionización por electrospray (ESI). Las GA1 y GA4 se identificaron por comparación de tiempos de retención con el estándar puro, y los iones se monitorearon por reacción múltiple (función MRM), siguiendo las masas moleculares y las masas de transición para GA1 y 2H2-GA1: $348>242$ y $350>244$, mientras que para GA4 y 2H2-GA4: $332>244$ y $334>246$. La cuantificación se hizo sacando la relación de áreas endógeno/deuterado, y extrapoladas a través de una curva de calibración elaborada con concentraciones conocidas.

\section{Análisis de los resultados}

En todos los casos se diseñaron experimentos de bloques al azar, con un mínimo de tres bloques $y$ tres repeticiones por tratamiento.

A los resultados obtenidos se les aplicó el análisis de la varianza o de la regresión, con un nivel de confianza entre $P=0.01$ y $P=0.05$. Para la separación de medias se aplicó el test de StudentNewman-Keuls. A los valores porcentuales se les aplicó la transformación arcsen $(\sqrt{ } p)$ para normalizar la muestra. 
Resultados 

1. Capítulo 1. Interrelaciones floración-fructificación en los cítricos. Estudio del comportamiento alternante.

La evolución anual de la floración de 10 árboles de naranjo dulce cv. 'Salustiana' seleccionados por su intensidad de floración, muestra el carácter alternante de este cultivar (Fig. 1.1). Clasificados los árboles desde el de mayor intensidad de floración (71.7 flores/100 nudos) al de floración más baja (1.7 flores /100 nudos), los 5 con la mayor floración (hasta 29.7 flores/100 nudos) y los 3 con la menor ( $\leq 5$ flores/100 nudos) mostraron dicho carácter de modo marcado y con los ciclos cambiados, como corresponde a su floración. Mientras los primeros sufrieron una reducción drástica de su floración el segundo año de experimento (0.1 - 3.0 flores/100 nudos), los segundos la incrementaron extraordinariamente (20.8 - 47.1 flores/100 nudos) (Fig. 1.1). Yesa tendencia alternante se mantuvo en años sucesivos hasta los 4 estudiados. Los árboles con floraciones intermedias, entre 10 y 15 flores/100 nudos (árboles 6 y 7), no mostraron alternancia alguna en nuestro experimento (Fig. 1.1).

La evolución anual de la producción, expresada en frutos/1000 nudos, fue, a su vez, alternante con la floración. Así, la producción correspondiente a la floración del año 1 fue mayor (8.3 - 15.9 frutos/1000 nudos) en los árboles que más florecieron y menor $(2.8$ - 6.3 frutos/1000 nudos) en los que florecieron menos (Fig. 1.2). También para la cosecha la tendencia alternante se mantuvo en años sucesivos. Cuando los resultados se expresan en kg/árbol (valores con menor variabilidad que los expresados en frutos/1000 nudos) el comportamiento alternante del cv. 'Salustiana' fue evidente (Fig. 1.3). 


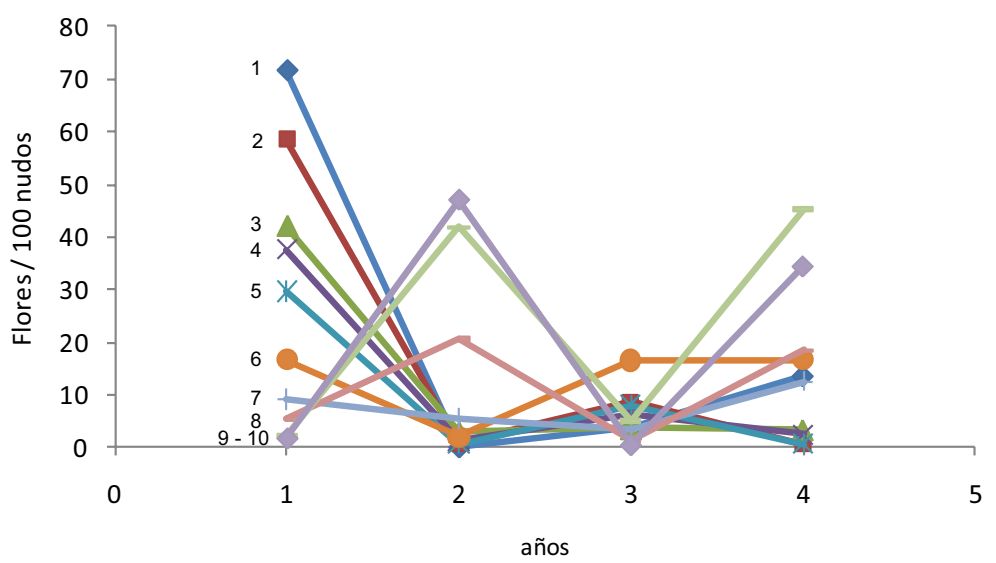

Figura 1. 1. Evolución con los años de la floración de 10 árboles de naranjo dulce cv. 'Salustiana' seleccionados por su intensidad de floración.

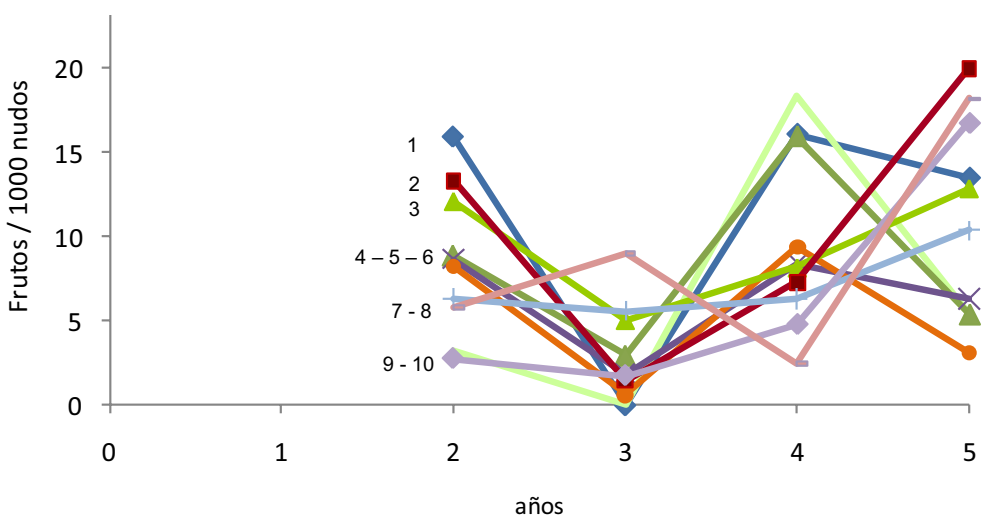

Figura 1. 2. Evolución con los años del número de frutos por 1000 nudos de 10 árboles de naranjo dulce cv. 'Salustiana' seleccionados por su intensidad de floración.

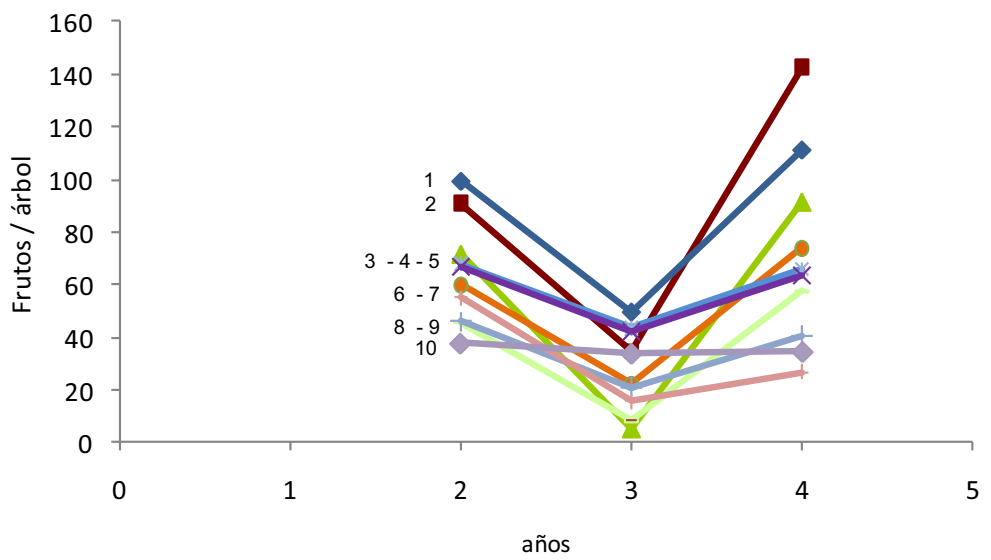

Figura 1. 3. Evolución con los años del número de frutos por árbol de 10 árboles de naranjo dulce cv. 'Salustiana' seleccionados por su intensidad de floración. 
Esta alternancia floración - cosecha tiene su origen en la dependencia que la segunda tiene de la primera en esta especie. Para los 4 años del experimento, la relación floración - fructificación sigue una curva logarítmica en dos fases, una primera con una fuerte dependencia positiva entre el número de frutos que se recolectan y el número de flores inicialmente formadas, y una segunda, en la que ambas variables son independientes (Fig. 1.4). Esta relación floración-fructificación fue estadísticamente significativa a lo largo de los años de estudio, con valores de los coeficientes de regresión entre $r=+\quad 0.61(P \leq 0.05)$ y $r=+\quad 0.89(P \leq 0.01)$. Resulta interesante que habiendo elegido árboles con diferente intensidad de floración y habiendo demostrado su alternancia, la relación floración-fructificación sea prácticamente idéntica año tras año para el conjunto de los mismos. Para comprender mejor este fenómeno, se han inscrito en un círculo rojo los 5 árboles inicialmente en año on, es decir, con mayor intensidad de floración (árboles 1, 2, 3, 4 y 5), y en un círculo gris los tres árboles inicialmente en su ciclo off, es decir, con menor floración (árboles 8,9 y 10) (ver Fig. 1.1).
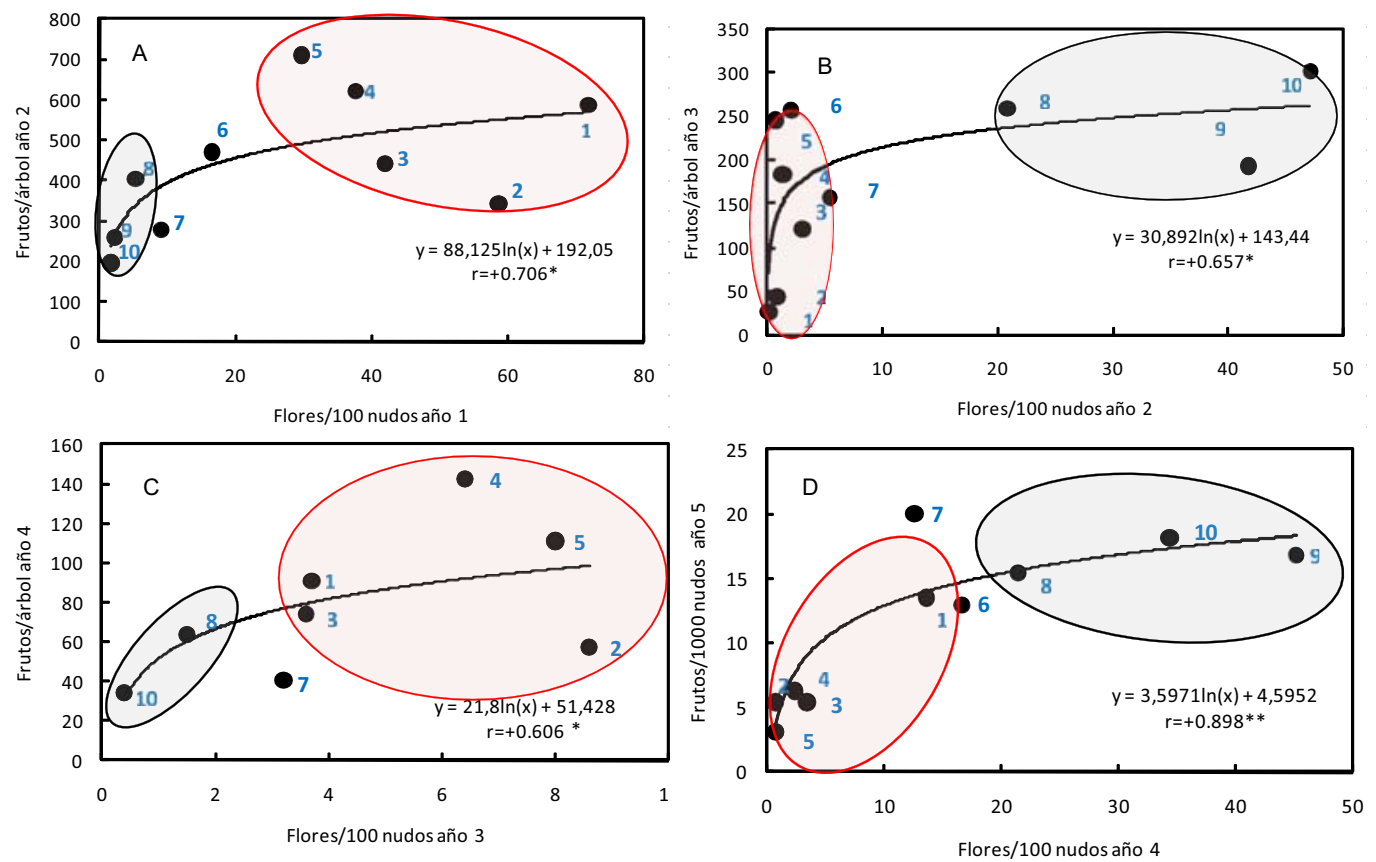

Figura 1.4. Relación floración-fructificación en el naranjo dulce cv.'Salustiana' durante cuatro años consecutivos. Inscritos en un círculo rojo se puede seguir la evolución anual de dicha relación en los árboles con una mayor intensidad de floración inicial, e inscritos en un círculo gris los de menor intensidad. * ssignif. $P \leq 0.05 ;{ }^{* *}=$ signif. $P \leq 0.01$. 
Siguiendo las figuras de la regresión de los diferentes años se observa como los árboles del círculo rojo se desplazan en el gráfico de derecha (Fig. 1.4 A) a izquierda (Fig. 1.4 B), es decir de mayor a menor floración, en el primer ciclo de alternancia, y de nuevo a la derecha (Fig. $1.4 \mathrm{C}$ ) y de allí otra vez a la izquierda (Fig. 1.4 D), es decir de nuevo a mayor y luego a menor intensidad de floración, respectivamente, en los dos ciclos siguientes, mientras que los árboles inscritos en el círculo gris llevan siempre un camino opuesto (Fig. 1.4). Los árboles con una intensidad de floración intermedia ( 6 y 7) no sufren ningún cambio al respecto, es decir, presentan una posición relativa respecto de los dos grupos anteriores, estable con los años, de floración-fructificaciónfloración (Fig. 1.4).

La relación entre el número de frutos cosechados y la floración siguiente siguió, por el contrario, una relación negativa (Fig. 1.5), es decir, cuanto mayor fue el número de frutos cosechados, menor lo fue la intensidad de floración siguiente. En las tres relaciones de este tipo que se pueden determinar con 4 años de floración y sus tres cosechas intermedias, se observó siempre una correlación potencial de ambas variables que solo en uno de los casos (año 3) no alcanzó la significación estadística ( $r=-0.441$; $P \leq 0.01$; Fig. 1.5 B). También en este caso se han inscrito en un círculo rojo y gris los árboles con una mayor y menor intensidad de floración inicial, respectivamente. Aquí la fructificación alterna de derecha (Figs. 1.5 A y $1.5 \mathrm{C}$ ) a izquierda (Fig. 1.5 B) y la floración de arriba (Figs. $1.5 \mathrm{~A}$ y $1.5 \mathrm{C}$ ) abajo (Fig. $1.5 \mathrm{~B}$ ): es decir, ambas variables alternaron con los años.
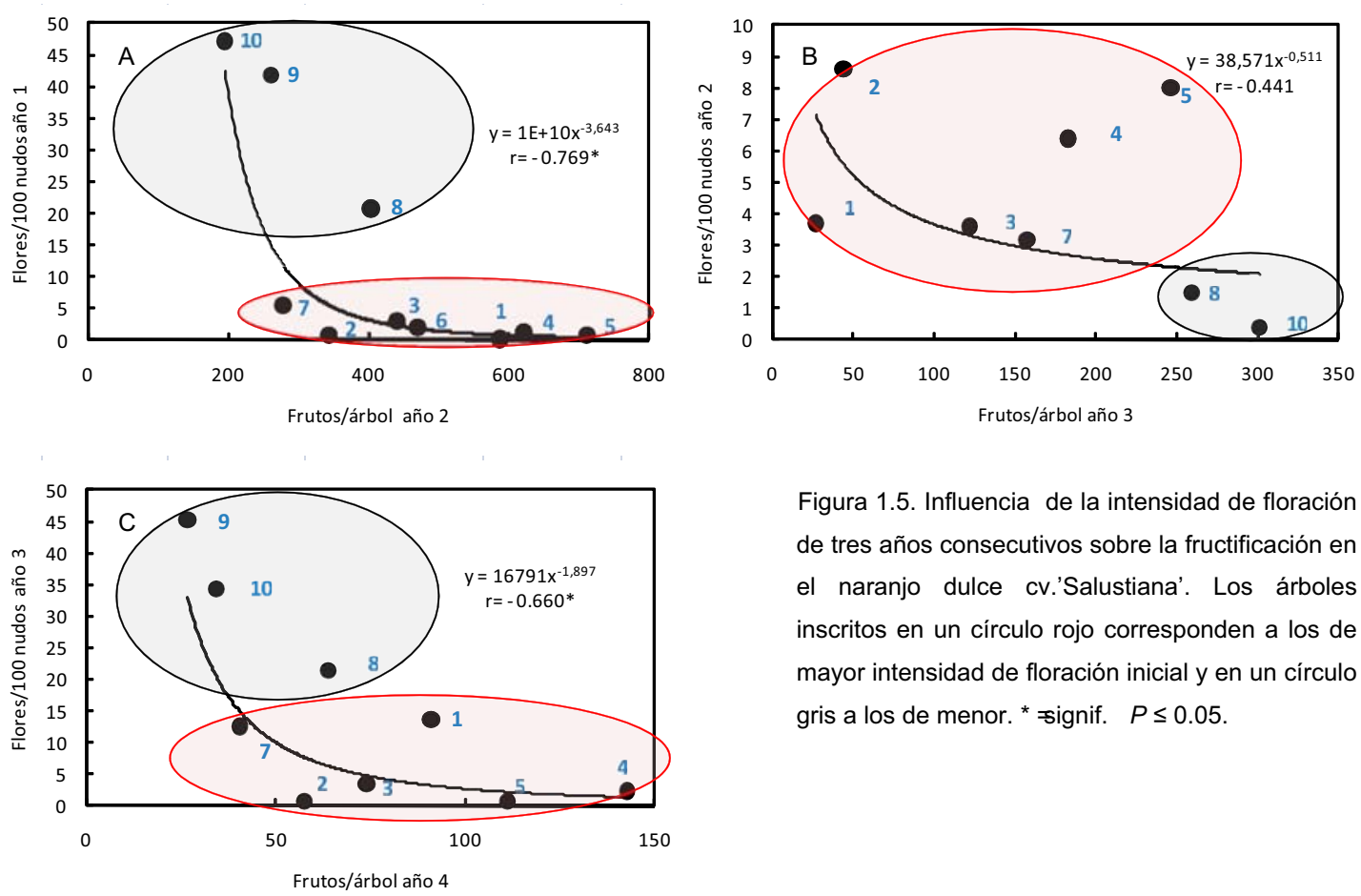

Figura 1.5. Influencia de la intensidad de floración de tres años consecutivos sobre la fructificación en el naranjo dulce cv.'Salustiana'. Los árboles inscritos en un círculo rojo corresponden a los de mayor intensidad de floración inicial y en un círculo gris a los de menor. * signif. $P \leq 0.05$. 
Estas relaciones, sin embargo, se hallan parcialmente enmascaradas por las variaciones en el porcentaje de flores cuajadas, que es inversamente proporcional a la intensidad de floración, de modo que los árboles con mayor floración cuajaron en menor proporción que los árboles de menor floración (Tabla 1.1). Este efecto, sin embargo, no indica, necesariamente, que el número de frutos desarrollados en los primeros sea menor que en los segundos, antes al contrario, los árboles con mayor número de flores desarrollan más frutos, pero dicho efecto compensa, en parte, la relación positiva floración-fructificación, y por eso, esta relación acaba saturándose (Fig. 1.4). A pesar de ello, el fenómeno es tan consistente que aún con estas compensaciones prevalece, como efecto principal entre años, la alternancia de la intensidad de floración.

En efecto, la relación entre dos floraciones sucesivas siguió, también, una curva potencial, de pendiente negativa, en las tres relaciones anuales posibles de nuestro experimento (4 años) y estadísticamente significativa en todos los casos (Fig. 1.6). Es decir, a un año de floración elevada le siguió otro de baja floración y a éste otro de floración elevada, y así sucesivamente. Yambién en este caso, aún habiendo elegido árboles con intensidades de floración distintas, y habiendo demostrado su alternancia, la relación entre la intensidad de floración de dos años sucesivos fue prácticamente idéntica para el conjunto de los mismos. La razón de ello es la fructificación intermedia entre dos floraciones, que es la que finalmente marca la floración siguiente, es decir, es el fruto el que regula la floración y, por tanto, el responsable de la alternancia de cosechas en el naranjo dulce.

Tabla 1.1. Evolución anual del porcentaje de flores cuajadas en el naranjo dulce cv. 'Salustiana' en los cuatro años del experimento. El orden inicial del año, 1-2, se corresponde con los árboles de floración decreciente (ver Fig. 1.1).

\begin{tabular}{|lllll|}
\hline árbol & \multicolumn{4}{c|}{ años } \\
\hline $\mathbf{1}$ & $\mathbf{1 - 2}$ & $\mathbf{2}-\mathbf{3}$ & $\mathbf{3} \mathbf{- 4}$ & $\mathbf{4}$ - \\
\hline $\mathbf{2}$ & 2.2 & - & 43.5 & 9.9 \\
\hline $\mathbf{3}$ & 0.5 & - & 21.4 & 77.1 \\
\hline $\mathbf{4}$ & 2.1 & 9.83 & 44.5 & 15.9 \\
\hline $\mathbf{5}$ & 2.3 & 14.5 & 13.1 & 26.3 \\
\hline $\mathbf{6}$ & 7.3 & 8.7 & 11.7 & 44.3 \\
\hline $\mathbf{7}$ & 14.7 & 25.5 & 4.9 & 7.8 \\
\hline $\mathbf{8}$ & 11.9 & 2.7 & 22.8 & 15.9 \\
\hline $\mathbf{9}$ & 12.6 & 2.7 & 42 & 5.6 \\
\hline $\mathbf{1 0}$ & 34.2 & 0.4 & 9.8 & 3.7 \\
\hline
\end{tabular}



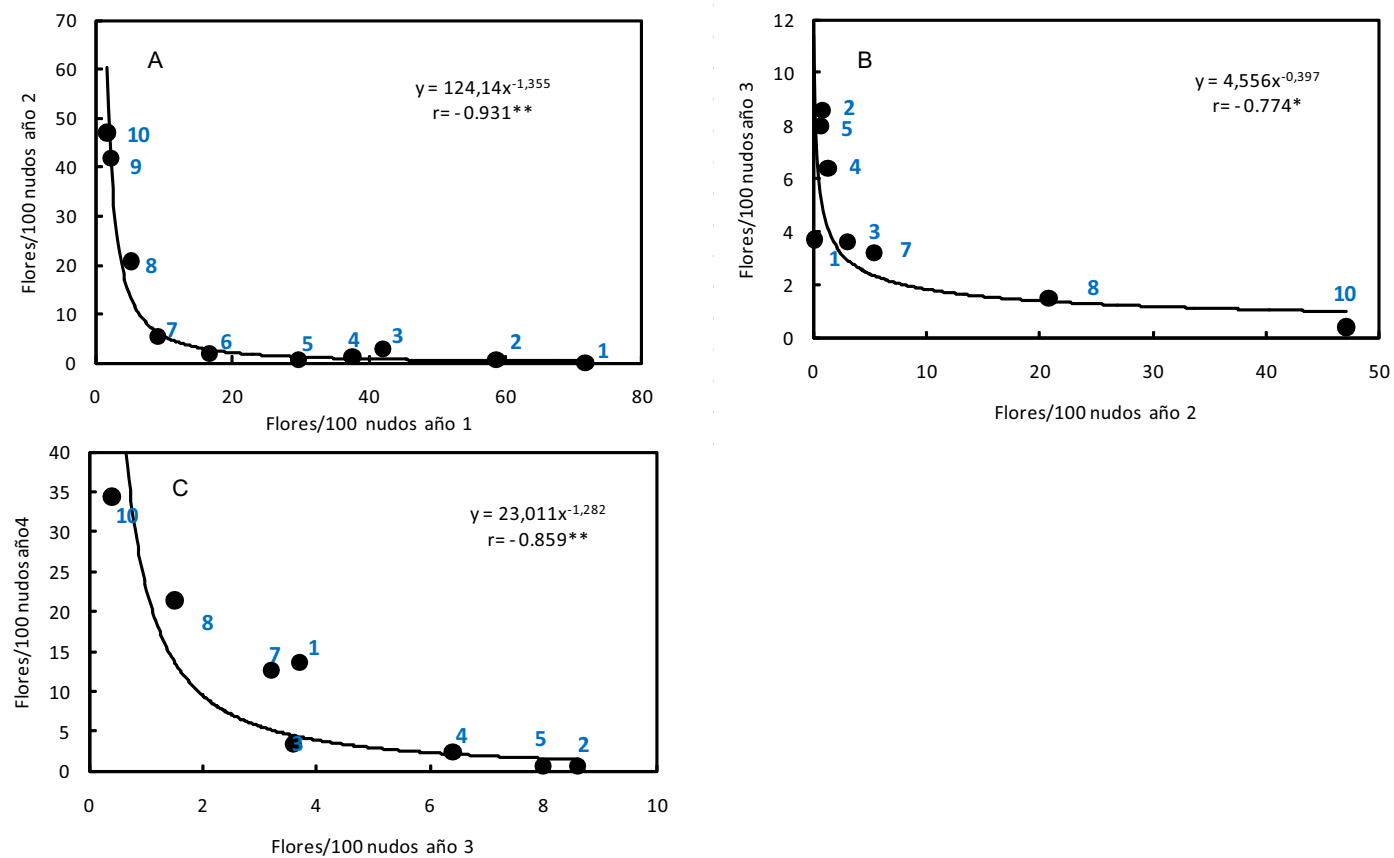

Figura 1.6. Relación entre dos floraciones sucesivas en el naranjo dulce cv.'Salustiana' a lo largo de los cuatro años consecutivos del experimento. Los árboles han sido numerados desde el de mayor floración (1) al de menor (10) al inicio del experimento (ver Fig. 1.1). * signif. $P \leq 0.05 ;{ }^{* *}=$ signif . $P \leq 0.01$

Por tanto, haber seleccionado árboles dentro de un amplio rango de intensidades de floración ha permitido demostrar, 1) el fenómeno alternante de la floración, 2) que la fructificación en este tipo de variedades se halla positiva y significativamente determinada por la floración, 3) que en ellas la floración se halla negativa y significativamente determinada por la fructificación previa, 4) que lo que son alternantes son los árboles, y 5) que el fenómeno de la relación floraciónfructificación de una población se perpetúa, precisamente, porque son sus árboles los que alternan en años on y off.

La alternancia de la floración es un fiel reflejo de la alternancia del tipo de brotes. En la figura 1.7 se muestra la evolución con los años del número de brotes reproductivos con hojas (Fig. 1.7 A) y sin hojas (Fig. 1.7 B). Aparentemente, los brotes reproductivos con hojas muestran una alternancia más marcada con los años que los reproductivos sin hojas, si bien su menor número (entre 1 y 7 brotes/100 nudos) frente al de los segundos (entre 1 y 20 brotes/100 nudos, aproximadamente) resta importancia, en su cómputo, sobre la intensidad de floración global (Fig. 1.1). Los brotes vegetativos muestran, en general, una alternancia opuesta (Fig. 1.7 C) a los reproductivos. 

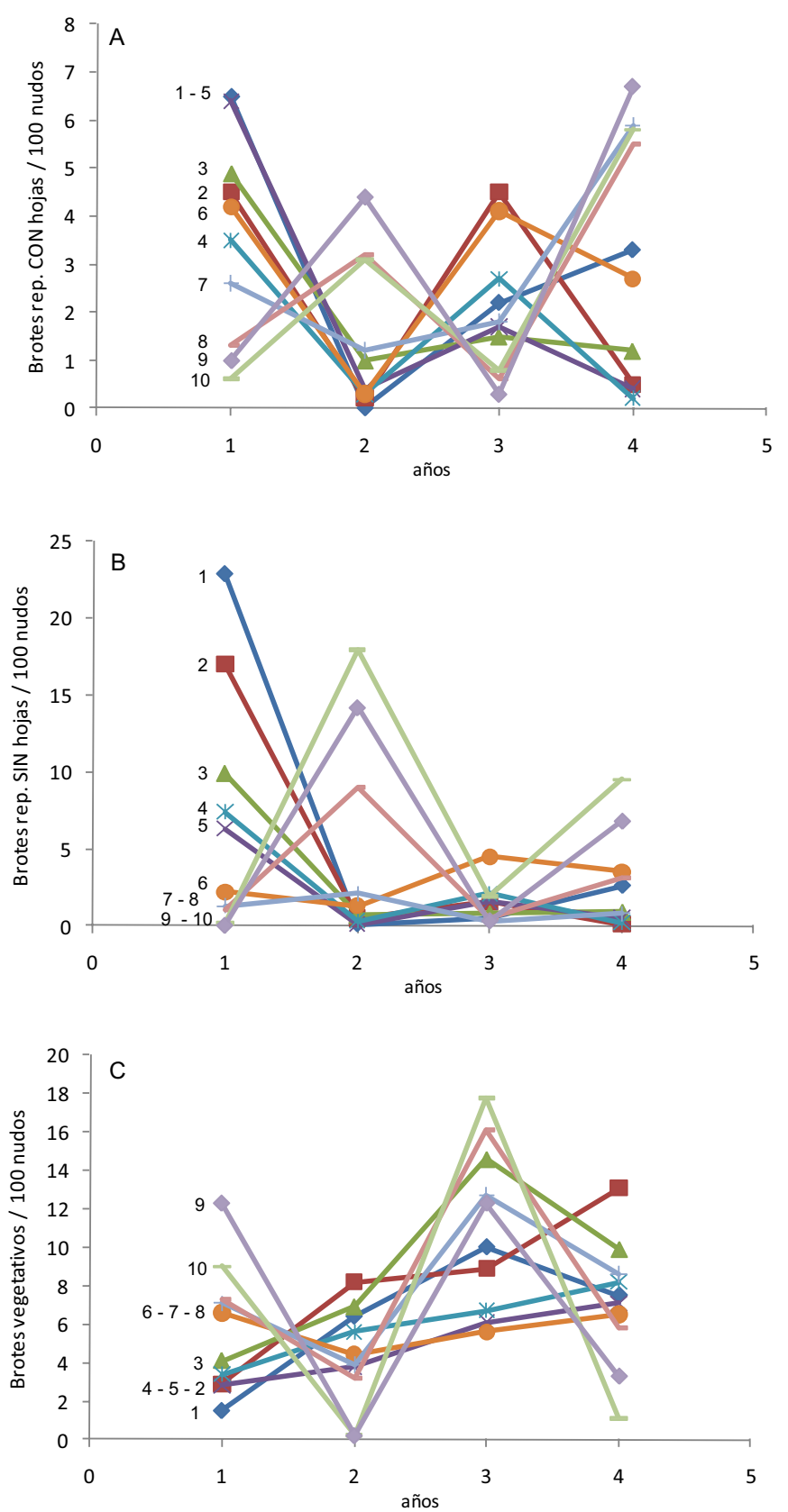

Figura 1.7. Evolución anual del número de brotes florales con hojas (A), sin hojas (B) y vegetativos (C) de árboles de naranjo dulce cv.'Salustiana' con diferente intensidad de floración inicial (año 1). Los árboles han sido numerados desde el de mayor floración (1) al de menor (10) al inicio del experimento (ver Fig. 1.1). 
Esta notable alternancia entre brotes reproductivos con hojas se refleja, también, en la dependencia que su presencia tiene de un año para otro. Así, la relación entre su número por 100 nudos entre dos años consecutivos presentó índices de regresión negativos y significativos de $r=-0.664(P \leq 0.05)$ para los años 3-4 y $r=-0.849(P \leq 0.01)$ y $r=-0.94(P \leq 0.01)$ para los años $1-2$ y 2-3, respectivamente (Figs. 1.8 A, B y C). Los brotes reproductivos sin hojas, sin embargo, y como corresponde a su menor alternancia, presentaron correlaciones poco estrechas, de modo que solamente los años 1-2 (Fig. 1.8 D) mostraron una relación estadísticamente significativa $(r=$ 816; $P \leq 0.05$ ); en los años 2-3 (Fig. 1.8 E) y 3-4 (Fig. 1.8 F) la relación interanual entre los brotes reproductivos sin hojas alcanzó coeficientes de regresión de $r=-0.237$ y $r=-0.119$, no estadísticamente significativos.
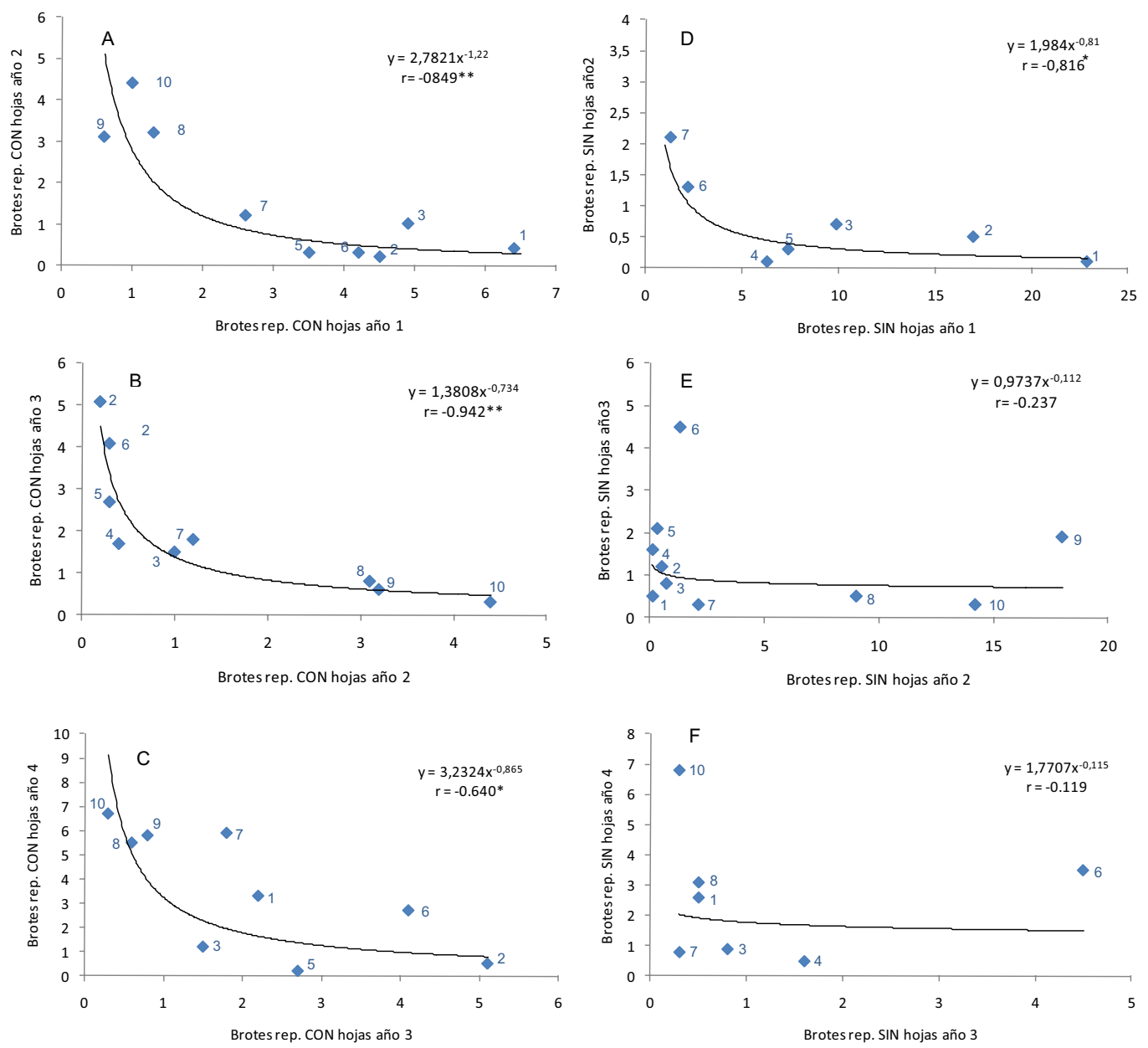

Figura 1.8. Interrelaciones anuales de los brotes con hojas (A, B y C) y sin hojas (D, E y F) del naranjo dulce cv.'Salustiana' a lo largo de cuatro años consecutivos. łores expresados por 100 nudos. Los árboles han sido numerados desde el de mayor floración (1) al de menor (10) al inicio del experimento (ver Fig. 1.1). * ssignif. $P \leq 0.05$; ** signif. $P \leq 0.01$. 
La importancia de la alternancia del tipo de brotes radica en su aportación a la cosecha. En efecto, la relación entre el número de brotes reproductivos con hojas y el número de frutos de la cosecha siguiente para los años 1-2 (Fig. 1.9 A) sigue una curva logarítmica con un coeficiente de regresión $r=+0.691$ ( $P \leq 0.05$ ). Los brotes sin hojas también presentan una correlación logarítmica con los frutos producidos por árbol (Fig. 1. 9 B) pero dada la escasa influencia que tienen sobre la cosecha siguiente, no alcanza la significación estadística ( $r=+0.412)$. Relaciones similares se encontraron para los cuatro años de nuestro experimento (datos no presentados).
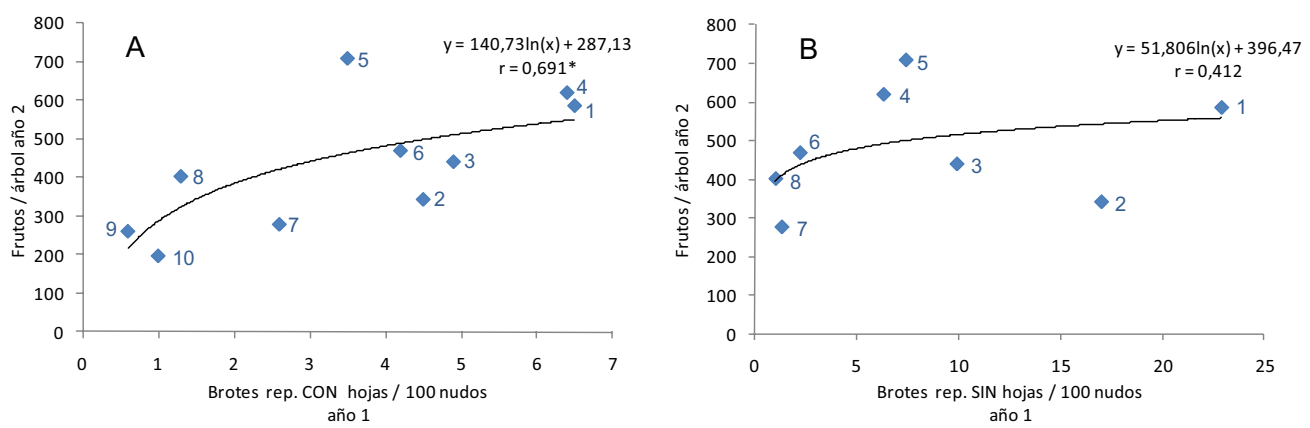

Figura 1.9. Influencia del número de brotes florales con hojas (A) y sin hojas (B) sobre la cosecha en el naranjo dulce cv.'Salustiana'. Los árboles han sido numerados desde el de mayor floración (1) al de menor (10) al inicio del experimento (ver Fig. 1.1). * signif. $P \leq 0.05$. 
Es de destacar las relaciones encontradas entre el número de brotes vegetativos y la intensidad de floración del año siguiente. Para todos los años estudiados, la relación entre ambas variables fue exponencial, positiva y significativa (Fig. 1.10). Es más, para los años 1-2 (Fig. $1.10 \mathrm{~A}$ ) y 3-4 (Fig. $1.10 \mathrm{C}$ ), esto es, para las floraciones de los años 2 y 4 , el número de brotes vegetativos fue mayor (véase el eje de abscisas) que para los años 2-3 (Fig. $1.10 \mathrm{~B}$ ), esto es, para la floración del año 3, lo que coincide con la mayor floración de los años 2 y 4 frente a la del año 3 . En los dos primeros casos los coeficientes de regresión fueron $r=+0.910(P \leq 0.01)$ y $r=+0.816(P \leq 0.01)$, respectivamente, y para el tercero $r=0.649$ ( $P \leq 0.05)$. Este hecho, a su vez, demuestra que en los cítricos la brotación y, por consiguiente, la floración de un año dado son dependientes de la brotación vegetativa del año anterior.
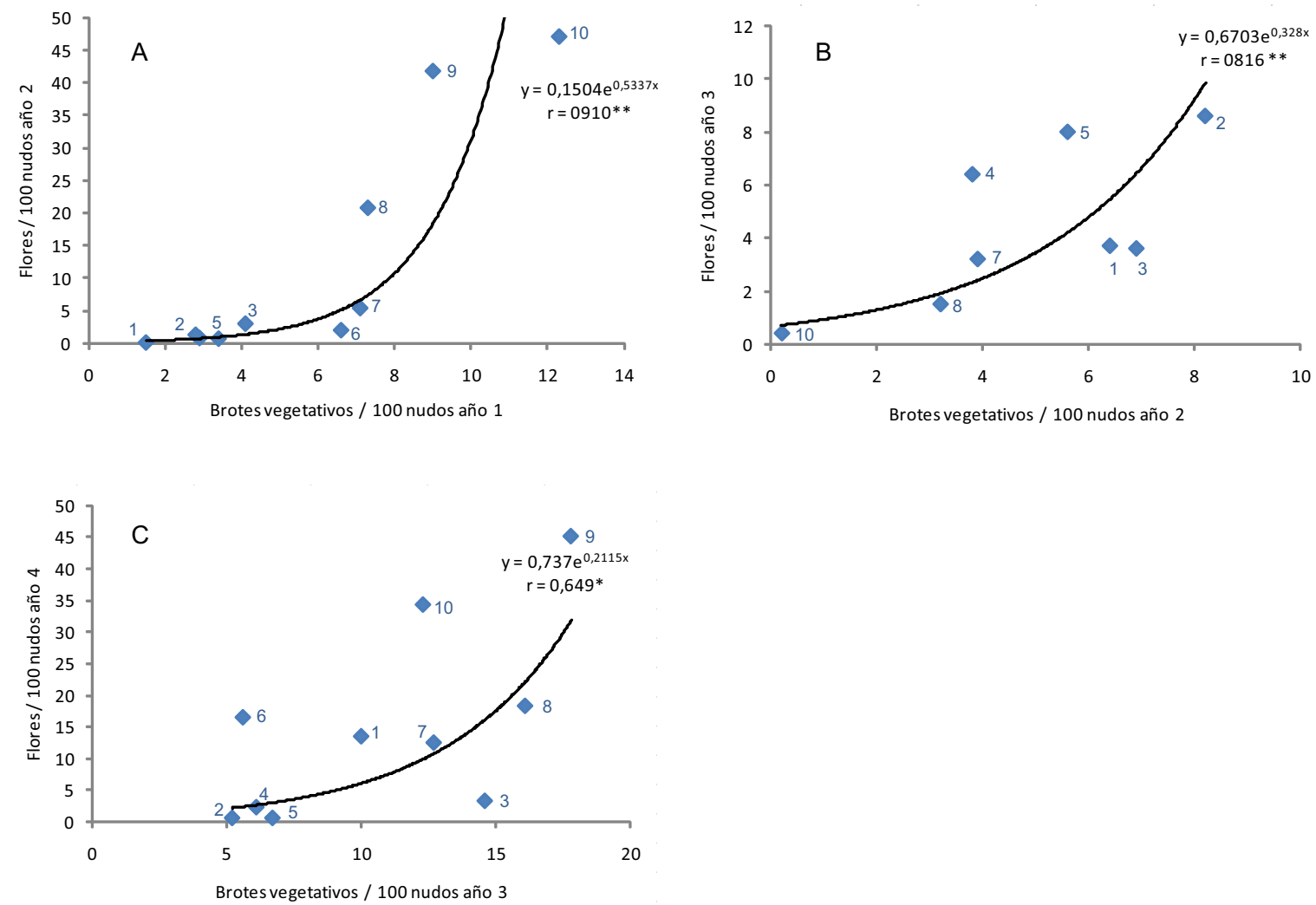

Figura 1.10. Relación entre el número de brotes vegetativos y la floración del naranjo dulce cv.'Salustiana' a lo largo de cuatro años consecutivos. Los árboles han sido numerados desde el de mayor floración (1) al de menor (10) al inicio del experimento (ver Fig. 1.1). * signif. $P \leq 0.05 ;{ }^{* *}=$ signif. $P \leq 0.01$. 
El descenso en el estudio hasta la determinación de si el número de flores por inflorescencia alterna o no con la cosecha, no reveló una tendencia clara (Fig. 1.11), de modo que el número de flores por inflorescencia fue, prácticamente, constante con independencia de la cosecha anterior y del número desarrollado de cada una de ellas. Yana respuesta similar se obtuvo con el número de hojas por brote en los brotes mixtos, multi y uniflorales (datos no presentados).
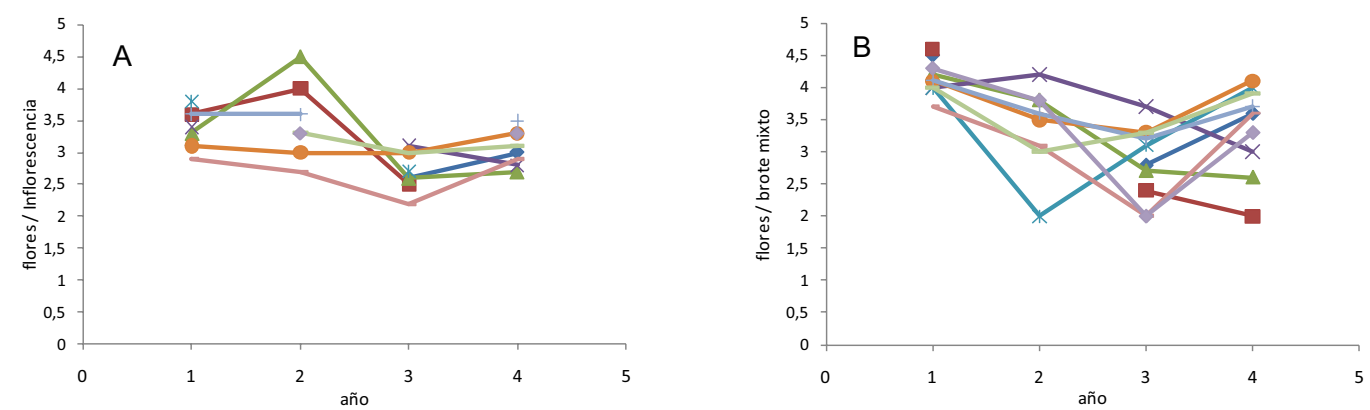

Figura 1. 11. Evolución del número de flores por inflorescencia $(A)$ y por brote mixto $(B)$ del naranjo dulce cv. 'Salustiana' durante cuatro años consecutivos. Los árboles han sido numerados desde el de mayor floración (1) al de menor (10) al inicio del experimento (ver Fig. 1.1).

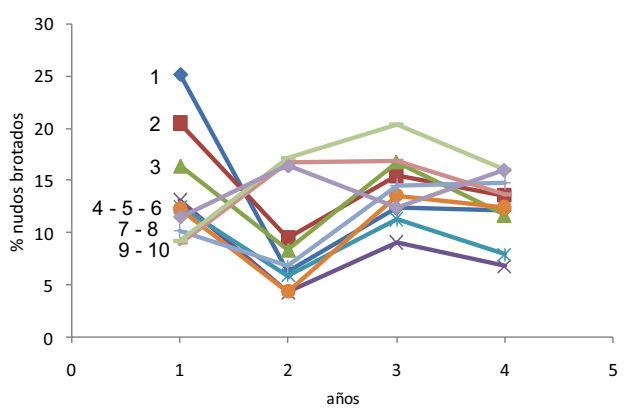

Figura 1. 12. Evolución de la brotación del naranjo dulce cv. 'Salustiana' durante cuatro años consecutivos. Los árboles han sido numerados desde el de mayor floración (1) al de menor (10) al inicio del experimento (ver Fig. 1.1). 
Finalmente, la brotación, mostró la misma tendencia que la floración a la alternancia, si bien menos acusada entre años (Fig. 1.12). Ello se debe a que parte de los nudos brotados dieron lugar a brotes vegetativos que, lógicamente, no computan en la floración y éstos son tanto más numerosos cuanto menor es la floración, y viceversa, compensando las diferencias entre años encontradas para la floración y modulando, de este modo, la alternancia de la brotación. En todo caso, la brotación y la floración presentaron una relación positiva, lineal y significativa (Fig. 1.13) en todos los años del experimento.

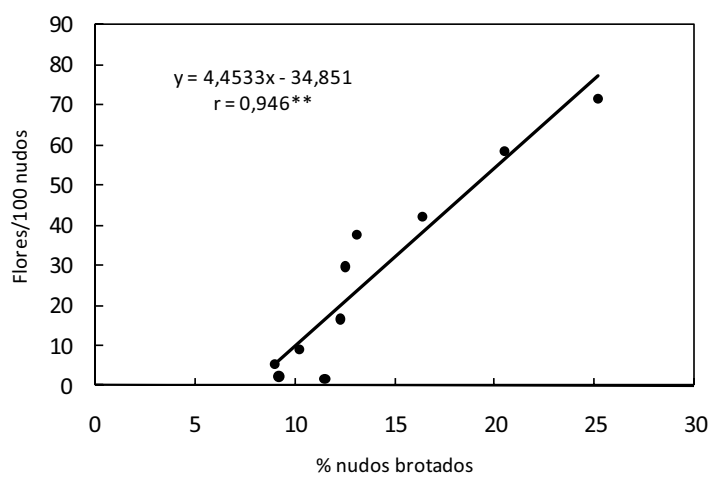

Figura 1. 13. Relación brotación - floración en el naranjo dulce cv. 'Salustiana'. $₫$ lores correspondientes al año $1 .{ }^{* *}=$ signif. $P \leq 0.01$.

Una respuesta fructificación-floración similar a la descrita para el naranjo dulce cv. 'Salustiana' (ver Fig. 1.5) se observó en el Tangor 'Nadorcott' (Fig. 1.14), de modo que cuanto mayor fue el número de frutos cosechados menor fue la floración del año siguiente, estando ambas variables relacionadas también según una función potencial y alcanzando la significación estadística $(r=-0.727 ; P \leq 0.05)$.

Un aspecto relevante de este estudio es la existencia de independencia entre ramas en las interrelaciones floración-fructificación. En un experimento con mandarino Clementino cv. 'Hernandina' en la que, por razones naturales, la cosecha se había distribuido asimétricamente, estando en su práctica totalidad ( $\geq 50 \mathrm{~kg} / a ́ r b o l)$ localizada en la cara este de los árboles, mientras que la cara oeste apenas tenía cosecha ( $\leq 10 \mathrm{~kg} / a ́ r b o l)$, se evaluó la brotación y la floración y su distribución en las caras este y oeste. En la cara con cosecha, el año siguiente brotaron el 22\% de los nudos, mientras que en la cara sin cosecha brotaron el $32 \%(P \leq 0.05)$. Es más, en la primera las flores apenas alcanzaron las 12 flores por 100 nudos, mientras que en la segunda superó las 30 flores por 100 nudos ( $P \leq 0.05)$ (Fig. 1.15). 


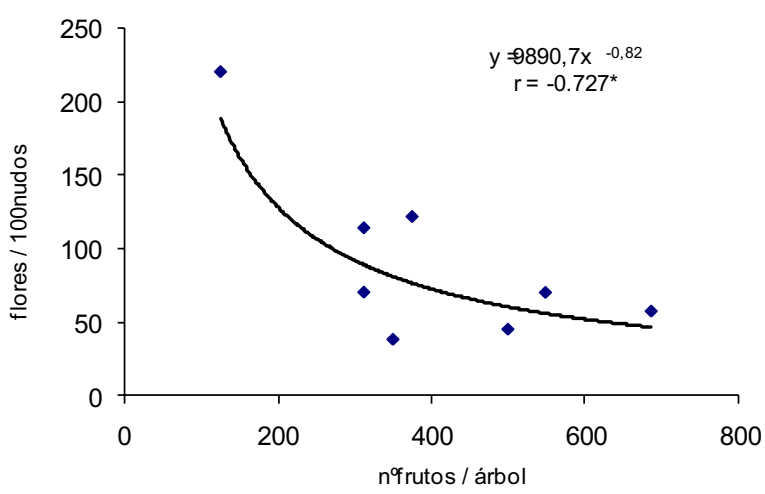

Figura 1.14. Influencia del número de frutos por árbol sobre la floración siguiente en el Tangor 'Nadorcott'. Cada valor es la media de nueve árboles. ${ }^{*}=$ signif. $\mathrm{P} \leq 0.05$.

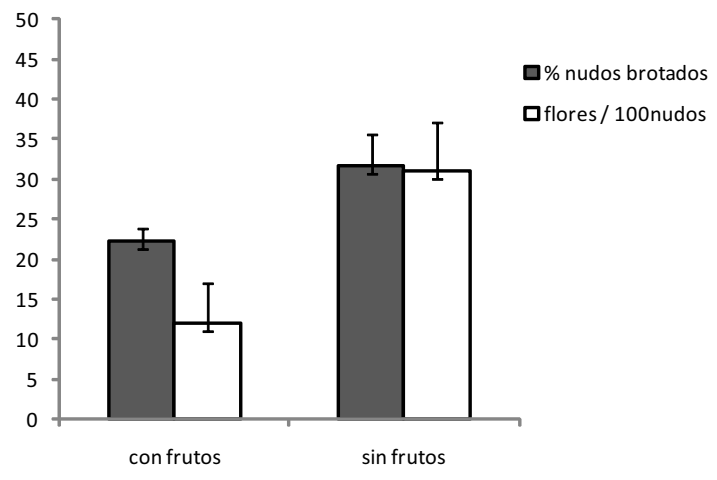

Figura 1.15. Comparación de la brotación y la floración entre la parte con frutos (cosecha $\geq 50 \mathrm{Kg} /$ árbol) y sin frutos (cosecha $\leq 10 \mathrm{Kg} / a ́ r b o l)$ de árboles de mandarino Clementino cv. 'Hernandina'. Las barras verticales indican el error estándar. Cada valor es la media de 6 árboles. 
También en esta especie, los tipos de brotes alternaron entre sí dependiendo de la cosecha previa. Así, el número de brotes multiflorales con hojas (brotes mixtos) al año siguiente de la cosecha evaluada fue de 0.2 brotes/100 nudos en la cara con frutos y de 2.1 brotes/100 nudos en la cara sin frutos $(P \leq 0.05)$, y el de los multiflorales sin hojas (ramos de flor) de 0.2 brotes/100 nudos y 1.3 brotes $/ 100$ nudos $(P \leq 0.05)$, respectivamente (Tabla 1.2). Los brotes uniflorales con hojas pasaron de 5.1 brotes/100 nudos en la cara con frutos a 7.9 brotes/100 nudos en la cara sin frutos $(P \leq 0.05)$, y las flores solitarias de 6.0 brotes/100 nudos a 14.1 brotes/100 nudos $(P \leq 0.05)$, respectivamente. Finalmente, los brotes vegetativos del mandarino Clementino cv. 'Hernandina', al igual que en el caso del naranjo dulce 'Salustiana', aumentaron con la cosecha previa, contabilizándose en la cara del árbol que había desarrollado una mayor cosecha 15.2 brotes/100 nudos y 13.2 brotes/100 nudos de la cara sin cosecha, si bien sin alcanzar la significación estadística (Tabla 1.2).

Tabla 1.2. Distribución de la brotación en árboles de mandarino Clementino cv. 'Hernandina'. Influencia de la presencia del fruto. \&lores expresados por 100 nudos . Cada valor es la media de 6 árboles. * $=$ signif. $P \leq 0.05$.

\begin{tabular}{|llllll|} 
& FS & FC & BM & RF & BV \\
\hline Sin frutos & 14.1 & 7.9 & 2.1 & 1.3 & 13.2 \\
\hline Con frutos & 6.0 & 5.1 & 0.2 & 0.2 & 15.2 \\
\hline Signif. & $*$ & $*$ & $*$ & $*$ & \\
\hline
\end{tabular}


2. Capítulo 2. Efecto del tiempo de permanencia del fruto en el árbol sobre la floración siguiente.

Los resultados anteriores demuestran que el fruto es, probablemente, el factor endógeno más importante en la regulación de la floración. Es más, existe una relación cuantitativa que indica que cuanto mayor es el número de frutos por árbol, menor es la floración de la primavera siguiente (Fig. 1.5). Es decir, su acción en el árbol depende del número de los que se desarrollan, pero no sabemos con precisión a partir de qué momento ejerce su acción o si su efecto es continuo en el tiempo o si existen épocas de mayor o menor sensibilidad. Para ello se diseñó un experimento, en árboles de naranjo dulce cv. 'Valencia', en el que los frutos de ramas previamente seleccionadas se eliminaron en etapas diferentes del desarrollo del fruto desde el inicio de la fase II (mediados de junio) hasta su recolección (finales de abril) y se contaron las flores de la brotación siguiente.

La floración resultó inversamente relacionada con el tiempo de permanencia del fruto en el árbol (Fig. 2.1), mostrando dos épocas de influencia del fruto sobre la floración: 1) desde el inicio de la caída fisiológica de frutos en Junio hasta el casi completo desarrollo del fruto (septiembre), y 2) desde la fecha en que el fruto alcanza su máximo tamaño (noviembre) hasta la completa maduración, coincidiendo este último con el momento de la recolección. Para el primer periodo, la floración de la primavera siguiente alcanzó un valor medio de 41.8 flores/100 nudos, mientras que para el segundo resultó inferior a 10 flores/100 nudos (6.9 flores/100 nudos de valor medio) (Fig. 2.1). Una reducción adicional en la intensidad de floración, marcadamente menos importante, se observó a lo largo de este segundo periodo, desde el inicio del cambio de color (noviembre) hasta la completa maduración del fruto (abril). Es importante destacar que este último estado de desarrollo coincidió con la brotación siguiente. 


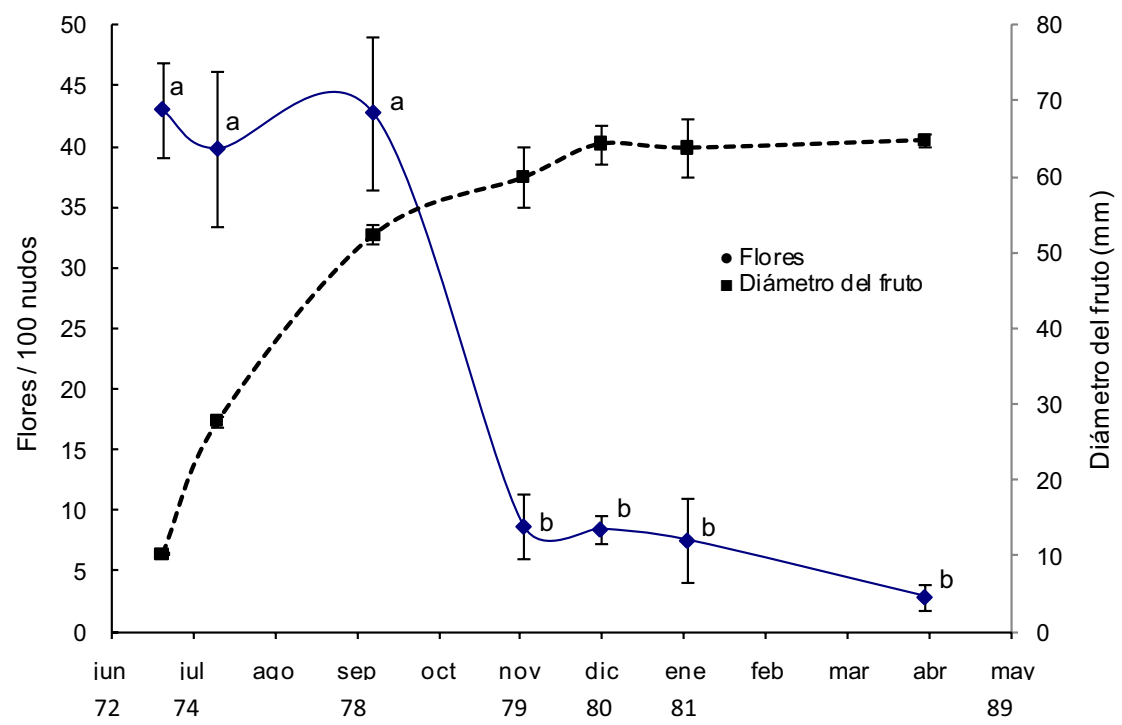

Estado fenológico de la escala $\mathrm{BBCH}$ en el momento de eliminación de los frutos

Figura 2.1. Influencia del tiempo de permanencia de los frutos en el árbol sobre la floración siguiente en el naranjo dulce cv. 'Valencia'. Evolución del desarrollo del fruto. En cada fecha indicada se eliminó el total de frutos y se midió su diámetro. Cada valor es la media de 10 árboles. Las barras verticales indican el error estándar. Letras distintas indican diferencias significativas $(P \leq 0.05)$.

La brotación siguió una tendencia decreciente con la reducción de la floración (Fig. 2.2), existiendo una relación significativa entre el porcentaje de yemas brotadas y el número de flores/100 nudos ( $r=+0.976$; $P \leq 0.05)$, de un modo similar a lo ocurrido al comparar árboles del cv. 'Salustiana' con diferentes intensidades de floración (Fig. 1.13).

El número de brotes de verano y otoño también se redujo significativamente $(P \leq 0.05)$ cuando los frutos permanecieron en el árbol desde el momento que alcanzaron su máximo tamaño hasta su completa maduración ( 0.5 brotes por 100 nudos de media), en comparación con la presencia de los frutos desde la caída fisiológica (mediados de junio) hasta su completo desarrollo (3.4 brotes por 100 nudos de media).

Las yemas de brotes reproductivos (con o sin hojas) fueron las más sensibles al efecto inhibidor del fruto. Comparando los dos periodos de sensibilidad descritos, la frecuencia de este tipo de brotes se redujo en un $80 \%$, por término medio, debido a la permanencia del fruto desde el inicio del cambio de color (noviembre) en adelante (Fig. 2.3). Por el contrario, la frecuencia de distribución de los brotes vegetativos fue incrementada en un $60 \%$. Estos resultados son similares a los obtenidos comparando árboles del cv. 'Salustiana' con diferente número de frutos (ver Capítulo 1). 


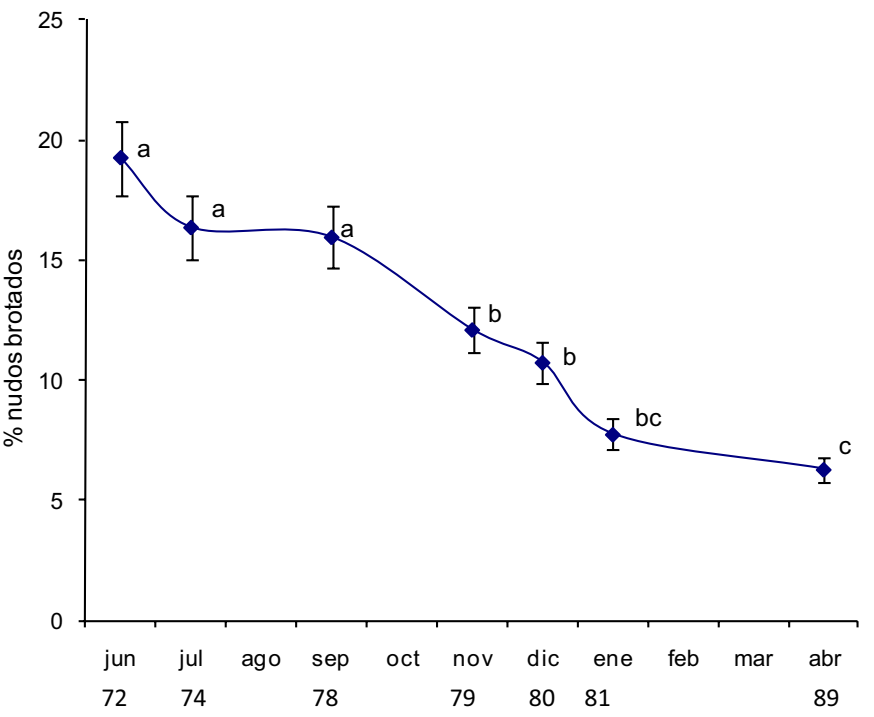

Estado fenológico de la escala $\mathrm{BBCH}$ en el momento de eliminación de los frutos

Figura 2. 2. Influencia del tiempo de permanencia de los frutos en el árbol sobre el porcentaje de nudos brotados en el naranjo dulce cv. 'Valencia'. En cada fecha indicada se eliminó el total de frutos. Cada valor es la media de diez árboles. Las barras verticales indican el error estándar. Letras distintas indican diferencias significativas $(P \leq 0.05)$. 


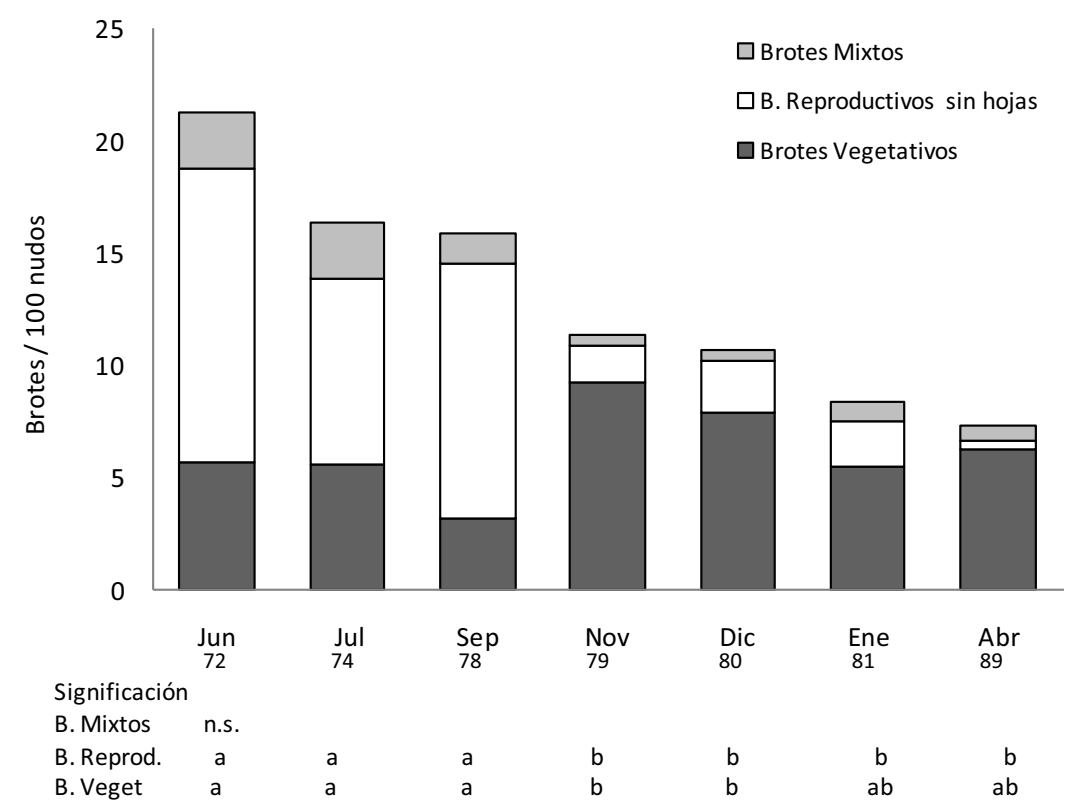

Figura 2.3. Influencia del tiempo de permanencia de los frutos en el árbol sobre el número de los tipos de brotes desarrollados en el naranjo dulce cv. 'Valencia'. En cada fecha indicada se eliminó el total de frutos. Cada valor es la media de diez árboles. Letras distintas indican diferencias significativas $(P \leq 0.05)$. En cada fecha se indica el estado $\mathrm{BBCH}$.

En valores absolutos, los brotes multiflorales sin hojas (inflorescencias) se redujeron de 7.8 a 1.2 brotes/100 nudos, por término medio $(P \leq 0.05)$, cuando se compararon los dos periodos de permanencia de los frutos, y los brotes uniflorales sin hojas (flores solitarias) de 3.0 a 0.4 brotes por 100 nudos $(P \leq 0.05)$; sus equivalentes con hojas se redujeron solo ligeramente por efecto del fruto, de 1.2 a 0.8 los multiflorales (brotes mixtos) y de 0.5 a 0.3 los uniflorales (brotes campaneros).

Las características de los brotes, esto es, número de flores y/o hojas por brote, no fueron modificadas significativamente por la presencia del fruto, con independencia del tipo de brote (datos no presentados). Esta respuesta también es similar a la encontrada al comparar árboles con diferente número de frutos (Fig. 1.11).

Coincidente con estos resultados, la aplicación de $\mathrm{GA}_{3}$ a finales de septiembre, cuando la influencia del fruto sobre la floración ya resulta marcada (Fig. 2.1.), redujo significativamente la floración de la primavera siguiente en el naranjo dulce cv. 'Navelate'. La respuesta fue progresiva con el aumento de la concentración, siendo máxima para $30 \mathrm{mg} \mathrm{l}^{-1} \mathrm{o}$ concentraciones superiores (Tabla 2.1). La reducción de la floración pasó de 35.4 flores/100 nudos en los árboles control a 13.6 
flores/100 nudos $(P \leq 0.05)$ en los tratados con $30 \mathrm{mg} \mathrm{l}^{-1}$ de $\mathrm{GA}_{3}$ y aunque se redujo hasta 5.3 flores/100 nudos para $50 \mathrm{mg} \mathrm{l}^{-1}$ de $\mathrm{GA}_{3}$, la diferencia no alcanzó la significación estadística. Aunque la brotación también se redujo paralelamente a la reducción de la floración, el efecto sobre ella no alcanzó la significación estadística para ninguna de las concentraciones ensayadas (Tabla 2.1). La distribución de los brotes también fue significativamente alterada, disminuyendo el número de brotes florales y aumentando el número de brotes vegetativos (Tabla 2.2).

Tabla 2.1. Efecto de la dosis de aplicación de $\mathrm{GA}_{3}$ sobre la brotación y floración del naranjo dulce cv. 'Navelate". Cada valor es la media de 8 árboles. Letras diferentes en una misma columna indican diferencias significativas $(P \leq 0.05)$.

\begin{tabular}{|c|c|c|}
\hline & Brotes / 100 nudos & Flores / 100 nudos \\
\hline Control & 20.9 & $35.4 \mathrm{c}$ \\
\hline $\mathrm{GA}_{3} 10 \mathrm{mg} \mathrm{l}^{-1}$ & 22.9 & $35.0 \mathrm{c}$ \\
\hline $\mathrm{GA}_{3} 20 \mathrm{mg} \mathrm{l}^{-1}$ & 22.1 & $25.6 \mathrm{bc}$ \\
\hline $\mathrm{GA}_{3} 30 \mathrm{mg} \mathrm{l}^{-1}$ & 18.0 & $13.6 a b$ \\
\hline $\mathrm{GA}_{3} 40 \mathrm{mg} \mathrm{l}^{-1}$ & 17.8 & $6.2 \mathrm{a}$ \\
\hline $\mathrm{GA}_{3} 50 \mathrm{mg} \mathrm{l}^{-1}$ & 17.4 & $5.3 \mathrm{a}$ \\
\hline
\end{tabular}

Tabla 2.2. Efecto de la dosis de aplicación de $\mathrm{GA}_{3}$ sobre la distribución de los tipos de brotes en el naranjo dulce cv. 'Navelate'. Valores expresados por cien nudos. Cada valor es la media de 8 árboles. Letras diferentes en una misma columna indican diferencias significativas $(P \leq 0.05)$.

\begin{tabular}{|c|c|c|c|c|c|}
\hline & FS & FC & BM & RF & BV \\
\hline Control & $2.68 c$ & $2.35 \mathrm{~b}$ & $4.90 \mathrm{~b}$ & $2.35 \mathrm{~b}$ & $8.84 \mathrm{a}$ \\
\hline $\mathrm{GA}_{3} 10 \mathrm{mg} \mathrm{l}^{-1}$ & $1.78 a b c$ & $2.27 \mathrm{~b}$ & $4.61 \mathrm{~b}$ & $2.87 \mathrm{~b}$ & $11.45 a b$ \\
\hline $\mathrm{GA}_{3} 20 \mathrm{mg} \mathrm{l}^{-1}$ & $2.38 \mathrm{bc}$ & $1.23 \mathrm{ab}$ & $2.78 \mathrm{ab}$ & $2.84 \mathrm{~b}$ & $12.17 \mathrm{ab}$ \\
\hline $\mathrm{GA}_{3} 30 \mathrm{mg} \mathrm{l}^{-1}$ & $0.81 \mathrm{ab}$ & $1.72 \mathrm{ab}$ & $1.81 \mathrm{a}$ & $1.03 \mathrm{ab}$ & $12.67 \mathrm{ab}$ \\
\hline $\mathrm{GA}_{3} 40 \mathrm{mg} \mathrm{l}^{-1}$ & $0.27 \mathrm{a}$ & $1.22 \mathrm{ab}$ & $0.95 a$ & $0.39 \mathrm{a}$ & $14.99 \mathrm{~b}$ \\
\hline $\mathrm{GA}_{3} 50 \mathrm{mg} \mathrm{l}^{-1}$ & $0.21 \mathrm{a}$ & $0.89 \mathrm{a}$ & $0.78 \mathrm{a}$ & $0.21 \mathrm{a}$ & $15.28 \mathrm{~b}$ \\
\hline
\end{tabular}


Un estudio más detallado del efecto del fruto sobre la floración, a partir del inicio del cambio de color hasta la completa maduración del fruto, se llevó a cabo en el Tangor 'Nadorcott', fraccionando, por una parte, el volumen de cosecha recolectado entre febrero y abril, y evaluando, por otra, la influencia de diferentes cuantías de cosecha según su momento de recolección, así como su interacción. En el primer caso, la cosecha (200-205 Kg/árbol de valor medio) se recolectó en el mes de febrero: en su totalidad (3/3), 2/3, 1/3 o se dejó para la segunda fecha de recolección, abril; en este mes se recolectó: nada, 1/3, 2/3 o la totalidad, respectivamente. Cuanto menor fue el porcentaje de cosecha recolectado en la primera fecha, mayor fue la floración siguiente, y viceversa, reduciéndose paulatinamente la intensidad de floración a medida que se redujo aquel desde 54 flores/100 nudos, en los árboles en los que se recolectó la totalidad de los frutos en febrero, hasta 27 flores/100 nudos en los que todos los frutos se recolectaron en abril (Tabla 2.3). También en este caso existió una variación paralela de la intensidad de brotación (porcentaje de nudos brotados) y la intensidad de floración (flores/100 nudos) (Tabla 2.3).

Tabla 2.3. Influencia del tiempo de permanencia del fruto maduro en el árbol determinado por el momento de su recolección y su fraccionamiento, sobre la floración y brotación siguientes en el Tangor 'Nadorcott'. Efecto del fraccionamiento de la recolección. La cosecha se recolectó en su totalidad (3/3) o parcialmente el 21 de febrero y se completó el 7 de abril. Cada valor es la media de 15 árboles. Letras distintas en la misma columna indican diferencia significativa $(P \leq 0.05)$

\begin{tabular}{|ccc|}
\hline Cosecha recolectada & Flores/100 nudos & \%brotación \\
\hline $3 / 3$ & $54.7 \mathrm{~b}$ & $50.9 \mathrm{~b}$ \\
\hline $\mathbf{2 / 3}$ & $43.5 \mathrm{ab}$ & $45.5 \mathrm{ab}$ \\
\hline $1 / 3$ & $27.1 \mathrm{a}$ & $34.9 \mathrm{a}$ \\
\hline--- & $27.2 \mathrm{a}$ & $36.9 \mathrm{a}$ \\
\hline
\end{tabular}


En el segundo caso, en árboles de Tangor 'Nadorcott', que diferían notablemente en su cosecha (entre 100 y más de $200 \mathrm{~kg} / a ́ r b o l)$ y que se recolectaron en tres fechas distintas, entre finales de febrero y principio de abril, tanto la cuantía de la cosecha como la fecha de recolección se relacionaron negativamente con la floración siguiente (flores/100 nudos) (Tabla 2.4). Así, la comparación del efecto de la cosecha con independencia de la fecha de recolección indica que, la intensidad de floración se redujo significativamente de 55.5 flores/100 nudos, en los árboles con un rango de cosecha de 100-150 kg/árbol, a 24.5 flores/100 nudos en los árboles con una cosecha superior a $150 \mathrm{~kg} / a$ rbol; cosechas superiores a $200 \mathrm{~kg} / a$ rbol redujeron aún más la floración, hasta casi 12 flores/100 nudos, pero sin alcanzar la significación estadística respecto a los árboles del rango $150-200 \mathrm{~kg}$ de cosecha. Por otro lado, los árboles recolectados el 23 de febrero presentaron una floración media de 41.1 flores/100 nudos, sin tener en cuenta la cuantía de la cosecha, mientras que la de los recolectados el 10 de abril fue de 20.5 flores/100 nudos $(P \leq 0.05)$; los recolectados en una fecha intermedia (21 de marzo), presentaron una respuesta, a su vez, intermedia, sin diferir estadísticamente de las dos fechas extremas (Tabla 2.3). La interacción cosecha-floración alcanzó la significación estadística ( $P \leq 0.05)$. Como en los casos anteriores, los cambios en la floración fueron paralelos a los cambios en la brotación (Tabla 2.4).

Tabla 2.4. Influencia de la cuantía de la cosecha y el tiempo de permanencia del fruto maduro en el árbol, determinado por la fecha de recolección, sobre la floración y brotación siguientes en el Tangor 'Nadorcott'. Cada valor es la media de 5 árboles. Las fechas de recolección fueron: 1: 23 febrero; 2: 21 marzo; 3: 10 abril.

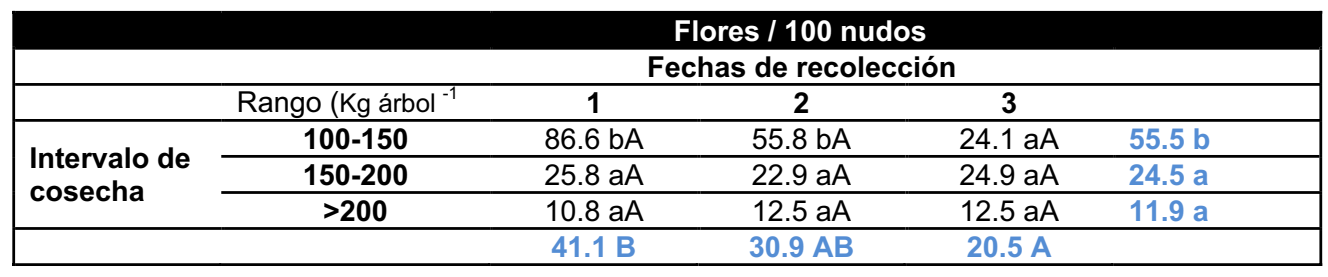

\begin{tabular}{|lccccc|}
\hline \multirow{2}{*}{$\begin{array}{l}\text { Intervalo de } \\
\text { cosecha }\end{array}$} & \begin{tabular}{l} 
Rango $\left(\mathrm{Kg} \mathrm{árbol}^{-1}\right.$ \\
\cline { 2 - 6 }
\end{tabular} & $66.2 \mathrm{bA}$ & $49.2 \mathrm{bA}$ & $31.7 \mathrm{aA}$ & $49.0 \mathrm{~b}$ \\
\cline { 2 - 6 } & $\mathbf{1 0 0 - 1 5 0}$ & $32.7 \mathrm{aA}$ & $26.2 \mathrm{aA}$ & $28.1 \mathrm{aA}$ & $28.9 \mathrm{a}$ \\
\hline & $\mathbf{1 5 0 - 2 0 0}$ & $22.8 \mathrm{aA}$ & $20.0 \mathrm{aA}$ & $21.7 \mathrm{aA}$ & $21.5 \mathrm{a}$ \\
\hline
\end{tabular}

Letras mayúsculas distintas indican diferencias significativas entre fechas para un mismo intervalo de cosecha.

Letras minúsculas distintas indican diferencias significativas entre intervalos de cosecha para una misma fecha. 
El contenido en carbohidratos de las hojas de los árboles del cv. 'Valencia', presentó diferencias significativas debido a la presencia del fruto, dependiendo la intensidad de la respuesta de la fecha de análisis (Tabla 2.5). Mientras la concentración de glucosa fue significativamente menor en las hojas de las ramas en las que el fruto estuvo ausente desde inicio de su desarrollo lineal (junio), tanto al final del periodo de desarrollo de éste (septiembre) como al inicio del cambio de color (enero), la concentración de fructosa fue significativamente inferior únicamente durante el cambio de color, y la de sacarosa sólo al final del desarrollo del fruto. Las hojas de las ramas que mantuvieron todos sus frutos hasta la maduración presentaron el menor contenido en almidón en abril, al final del periodo de permanencia del fruto en el árbol, coincidente con la brotación. Excepto para el almidón y la glucosa en las ramas en las que el fruto estuvo ausente desde el inicio de la fase lineal del desarrollo (mediados de junio), todos los azúcares presentaron concentraciones más elevadas en el momento del cambio de color, independientemente de la presencia del fruto. Para el almidón, se observó una concentración mayor en el momento de la brotación, independientemente de la permanencia de los frutos.

La concentración de $\mathrm{NO}_{3}{ }^{-}-\mathrm{N}$ acumulada en las hojas de las ramas que mantuvieron todos sus frutos hasta la maduración fue significativamente menor de la acumulada en las hojas de las ramas en las que los frutos estuvieron ausentes desde el inicio del desarrollo lineal (junio). Las primeras presentaron concentraciones casi constantes durante las dos últimas fechas de análisis, mientras que los niveles en las últimas descendieron de 68 a $29 \mu \mathrm{g} \mathrm{g}^{-1} \mathrm{PS}$ (Tabla 2.6). Así, en el momento del cambio de color (enero) la concentración de $\mathrm{NO}_{3}^{-}-\mathrm{N}$ en las hojas de las ramas con todos los frutos era $27 \mathrm{\mu g} \mathrm{g}^{-1}$ PS inferior a la de las hojas de ramas sin frutos, mientras que en el momento de su recolección, coincidente con la brotación, el contenido foliar era $17 \mu \mathrm{g} \mathrm{g}^{-1} \mathrm{PS}$ superior.

El contenido de la fracción $\mathrm{NH}_{4}{ }^{+}-\mathrm{N}$ en las hojas se incrementó durante el periodo de desarrollo del fruto independientemente de su presencia en el árbol, y el contenido en las hojas de las ramas que mantuvieron todos los frutos también permaneció constante a partir del cambio de color, desde enero hasta abril (28-29 $\mathrm{g} \mathrm{g} \mathrm{g}^{-1} \mathrm{PS}$ ); no se encontraron diferencias significativas debidas al efecto del fruto durante el desarrollo del mismo (septiembre) ni en el momento del cambio de color (enero); sin embargo, durante la brotación (coincidente con la plena madurez del fruto, abril), la concentración de $\mathrm{NH}_{4}{ }^{+}-\mathrm{N}$ de las hojas que mantuvieron todos sus frutos (29 $\mathrm{gg} \mathrm{g}^{-1}$ PS) fue significativamente inferior a la de las hojas de las ramas que no soportaban frutos (36 $\mu \mathrm{g} \mathrm{g}^{-}$ 
${ }^{1}$ PS). Cabe destacar que, mientras en estas últimas, la concentración foliar de $\mathrm{NO}_{3}^{-}-\mathrm{N}$ se redujo significativamente, la de $\mathrm{NH}_{4}{ }^{+}-\mathrm{N}$ se incrementó significativamente desde el inicio del cambio de color. No se encontraron diferencias significativas en las hojas de las ramas que mantuvieron todos sus frutos a partir de dicho momento (Tabla 2.6). Tampoco se encontraron diferencias significativas en la fracción de nitrógeno proteico debido a la presencia del fruto (Tabla 2.6); no obstante, en momento de la recolección, coincidente con el de la brotación (abril), la concentración en las hojas de las ramas que mantuvieron todos los frutos y en las hojas de las ramas $\sin$ fruto fue $4.5 \mathrm{y} 4.1 \mathrm{\mu g}$ $\mathrm{g}^{-1}$ PS inferior, respectivamente, a la concentración que tenían en el momento del cambio de color (enero). 


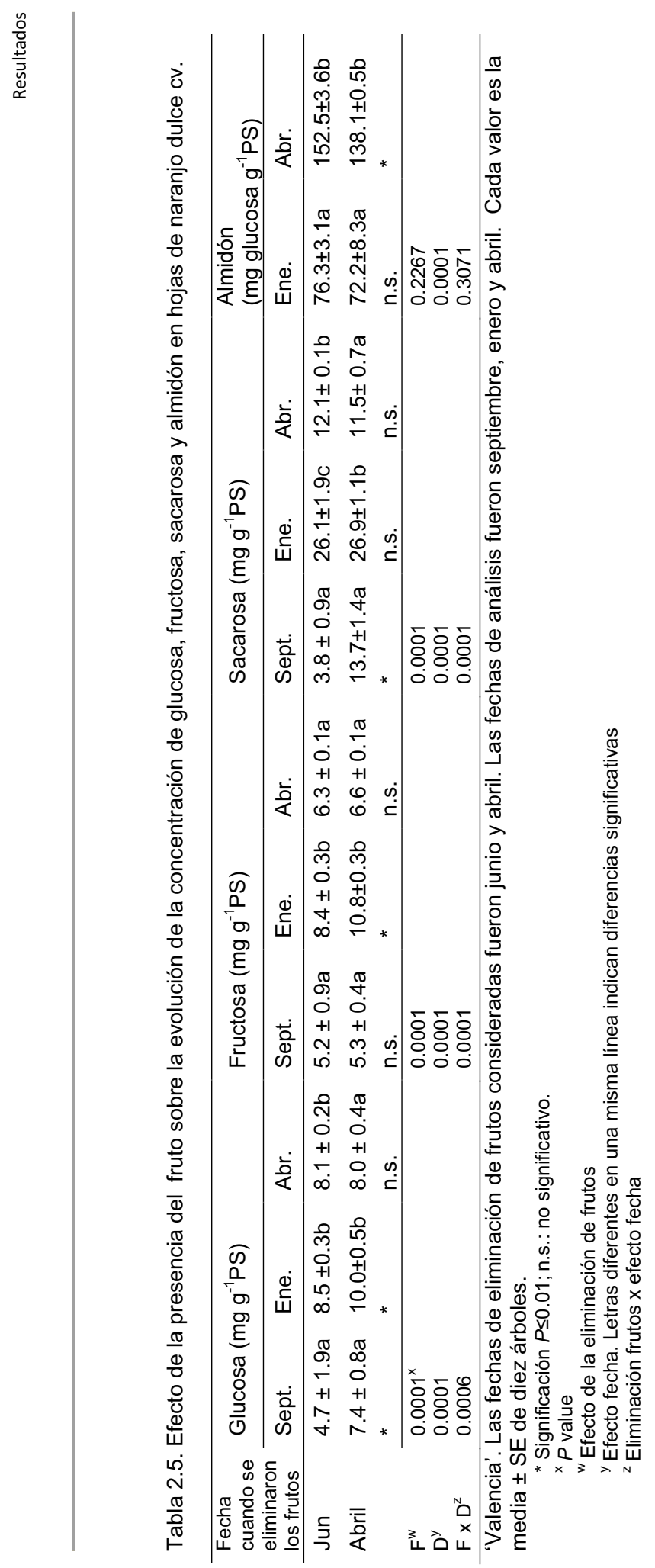




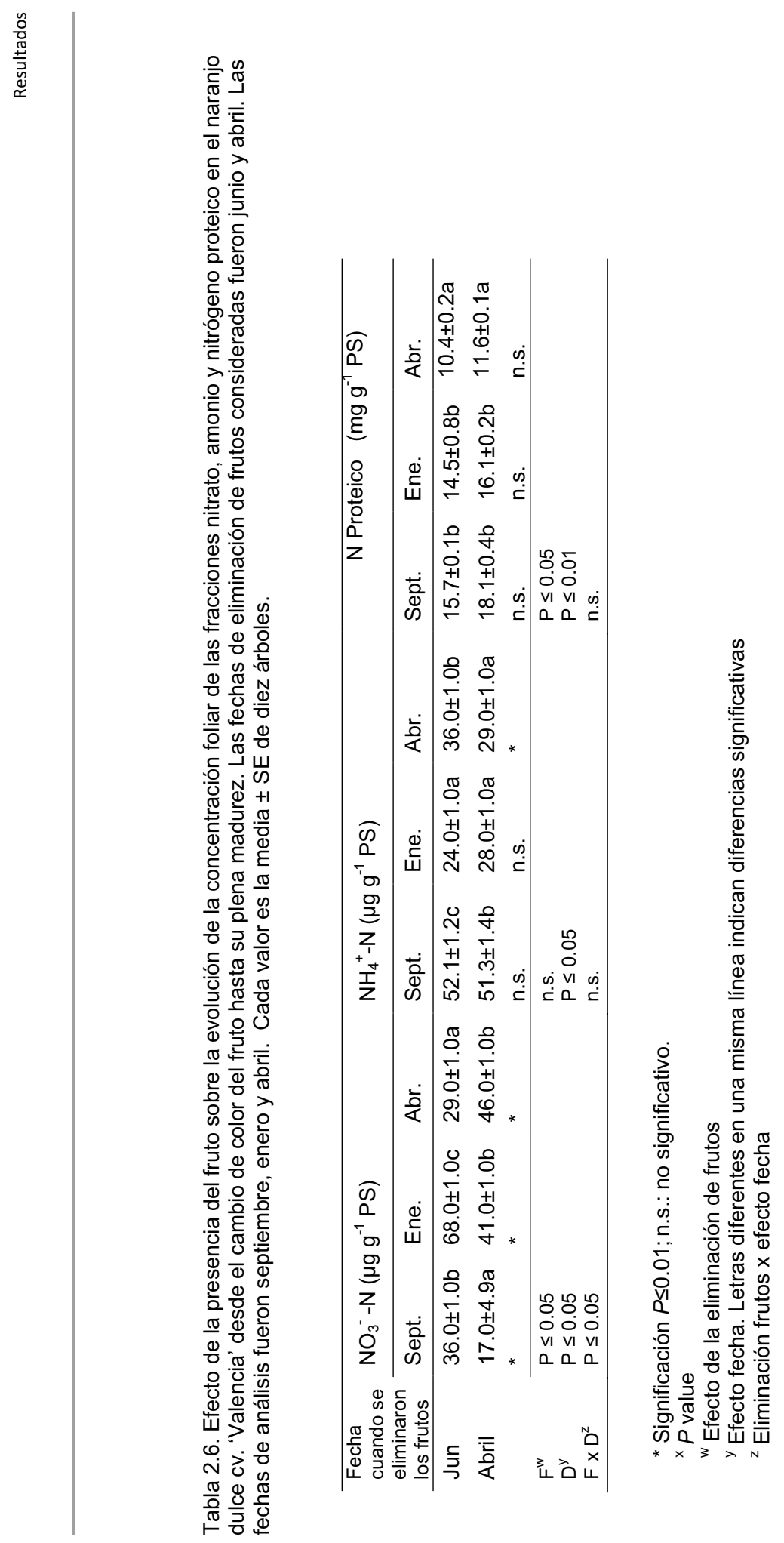



3. Capítulo 3. Efecto del aislamiento parcial del fruto sobre la floración. Micro-rayado de la corteza del pedúnculo.

El aislamiento parcial del fruto de brotes campaneros, mediante la interrupción del transporte floemático a través de un anillado permanente en su pedúnculo, modificó la pauta de brotación de primavera de las yemas adyacentes. Así, en un experimento llevado a cabo durante tres años en el naranjo dulce cv. 'Valencia', en el primer año (año I) el anillado del pedúnculo del fruto en el mes de noviembre, cuando el fruto se encontraba en el estado fenológico 79 de la escala BBCH y había iniciado la degradación de clorofilas del flavedo $(a / b=-0.3)$, incrementó significativamente el número de nudos brotados la primavera siguiente en el propio brote en el que se encontraba el fruto.

Todos los brotes fueron vegetativos, sin diferencias significativas en su longitud y con un número de hojas por brote similar (Tabla 3.1).

Tabla 3.1. Efecto del anillado del pedúnculo del fruto de un brote campanero de naranjo dulce cv. 'Valencia' (Lliria) sobre la brotación de primavera de sus yemas. El anillado se efectuó a finales de noviembre (30 de noviembre, años I y III; 28 de noviembre, año II) en el estado fenológico 79 de la escala $\mathrm{BBCH}$. Cada valor es la media de 60 brotes campaneros repartidos entre 5 árboles. PF: peso fresco; $\mathrm{N}$ : $\mathrm{n}^{\circ}$ de nudos; NB: nudos brotados; $\mathrm{H}: \mathrm{n}^{\circ}$ de hojas; L: longitud del brote; FI: $\mathrm{n}^{\circ}$ de flores

\begin{tabular}{|c|c|c|c|c|c|c|c|c|}
\hline año & Fecha & $\begin{array}{l}\text { Fruto mad } \\
\text { (28 marzo) }\end{array}$ & & $\begin{array}{l}\text { Brotacióı } \\
\text { (2 junio) }\end{array}$ & y Floración & & & \\
\hline \multirow{4}{*}{ I } & \multirow{4}{*}{30 nov. } & $\begin{array}{c}\text { PF fruto }{ }^{-1} \\
\text { (g) }\end{array}$ & $\begin{array}{l}\text { Color } \\
\text { a HL }\end{array}$ & $\mathrm{N}$ brote $^{-1}$ & $\begin{array}{c}\text { NB brote } \\
(\%)\end{array}$ & $\mathrm{H}_{\text {brote }}{ }^{-1}$ & $\begin{array}{l}\mathrm{L} \mathrm{brote}^{-1} \\
(\mathrm{~cm})\end{array}$ & $\mathrm{FL} \mathrm{brote}^{-1}$ \\
\hline & & 221 & 18.1 & 7.7 & $0.7(9.9)$ & 3.8 & 6.6 & 0 \\
\hline & & 174 & 9.3 & 8.1 & $1.1(15.4)$ & 4.3 & 7.2 & 0 \\
\hline & & * & $*$ & n.s. & * & n.s. & n.s. & n.s. \\
\hline \multirow{6}{*}{ II } & & $\begin{array}{l}\text { Fruto mad } \\
\text { (28 abril) }\end{array}$ & & $\begin{array}{l}\text { Brotació } \\
\text { (16 mayo }\end{array}$ & y Floración & & & \\
\hline & \multirow{4}{*}{28 nov. } & $\begin{array}{l}\text { PF } \text { fruto }^{-1} \\
\text { (g) }\end{array}$ & $\begin{array}{l}\text { Color } \\
\text { a HL }\end{array}$ & $\mathrm{N}$ brote $^{-1}$ & $\begin{array}{c}\text { NB brote }{ }^{-1} \\
(\%)\end{array}$ & $\mathrm{H}_{\text {brote }}{ }^{-1}$ & $\begin{array}{l}\mathrm{L} \mathrm{brote}^{-1} \\
(\mathrm{~cm})\end{array}$ & FL brote $^{-1}$ \\
\hline & & 140 & 17.6 & 7.8 & $0.9(12.6)$ & - & - & 0 \\
\hline & & 77 & 13.3 & 7.2 & $1.5(19.8)$ & - & - & 0 \\
\hline & & * & $*$ & n.s. & * & & & n.s. \\
\hline & & $\begin{array}{l}\text { Fruto mad } \\
\text { (15 abril) }\end{array}$ & & $\begin{array}{l}\text { Brotació } \\
\text { (15 abril) }\end{array}$ & y Floración & & & \\
\hline \multirow{4}{*}{ III } & \multirow{4}{*}{30 nov. } & $\begin{array}{l}\text { PF fruto }{ }^{-1} \\
\text { (g) }\end{array}$ & $\begin{array}{l}\text { Color } \\
\text { a HL }\end{array}$ & $\mathrm{N}$ brote $^{-1}$ & $\begin{array}{c}\text { NB brote }{ }^{-1} \\
(\%)\end{array}$ & $\mathrm{H}_{\text {brote }}{ }^{-1}$ & $\begin{array}{l}\mathrm{L} \mathrm{brote}^{-1} \\
(\mathrm{~cm})\end{array}$ & FL brote $^{-1}$ \\
\hline & & 136 & 17.4 & 7.1 & $0.1(0.90)$ & 4.5 & 10.0 & 0 \\
\hline & & 105 & 11.8 & 7.2 & $1.1(15.52)$ & 4.9 & 8.6 & 0 \\
\hline & & * & $*$ & n.s. & * & n.s. & n.s. & n.s. \\
\hline
\end{tabular}

*: significativo $(P<0.05)$; n.s: no significativo. 
El anillado también anticipó el inicio de la brotación (Fig. 3.1.), de modo que el 28 de marzo, momento de la recolección, en los brotes con fruto control solamente había brotado el $3 \%$ de las yemas (0.7 brotes), mientras que en los anillados el porcentaje de brotación fue del 15.4\% (1.1 brotes). A partir de esa fecha, el porcentaje de brotación en los controles aumentó con el tiempo, alcanzando un valor del $9.9 \%$ a finales de mayo. En los brotes con fruto anillados el porcentaje de brotación no se alteró con el tiempo (15.4\%), siendo siempre significativamente superior al de los brotes con fruto sin anillar. Visto de otro modo, el $85 \%$ de las yemas del brote campanero con el pedúnculo del fruto rayado no brotaron $y$, de las que lo hicieron, ninguna dio flores (Fig. 3.1.).

Figura 3.1. Efecto del anillado del pedúnculo del fruto de un brote campanero de naranjo dulce cv. 'Valencia' (Lliria) . sobre la evolución de la brotación de primavera de sus yemas. La flecha indica el momento de recolección del fruto. Valores correspondientes al año I. El anillado se realizo cuando el fruto se encontraba en el estado fenológico 78 de la escala $\mathrm{BBCH}$ y sin haber cambiado de color $(a=-5.7)$. Cada valor es la media \pm ES de 60 brotes campaneros repartidos entre 5 árboles. Todas las diferencias son estadísticamente significativas $(P<0.05)$.

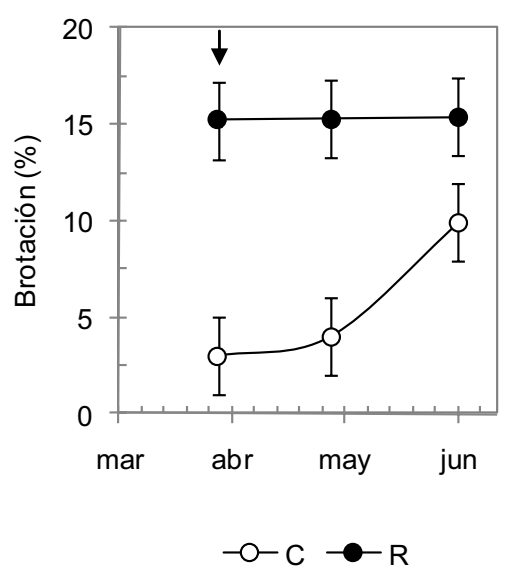

En los otros dos años del experimento los resultados fueron similares. Así, en el año II todos los brotes obtenidos fueron, también, vegetativos, brotando en los brotes con fruto control el $12.6 \%$ de las yemas ( 0.9 brotes), y en los rayados el 19.8\% (1.5 brotes) (Tabla 3.1), siendo estas diferencias estadísticamente significativas. Este año los frutos de los brotes sin rayar pesaron, en el momento de la recolección, $140 \mathrm{~g}$ y los de los rayados $77(P \leq 0.05)$, y el valor de la coordenada a de Hunter fue de 17.6 y 13.3, respectivamente $(P \leq 0.05)$. En el año III, el porcentaje de yemas brotadas fue de $0.9 \%$ en los brotes con fruto control y de $15.5 \%$ en los rayados $(P \leq 0.05)$, dando lugar a 0.1 y 1.1 brotes, respectivamente $(P \leq 0.05)$, el peso de los frutos maduros de $136 \mathrm{~g}$ y $105 \mathrm{~g}$, respectivamente $(P \leq 0.05)$, y la coloración, medida por la coordenada a de Hunter, 17.4 y 11.8, 
respectivamente $(P \leq 0.05)$ (Tabla 3.1). También este año todos los brotes fueron vegetativos y no se detectaron diferencias significativas en su longitud ni en el número de hojas por brote.

La respuesta encontrada en la brotación de primavera dependió de la época en la que se aisló al fruto, esto es, de su estado fenológico. Así, en el naranjo dulce cv. 'Valencia' y para el ciclo vegetativo del año I, cuando el anillado del pedúnculo se realizó en el mes de septiembre (estado 78 de la escala $\mathrm{BBCH}$; relación de coordenadas Hunter $a / b=-0.65$ ) o de noviembre (estado $79 ; a / b$ $=-0.40$ ), el porcentaje de brotación de las yemas adyacentes al fruto mostró una respuesta similar y $\sin$ diferencias estadísticamente significativas entre ellos, registrándose un $24.5 \%$ de yemas brotadas (2.1 brotes) y un $31.9 \%$ (2.6 brotes), respectivamente, que difirieron significativamente de los brotes con fruto control sin rayar ( $19.9 \%$ de yemas brotadas y 1.9 brotes), pero cuando se realizó en el mes de enero (estado 88 de la escala $\mathrm{BBCH}$; y relación $a / b=+0.49$ ) tanto el porcentaje de yemas brotadas, $21.5 \%$, como el número de brotes, 2.0 brotes, no difirieron significativamente de los valores de los brotes con fruto control sin rayar (Tabla 3.2). Una respuesta similar se encontró en el naranjo dulce cv. 'Navelate' para el mismo año. La brotación de los pedúnculos con frutos rayados en los estados fenológicos $76(a / b=-14.6)$ y $78(a / b=-14.1)$ no difirieron entre sí, con porcentajes de nudos brotados de $22.4 \%$ y $24.6 \%$, respectivamente, y número de brotes por pedúnculo de 2.0 y 2.1 , respectivamente, pero sí lo hicieron del control, con $19.8 \%$ de yemas brotadas y 1.6 brotes (Tabla 3.2). El rayado en etapas más avanzadas del desarrollo, estados 79 y 88 de la escala $\mathrm{BBCH}$, no provocó una brotación significativamente distinta ( $19.0 \%$ y $20.9 \%$ de yemas brotadas y 1.6 y 1.4 brotes, respectivamente) del control sin rayar (Tabla $3.2)$. 
Tabla 3.2. Efecto del anillado del pedúnculo del fruto de un brote campanero de naranjo dulce cvs. 'Valencia' y 'Navelate' (Huelva) sobre la brotación de primavera de sus yemas. Año II del experimento. Cada valor es la media de 60 brotes campaneros repartidos entre 5 árboles. $\varnothing$ : diámetro del fruto; $\mathrm{N}: \mathrm{n}^{\circ}$ de nudos; NB: nudos brotados; $\mathrm{H}: \mathrm{n}^{\circ}$ de hojas; FI: $n^{\circ}$ de flores.

\begin{tabular}{|c|c|c|c|c|c|c|c|c|}
\hline \multirow[t]{2}{*}{$\begin{array}{l}\text { Naranjo } \\
\text { dulce cv. }\end{array}$} & \multirow[t]{2}{*}{$\begin{array}{l}\text { Fecha } \\
\text { anillado }\end{array}$} & \multirow{2}{*}{$\begin{array}{l}\text { Estado } \\
\text { fenológico } \\
\text { (BBCH/Color a/b) }\end{array}$} & \multicolumn{2}{|c|}{$\begin{array}{l}\text { Fruto maduro } \\
\text { (27 abril) }\end{array}$} & \multicolumn{4}{|c|}{$\begin{array}{l}\text { Brotación y Floración } \\
\text { (16 mayo) }\end{array}$} \\
\hline & & & $\begin{array}{l}\varnothing \text { fruto }^{-1} \\
(\mathrm{~mm})\end{array}$ & $\begin{array}{l}\text { Color } \\
\text { a }\end{array}$ & $\begin{array}{l}\mathrm{N} \\
\text { brote }^{-1}\end{array}$ & $\begin{array}{l}\text { NB brote } \\
{ }^{-}(\%)\end{array}$ & $\begin{array}{l}\mathrm{H} \\
\text { brote }^{-1}\end{array}$ & $\begin{array}{l}\mathrm{FI} \\
\text { brote }^{-1}\end{array}$ \\
\hline \multirow{6}{*}{ 'Valencia' } & - & - & $72.1 \mathrm{c}$ & $20.2 \mathrm{c}$ & 9.6 & $1.9(19.9)$ & 3.0 & 0.04 \\
\hline & 6 sept & $78 /-0.65$ & 55.7 a & $5.4 \mathrm{a}$ & 8.7 & $\begin{array}{l}a \\
2.1(24.5) \\
a b\end{array}$ & 3.7 & 0.05 \\
\hline & 23 nov & $79 /-0.40$ & $66.7 \mathrm{~b}$ & $17.5 \mathrm{~b}$ & 8.4 & $\begin{array}{l}2.6(31.9) \\
b\end{array}$ & 3.1 & 0 \\
\hline & \multirow[t]{3}{*}{21 ene } & \multirow[t]{3}{*}{$85 /+0.49$} & $70.8 \mathrm{c}$ & $21.6 \mathrm{c}$ & 8.9 & $\begin{array}{l}2.0(21.5) \\
a\end{array}$ & 3.0 & 0 \\
\hline & & & \multicolumn{2}{|c|}{$\begin{array}{l}\text { Fruto maduro } \\
\text { (22 febrero) }\end{array}$} & \multicolumn{4}{|c|}{$\begin{array}{l}\text { Brotación y floración } \\
\text { (27abril) }\end{array}$} \\
\hline & & & $\begin{array}{l}\varnothing \text { fruto }^{-1} \\
(\mathrm{~mm})\end{array}$ & $\begin{array}{l}\text { Color } \\
\text { a }\end{array}$ & $\begin{array}{l}\mathrm{N} \\
\text { brote }^{-1}\end{array}$ & $\begin{array}{l}\text { NB brote } \\
{ }^{-}(\%)\end{array}$ & $\begin{array}{l}\mathrm{H} \\
\text { brote }^{-1}\end{array}$ & $\begin{array}{l}\text { FI } \\
\text { brote }^{-1}\end{array}$ \\
\hline \multirow{5}{*}{ 'Navelate’ } & - & - & $82.9 \mathrm{~d}$ & $19.9 \mathrm{~d}$ & 7.7 & $\begin{array}{l}1.6(19.8) \\
a\end{array}$ & 3.9 & 0.15 \\
\hline & 13 jul & $76 /-14.6$ & 51.0 a & $0.8 \mathrm{a}$ & 8.0 & $\begin{array}{l}2.0(22.4) \\
a b\end{array}$ & 4.2 & 0.20 \\
\hline & 6 sept & $78 /-14.1$ & $66.4 \mathrm{~b}$ & $6.5 \mathrm{~b}$ & 8.1 & $\begin{array}{l}2.1(24.6) \\
b\end{array}$ & 4.7 & 0.13 \\
\hline & 23 nov & $79 /-9.9$ & $77.0 \mathrm{c}$ & $15.4 \mathrm{c}$ & 8.0 & $\begin{array}{l}1.6(19.0) \\
a\end{array}$ & 4.7 & 0 \\
\hline & 21 ene & $88 / 17.5$ & $80.0 \mathrm{~d}$ & $20.9 d$ & 7.8 & $\begin{array}{l}1.4(20.9) \\
a\end{array}$ & 4.1 & 0 \\
\hline
\end{tabular}

Letras distintas en una misma columna indican significación estadística $(P<0.05)$. 
En ambos cultivares y para todas las fechas de rayado, los brotes fueron, en casi su totalidad, vegetativos y sin diferencias estadísticamente significativas en su número de hojas (Tabla 3.2), como en los experimentos anteriores (Tabla 3.1). En este caso se registró la presencia de algunos brotes con flores, pero su número fue tan escaso (Tabla 3.2) que no merece ser destacado.

El análisis de carbohidratos en la corteza del brote en el que se encontraba el fruto y en las dos zonas independizadas por el anillado, próxima al fruto y sin yemas (zona apical) y por debajo del rayado y con yemas (zona basal), reveló diferencias estadísticamente significativas (Tabla 3.3). A los 40 días de efectuado el rayado, la concentración de glucosa y fructosa en los brotes con fruto control sin rayar era de $14 \mathrm{mg} \mathrm{l}^{-1}$ y $13 \mathrm{mg} \mathrm{l}^{-1}$ de materia seca, respectivamente, y en la zona basal del brote con fruto rayado de 15 y $13 \mathrm{mg} \mathrm{g}^{-1}$ de materia seca, sin que estos valores difirieran significativamente de los del control (Tabla 3.3.); en la zona apical del brote con fruto rayado la concentración de ambos azúcares fue de $4 \mathrm{mg} \mathrm{l}^{-1}$, difiriendo significativamente de la zona basal y de los brotes control sin rayar (Tabla 3.3.). La concentración de sacarosa de los brotes con fruto control era, en esa fecha, de $26 \mathrm{mg} \mathrm{g}^{-1}$ de materia seca, y en la zona basal del brote con fruto rayado de $30 \mathrm{mg} \mathrm{l}^{-1}$, diferencia que no alcanzó la significación estadística; sin embargo, en la zona apical de dicho brote la concentración se redujo hasta $9 \mathrm{mg} \mathrm{l}^{-1}$, significativamente distinta de la de la zona basal del brote con fruto rayado y de la del brote con fruto sin rayar (Tabla 3.3).

Tabla 3.3. Efecto del anillado del pedúnculo del fruto de un brote campanero de naranjo dulce cv. 'Valencia' sobre la concentración de carbohidratos del floema del brote 40 días después de su ejecución.. El anillado se efectuó a finales de noviembre en el estado fenológico 79 de la escala BBCH y sin haber cambiado de color del fruto $(a / b=-08)$. Cada valor es la media de 60 brotes campaneros repartidos entre 5 árboles.

\begin{tabular}{|c|c|c|c|}
\hline & $\begin{array}{c}\text { Glucosa } \\
\mathrm{mg} \mathrm{g}^{-1}\end{array}$ & $\begin{array}{c}\text { Fructosa } \\
\mathrm{mg} \mathrm{g}^{-1}\end{array}$ & $\begin{array}{c}\text { Sacarosa } \\
\mathrm{mg} \mathrm{g}^{-1}\end{array}$ \\
\hline Control & $14 b$ & $13 b$ & $26 \mathrm{~b}$ \\
\hline \multirow{2}{*}{ Rayado } & basal apical & basal apical & basal apical \\
\hline & $15 \mathrm{~b} \quad 4 \mathrm{a}$ & $\begin{array}{lll}13 \mathrm{~b} & 4 \mathrm{a}\end{array}$ & $30 \mathrm{~b}$ \\
\hline
\end{tabular}

Letras distintas en una misma fila y para un mismo metabolito indican significación estadística $(P<0.05)$. 
La eficacia del rayado del pedúnculo reduciendo el transporte de nutrientes al fruto queda, por tanto, demostrada, explicando la reducción del peso medio del fruto que, al final del experimento, era de $221 \mathrm{~g}$ en los brotes sin rayar y de $174 \mathrm{~g}$ en los brotes rayados. Asimismo, el cambio de color del fruto se retrasó significativamente, alcanzando la coordenada a de Hunter valores de 9.3 y 18.1, respectivamente para los frutos del año I (Tabla 3.1.). Resultados similares se dieron en el resto de años del experimento (Tabla 3.1).

La evolución de la concentración de giberelinas endógenas $\left(\mathrm{GA}_{1}\right.$ y $\left.\mathrm{GA}_{4}\right)$ en el floema de los brotes de frutos campaneros de naranjo dulce cv. 'Washington navel' y en el flavedo de éstos se presenta en la tabla 3.4. En el flavedo, la $\mathrm{GA}_{1}$ aumentó significativamente con el desarrollo del fruto desde $2.0 \mathrm{ng} \mathrm{g}^{-1}$ a finales de septiembre a $4.0 \mathrm{ng} \mathrm{g}^{-1}$ a finales de octubre, cuando el fruto aun presentaba valores negativos de $a / b$ (datos no presentados), disminuyendo a continuación a medida que el tejido cambiaba de color hasta $2.5 \mathrm{ng} \mathrm{g}^{-1}$ a mediados de noviembre. En el floema, sin embargo, entre estas dos fechas extremas, la concentración aumentó de $3.2 \mathrm{ng} \mathrm{g}^{-1}$ a $5.0 \mathrm{ng} \mathrm{g^{-1 }}$, aunque sin alcanzar la significación estadística.

La evolución de la $\mathrm{GA}_{4}$ en el flavedo fue similar a la de la $\mathrm{GA}_{1}$, aunque con valores marcadamente más altos, alcanzando también un máximo a finales de octubre, $50 \mathrm{ng} \mathrm{g}^{-1}$, respecto de finales de septiembre $\left(7.0 \mathrm{ng} \mathrm{g}^{-1}\right)$ y mediados de noviembre $\left(5.0 \mathrm{ng} \mathrm{g^{-1 }}\right)$. En el floema, y a diferencia de la $\mathrm{GA}_{1}$, la concentración aumentó significativamente desde finales de septiembre, 2.0 $\mathrm{ng} \mathrm{g}{ }^{-1}$, hasta mediados de noviembre, $11.5 \mathrm{ng} \mathrm{g}^{-1}$.

En los brotes anillados, la concentración de $\mathrm{GA}_{1}$ en el flavedo aumentó significativamente desde $1.9 \mathrm{ng} \mathrm{g}^{-1}$ a finales de septiembre hasta $5.2 \mathrm{ng} \mathrm{g}^{-1}$ a mediados de noviembre, manteniendo, además, valores negativos de $a / b$, esto es, permaneciendo el fruto verde. En la zona apical, respecto del rayado, de estos brotes la concentración de $\mathrm{GA}_{1}$ en el floema aumentó significativamente entre ambas fechas desde $3.0 \mathrm{ng} \mathrm{g}^{-1}$ a $14.0 \mathrm{ng} \mathrm{g}^{-1}$, y en la zona basal del brote, donde se sitúan las yemas, aumentó de $2.9 \mathrm{ng} \mathrm{g}^{-1}$ a $19.0 \mathrm{ng} \mathrm{g}^{-1}$, difiriendo significativamente tanto de su zona apical como de los brotes sin anillar.

La $\mathrm{GA}_{4}$ en el flavedo también aumentó significativamente entre las dos fechas extremas, si bien con valores marcadamente más altos, desde $7.0 \mathrm{ng} \mathrm{g}^{-1}$ a $80.0 \mathrm{ng} \mathrm{g}^{-1}$, y el mismo comportamiento se encontró en los brotes y en la zona basal respecto del rayado, en la que la concentración de $\mathrm{GA}_{4}$ pasó de $1.9 \mathrm{ng} \mathrm{g}^{-1}$ a $9.0 \mathrm{ng} \mathrm{g}^{-1}(P \leq 0.01)$. En la zona apical, respecto del rayado, la concentración de esta giberelina no difirió significativamente entre las dos fechas extremas, $2.1 \mathrm{ng} \mathrm{g}^{-1}$ y $2.9 \mathrm{ng} \mathrm{g}^{-1}$, respectivamente.

La suma de ambas giberelinas indica una mayor concentración de éstas por la presencia del fruto a mediados de noviembre en el floema en ambos tipos de brotes, control (16.5 $\mathrm{ng} \mathrm{g}^{-1}$ ) y con el pedúnculo del fruto rayado $\left(16.9 \mathrm{ng} \mathrm{g}^{-1}\right)$, pero el contenido en el flavedo fue mucho mayor en los frutos con su pedúnculo rayado $\left(85.2 \mathrm{ng} \mathrm{g}^{-1}\right)$ que en los controles $\left(7.5 \mathrm{ng} \mathrm{g}^{-1}\right)$. 
Tabla 3.4. Efecto del anillado del pedúnculo del fruto de un brote campanero de naranjo dulce cv. 'Washington navel' sobre la concentración de giberelinas $\left(G_{1}\right.$ y $\left.G A_{4}\right)$ del flavedo del fruto y del floema del brote en el momento de la maduración del fruto de los brotes sin anillar. Valores expresados en $\mathrm{ng} \mathrm{g}^{-1}$ de peso seco. El anillado se efectuó en el estado fenológico 78 de la escala $\mathrm{BBCH}$. Cada valor es la media de 5 brotes campaneros.

\begin{tabular}{|c|c|c|c|c|c|c|}
\hline Tratamiento & \multicolumn{3}{|c|}{ Flavedo } & \multicolumn{3}{|c|}{ Floema } \\
\hline & 27 sept & 27 oct & 12 nov & & 27 sept & 12 nov \\
\hline & \multicolumn{6}{|c|}{$\mathbf{G A}_{1}$} \\
\hline Control & $2.0 \mathrm{aA}$ & $4.0 \mathrm{aB}$ & $2.5 \mathrm{aAB}$ & & $3.2 \mathrm{aA}$ & $5.0 \mathrm{aA}$ \\
\hline \multirow{2}{*}{ Rayado } & \multirow{2}{*}{$1.9 \mathrm{aA}$} & \multirow{2}{*}{$5.0 \mathrm{aAB}$} & \multirow{2}{*}{$5.2 \mathrm{bB}$} & Basal & $2.9 \mathrm{aA}$ & $19.0 \mathrm{bB}$ \\
\hline & & & & Apical & $3.0 \mathrm{aA}$ & $14.0 \mathrm{bB}$ \\
\hline & \multicolumn{6}{|c|}{$\mathbf{G A}_{4}$} \\
\hline Control & $7.0 \mathrm{aA}$ & $50 \mathrm{~B}$ & $5.0 \mathrm{aA}$ & & $2.0 \mathrm{aA}$ & $11.5 \mathrm{bB}$ \\
\hline \multirow{2}{*}{ Rayado } & \multirow{2}{*}{$7.0 \mathrm{aA}$} & \multirow[b]{2}{*}{ n.d. } & \multirow{2}{*}{$80 \mathrm{bB}$} & Basal & $1.9 \mathrm{aA}$ & $9.0 \mathrm{bB}$ \\
\hline & & & & Apical & $2.1 \mathrm{aA}$ & $2.9 \mathrm{aA}$ \\
\hline
\end{tabular}

Letras mayúsculas distintas indican diferencias significativas entre fechas para un mismo tratamiento $(P<0.05)$. Letras minúsculas distintas indican diferencias significativas entre tratamientos para una misma fecha $(P<0.05)$. nd: no determinado. 



\section{Capítulo 4. Estudio de la aplicación de inhibidores de la síntesis de giberelinas sobre la} floración.

La aplicación de 1 g.árbol ${ }^{-1}$ de PBZ al suelo entre principios de octubre y mediados de noviembre, aumentó significativamente la brotación y la floración del Tangor 'Nadorcott', el naranjo dulce cv. 'Salustiana' y el mandarino Clementino cvs. 'Hernandina', 'Marisol' y 'Orogrande', si bien la cuantía de la respuesta estuvo ligada al cultivar y a las condiciones previas de cosecha (Tabla 4.1).

Tabla 4.1. Efecto de la fecha de aplicación de PBZ (1 g.arbol $\left.{ }^{-1}\right)$ al suelo sobre la brotación y floración del naranjo dulce cv. 'Salustiana' y el Tangor 'Nadorcott'. Cada valor es la media de 8 árboles. Letras diferentes en una misma columna y para un mismo cultivar indican diferencias significativas $(P \leq 0.05)$.

\begin{tabular}{|lllc|}
\hline \multirow{3}{*}{ 'Salustiana' } & Tratamiento & \% nudos brotados & Flores / 100 nudos \\
\cline { 2 - 4 } & Control & $14.5 \mathrm{a}$ & $6.2 \mathrm{a}$ \\
\cline { 2 - 4 } & PBZ oct. & $23.2 \mathrm{~b}$ & $14.8 \mathrm{~b}$ \\
\cline { 2 - 4 } & PBZ nov. & $22.9 \mathrm{~b}$ & $17.0 \mathrm{~b}$ \\
\hline \multirow{2}{*}{ 'Nadorcott' } & Control & $47.3 \mathrm{a}$ & $92.2 \mathrm{a}$ \\
\cline { 2 - 4 } & PBZ oct. & $58.4 \mathrm{~b}$ & $155.2 \mathrm{~b}$ \\
\cline { 2 - 4 } & PBZ nov. & $63.2 \mathrm{~b}$ & $206.3 \mathrm{c}$ \\
\hline
\end{tabular}

En el naranjo dulce cv. 'Salustiana', la floración pasó de 6.2 flores/100 nudos en los árboles control a 14.8 flores/100 nudos y 17 flores/100 nudos en los árboles tratados a principios de octubre o a principios de noviembre, respectivamente. $Y$ el porcentaje de nudos brotados del $14.5 \%$ en el control al $23 \%$, aproximadamente en ambos tratamientos (Tabla 4.1).

En el Tangor 'Nadorcott', la floración pasó de 92 flores/100 nudos a 155 flores/100 nudos en los árboles tratados a principios de octubre y a 206 flores/100 nudos los tratados a principios de noviembre (Tabla 4.1). En éste, la brotación también se incrementó significativamente por acción del PBZ pasando de $47.3 \%$ de nudos brotados en los árboles control a $58.4 \%$ y $63.2 \%$ en los árboles tratados a principios de octubre y de noviembre, respectivamente, sin que la diferencia entre fechas alcanzara la significación estadística (Tabla 4.1).

El número de brotes desarrollados también varió significativamente por efecto del PBZ. Así, en el naranjo dulce cv. 'Salustiana', el de flores campaneras aumentó de 1.5 brotes/100 nudos a 3.8 y 3.3 brotes/100 nudos en los árboles tratados en octubre y noviembre, respectivamente, con 1 $\mathrm{g}$ árbol $^{-1}$, y el de ramos florales de 0.1 brotes $/ 100$ nudos a 0.8 y 1 brote/100 nudos, respectivamente (Tabla 4.2). Los tipos de brotes restantes no variaron significativamente su número por efecto de los tratamientos. 
En el Tangor 'Nadorcott' el número de todos los brotes florales aumentó significativamente por efecto de los tratamientos, aunque con mayor intensidad en el realizado en noviembre $(P \leq 0.05)$; el número de brotes vegetativos disminuyó significativamente en ambas fechas de aplicación (Tabla 4.2). El número de brotes multiflorales, ramilletes de flor y brotes mixtos, se duplicó por acción del PBZ aplicado en noviembre, mientras que el de flores solitarias se triplicó; el de brotes campaneros se incrementó un 30\%. El número de brotes vegetativos pasó de 17 brotes/100 nudos en los árboles control a 13.1 brotes/100 nudos y 7.6 brotes/100 nudos en los tratados a principios de octubre y de noviembre, respectivamente (tabla 4.2).

Tabla 4.2. Efecto de la época de aplicación de PBZ $\left(1 \mathrm{~g}_{\text {árbol }}{ }^{-1}\right)$ al suelo sobre la distribución de los tipos de brotes en el naranjo dulce cv. 'Salustiana' y el Tangor 'Nadorcott'. Valores expresados por cien nudos. Cada valor es la media de 8 árboles. Letras diferentes en una misma columna y para un mismo cultivar indican diferencias significativas $(P \leq 0.05)$.

\begin{tabular}{|lllllll|}
\hline & Tratamiento & FS & FC & BM & RF & BV \\
\hline \multirow{3}{*}{ 'Salustiana' } & Control & 2.5 & $1.5 \mathrm{a}$ & 0.6 & $0.1 \mathrm{a}$ & 14.1 \\
\cline { 2 - 7 } & PBZ oct. & 4.8 & $3.8 \mathrm{~b}$ & 1.2 & $0.8 \mathrm{~b}$ & 13.6 \\
\cline { 2 - 7 } & PBZ nov. & 3.8 & $3.3 \mathrm{~b}$ & 2.0 & $1.0 \mathrm{~b}$ & 14.2 \\
\hline \multirow{3}{*}{ 'Nadorcott' } & Control & $26.4 \mathrm{a}$ & $13.9 \mathrm{a}$ & $11.1 \mathrm{a}$ & $3.0 \mathrm{a}$ & $17.0 \mathrm{~b}$ \\
\cline { 2 - 7 } & PBZ oct. & $59.8 \mathrm{~b}$ & $18.3 \mathrm{~b}$ & $17.4 \mathrm{~b}$ & $3.9 \mathrm{a}$ & $13.1 \mathrm{a}$ \\
\cline { 2 - 7 } & PBZ nov. & $78.1 \mathrm{c}$ & $20.1 \mathrm{~b}$ & $23.3 \mathrm{c}$ & $7.4 \mathrm{~b}$ & $7.6 \mathrm{a}$ \\
\hline
\end{tabular}

Por tanto, el PBZ aumenta la floración del naranjo dulce cv. 'Salustiana' y del Tangor 'Nadorcott', pero con diferencias conceptuales importantes. En efecto, en el naranjo dulce cv. 'Salustiana' y para el intervalo 100-700 frutos/árbol, la relación negativa entre el número de frutos cosechados por árbol y la intensidad de floración se mantuvo para todos los árboles, tratados o no, según una función potencial (Figura 4.1 A), de un modo similar a lo descrito en el Capítulo 1. Las pendiente de estas curvas no difieren entre sí, de modo que las diferencias significativas lo son para las ordenada en origen; es decir, estas curvas son estadísticamente paralelas pero sus puntos se distribuyen en valores más elevados (mayor número de flores/100 nudos, por tanto) para los tratamientos de noviembre y octubre (que no difieren entre sí) que para los controles $(P \leq 0.05)$. 

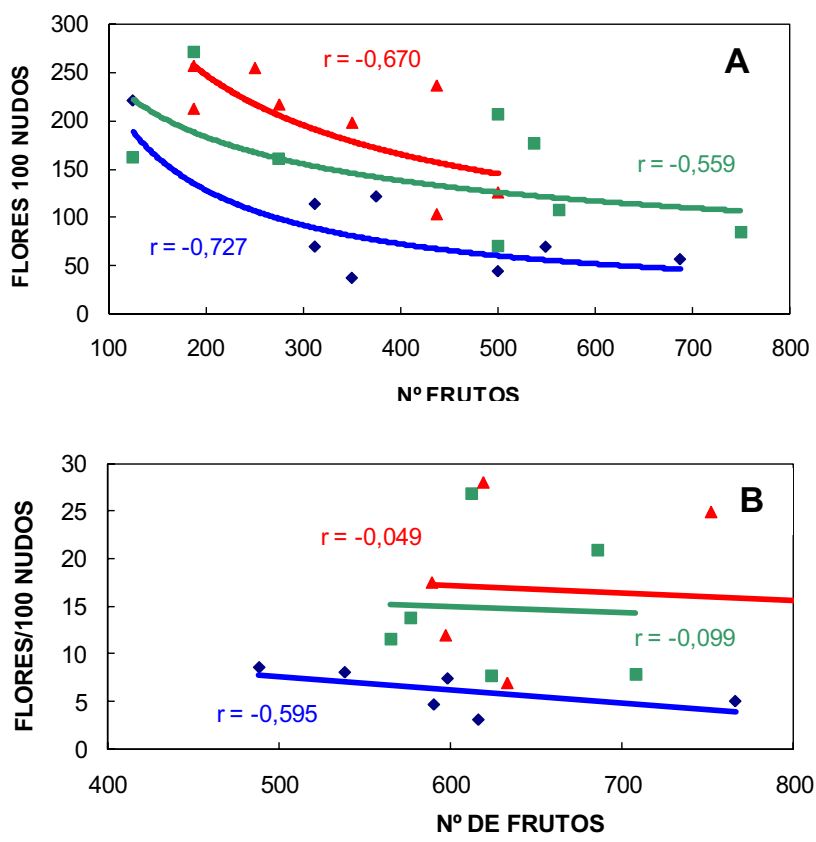

$\bullet$ CONTROL $\quad$ PCBOCT $\triangle$ PCBNOV

Figura 4.1. Efecto del número de frutos por árbol sobre la intensidad de floración siguiente en el naranjo dulce cv. 'Salustiana' (A) y el Tangor 'Nadorcott' (B). Influencia sobre la respuesta a la aplicación de PBZ (1 g.árbol $\left.{ }^{-1}\right)$ al suelo.

Para valores de fructificación más elevados, como es el caso del Tangor 'Nadorcott', la relación número de frutos-flores/100 nudos también se distribuye según una función potencial que no difiere, sin embargo, de una función lineal, como corresponde al segmento de mayor número de frutos de las curvas del naranjo dulce cv. 'Salustiana'. En este caso, además, la pendiente es casi cero para todos los casos, y las funciones difieren también en la ordenada en el origen. Es decir, son distribuciones paralelas cuyos puntos se distribuyen, como en el caso del naranjo dulce cv. 'Salustiana', en valores más elevados (mayor número de flores/100 nudos) para los tratamientos de noviembre y octubre (que no difieren entre sí) que para los controles ( $P \leq 0.05)$ (Fig. $4.1 \mathrm{~B})$. 
En un experimento adicional con el naranjo dulce cv. 'Navelate', la aplicación de 1 ó 2 g árbol $^{-1}$ de $\mathrm{PBZ}$ en septiembre, también aumentó significativamente la floración de la primavera siguiente (Tabla 4.3), paralelamente a un aumento de la brotación que, sin embargo, no alcanzó la significación estadística. Esta época es coincidente con la que se detectó, en el mismo cultivar, para el ácido giberélico como inhibidor de la floración (ver tabla 2.1). En este caso, dado que la producción del cv. 'Navelate' no es alternante, el aumento de la floración no acarreó un incremento de la cosecha que ya fue elevada en los árboles control, indicando, además, que 30 flores/100 nudos garantizan una buena cosecha (Tabla 4.3). La distribución de los tipos de brotes no sufrió modificaciones estadísticamente significativas (Tabla 4.4).

Tabla 4.3. Efecto de la dosis de aplicación de PBZ al suelo sobre la brotación y floración del naranjo dulce cv. 'Navelate'. Cada valor es la media de 8 árboles. Letras diferentes en una misma columna indican diferencias significativas $(P \leq 0.05)$.

\begin{tabular}{|ccc|}
\hline & Brotes / 100 nudos & Flores / 100 nudos \\
\hline Control & 20.86 & $32.26 \mathrm{a}$ \\
\hline${\text { PBZ 1 } \text { árbol }^{-1}}$ & 25.45 & $54.53 \mathrm{~b}$ \\
\hline PBZ 2 g árbol $^{-1}$ & 23.94 & $53.46 \mathrm{~b}$ \\
\hline
\end{tabular}

Tabla 4.4. Efecto de la época de dosis de PBZ al suelo sobre la distribución de los tipos de brotes en el naranjo dulce cv. 'Navelate'. Valores expresados por cien nudos. Cada valor es la media de 8 árboles. Letras diferentes en una misma columna indican diferencias significativas $(P \leq 0.05)$.

\begin{tabular}{|cccccc|} 
& FS & FC & BM & RF & BV \\
\hline Control & 2.77 & 2.45 & 4.45 & $2.19 \mathrm{a}$ & 8.89 \\
\hline PBZ 1 g árbol $^{-1}$ & 4.22 & 2.01 & 6.83 & $5.11 \mathrm{~b}$ & 7.26 \\
\hline${\text { PBZ 2 } \text { árbol }^{-1}}^{3}$ & 3.28 & 1.62 & 6.52 & $5.42 \mathrm{~b}$ & 7.09 \\
\hline
\end{tabular}


En el caso del mandarino Clementino cv. 'Hernandina', la aplicación de $1 \mathrm{~g}$ árbol $^{-1}$ de PBZ al suelo aumentó la floración como en los casos anteriores, pero la respuesta fue altamente dependiente de la presencia de frutos. Así, en el experimento reseñado en el capítulo 1 en el que la cosecha se había localizado asimétricamente solo en la cara este de los árboles, el número de flores desarrolladas por efecto del PBZ en la parte del árbol con frutos no alcanzó la significación estadística respecto de los controles sin tratar, pero en la parte del árbol sin frutos, se pasó de 31 flores/100 nudos a 87 flores/100 nudos con la aplicación de PBZ a finales de octubre y a 71 flores/100 nudos con la de mediados de noviembre, difiriendo ambos tratamientos del control $(P \leq 0.05)$ pero no entre sí (Tabla 4.5).

Tabla 4.5. Influencia de la presencia de frutos sobre la eficacia de la aplicación de PBZ (1 g.arbol ${ }^{-1}$ ) al suelo sobre la brotación y floración del mandarino Clementino cv. 'Hernandina'. Efecto de la fecha de tratamiento. Cada valor es la media de 6 árboles. Letras diferentes en una misma columna indican diferencias significativas $(P \leq 0.05)$.

\begin{tabular}{|clll|}
\hline & Tratamiento & \% nudos brotados & Flores / 100 nudos \\
\hline \multirow{2}{*}{\begin{tabular}{c} 
Con frutos $\begin{array}{c}\text { Control } \\
\text { on }\end{array}$ \\
\cline { 2 - 4 }
\end{tabular}} & PBZ oct. & 22.4 & 12.1 \\
\cline { 2 - 4 } & PBZ nov. & 28.5 & 17.7 \\
\hline \multirow{2}{*}{$\begin{array}{c}\text { Sin frutos } \\
\text { off }\end{array}$} & Control & $31.6 \mathrm{a}$ & 15.2 \\
\cline { 2 - 4 } & PBZ oct. & $44.2 \mathrm{~b}$ & $31.1 \mathrm{a}$ \\
\cline { 2 - 4 } & PBZ nov. & $40.1 \mathrm{~b}$ & $70.5 \mathrm{~b}$ \\
\hline
\end{tabular}

El aumento de la brotación también fue mayor en la parte del árbol sin frutos, en la que se pasó de un porcentaje de nudos brotados del $32 \%$ en el control al $44 \%$ y $40 \%$ en los tratamientos con PBZ de octubre y noviembre, respectivamente; en la parte con frutos el porcentaje de nudos brotados pasó del $22 \%$ en los controles al $29 \%$ y $27 \%$ en los tratados a principios de octubre y de noviembre, respectivamente (Tabla 4.5).

En la parte de los árboles con cosecha, la aplicación de PBZ se mostró ineficaz para modificar la distribución de los brotes en cualquiera de las dos fechas de tratamiento; sin embargo, en la parte de los árboles que no tuvieron cosecha fue modificada significativamente por el tratamiento (Tabla 4.6). El número de flores solitarias pasó de 14 brotes/100 nudos en los controles a 40 y 28 brotes/100 nudos en los árboles tratados a finales de octubre y mediados de noviembre, respectivamente; del mismo modo, los brotes mixtos pasaron de 2 brotes/100 nudos en los árboles control a 9 y 6 brotes $/ 100$ nudos, respectivamente, y los ramilletes de flor fueron incrementados significativamente de 1 brote/100 nudos a más de 5 con los tratamientos de PBZ realizados a mediados de noviembre. Los brotes campaneros no fueron significativamente alterados en número 
por acción del PBZ, mientras que los brotes vegetativos fueron significativamente reducidos de más de 13 brotes/100 nudos a menos de 5 en los árboles tratados a finales de octubre (Tabla 4.6). En ningún caso, se detectaron diferencias significativas debidas a la fecha de tratamiento.

Tabla 4.6. Efecto de la época de aplicación de PBZ $\left(1 \mathrm{~g}\right.$.árbol $\left.{ }^{-1}\right)$ al suelo sobre la distribución de la brotación del mandarino Clementino cv. 'Hernandina'. Influencia de la presencia de frutos. Valores expresados por cien nudos. Cada valor es la media de 6 árboles. Letras diferentes en una misma columna indican diferencias significativas $(P \leq 0.05)$.

\begin{tabular}{|cllllll|}
\hline \multirow{2}{*}{\begin{tabular}{c} 
Con frutos $\begin{array}{c}\text { Tratamiento } \\
\text { on }\end{array}$ \\
\cline { 2 - 7 }
\end{tabular}} & Fontrol & 6.0 & FC & BM & RF & BV \\
\cline { 2 - 7 } & PBZ oct. & 9.0 & 7.8 & 0.2 & 0.2 & 15.1 \\
\cline { 2 - 7 } & PBZ nov. & 6.6 & 7.8 & 0.4 & 0.04 & 19.6 \\
\hline \multirow{2}{*}{$\begin{array}{c}\text { Sin frutos } \\
\text { off }\end{array}$} & Control & $14.1 \mathrm{a}$ & 7.9 & $2.1 \mathrm{a}$ & $1 . \mathrm{a}$ & $13.2 \mathrm{~b}$ \\
\cline { 2 - 7 } & PBZ oct. & $39.8 \mathrm{~b}$ & 11.5 & $8.8 \mathrm{~b}$ & $3.2 \mathrm{ab}$ & $4.8 \mathrm{a}$ \\
\cline { 2 - 7 } & PBZ nov. & $27.8 \mathrm{ab}$ & 7.5 & $6.3 \mathrm{~b}$ & $5.5 \mathrm{~b}$ & $9.6 \mathrm{a}$ \\
\hline
\end{tabular}

Un experimento adicional con este mismo cultivar pero con árboles seleccionados con elevada cosecha (>100 kg/árbol) y sin cosecha (1-5 kg/árbol), ratificó la respuesta. Mientras en los árboles sin frutos, la aplicación de $1 \mathrm{~g}$ árbol $^{-1}$ de PBZ aumentó significativamente la floración, pasando de 97 flores/100 nudos a 107 flores/100 nudos, en los árboles con una cosecha elevada la respuesta fue inexistente (Tabla 4.7).

Tabla 4.7. Efecto de la aplicación de PBZ $\left(1\right.$ g.árbol $\left.^{-1}\right)$ al suelo durante el reposo vegetativo, sobre la floración de árboles con frutos y árboles sin frutos del mandarino Clementino, cv. 'Hernandina'. Valores expresados en flores/100 nudos. Cada valor es la media de 8 árboles. Letras diferentes en una misma columna indican diferencias significativas $(P \leq 0.05)$.

\begin{tabular}{|cll|}
\hline & Tratamiento & Flores / 100 nudos \\
\hline $\begin{array}{c}\text { Con frutos } \\
\text { on }\end{array}$ & Control & 1.4 \\
\cline { 2 - 3 } & PBZ & 0 \\
\hline $\begin{array}{c}\text { Sin frutos } \\
\text { off }\end{array}$ & Control & $96.9 \mathrm{a}$ \\
\cline { 2 - 3 } & PBZ & $107.3 \mathrm{~b}$ \\
\hline
\end{tabular}


La distribución de los brotes como consecuencia de la aplicación de PBZ tampoco se presentó uniforme en este caso, siendo las flores solitarias y los brotes mixtos, las inflorescencias más afectadas en los árboles sin cosecha, incrementándose en más del doble en ambos casos (Tabla 4.8). Como en los casos anteriores, el número de brotes vegetativos en los árboles tratados con PBZ fue significativamente reducido. En los árboles con cosecha, sin embargo, solo los brotes vegetativos fueron significativamente incrementados en número (Tabla 4.8). Esta respuesta ya se presentó en el experimento anterior aunque sin alcanzar la significación estadística (Tabla 4.6)

Tabla 4.8. Efecto de la aplicación de PBZ (1 g.árbol $\left.{ }^{-1}\right)$ al suelo durante el reposo vegetativo en la distribución de los brotes de árboles con frutos y árboles sin frutos de mandarino Clementino, cv. 'Hernandina'. Valores expresados por 100 nudos. Cada valor es la media de 8 árboles. Letras diferentes en una misma columna indican diferencias significativas $(P \leq 0.05)$

\begin{tabular}{|cllllll|}
\hline \multirow{2}{*}{$\begin{array}{c}\text { Con frutos } \\
\text { on }\end{array}$} & Tratamiento & FS & FC & BM & RF & BV \\
\cline { 2 - 7 } & PBZ & 0.1 & 0.1 & 0.1 & 0.1 & $19.5 \mathrm{a}$ \\
\hline $\begin{array}{c}\text { Sin frutos } \\
\text { off }\end{array}$ & Control & 0 & 0 & 0 & 0 & $25.8 \mathrm{~b}$ \\
\cline { 2 - 7 } & PBZ & $27.5 \mathrm{a}$ & 7.4 & $4.9 \mathrm{a}$ & 9.6 & 1.3 \\
\hline
\end{tabular}

En los otros cultivares de mandarino Clementino estudiados, 'Marisol' y 'Orogrande', la aplicación de PBZ también aumentó significativamente la floración (Fig. 4.2).

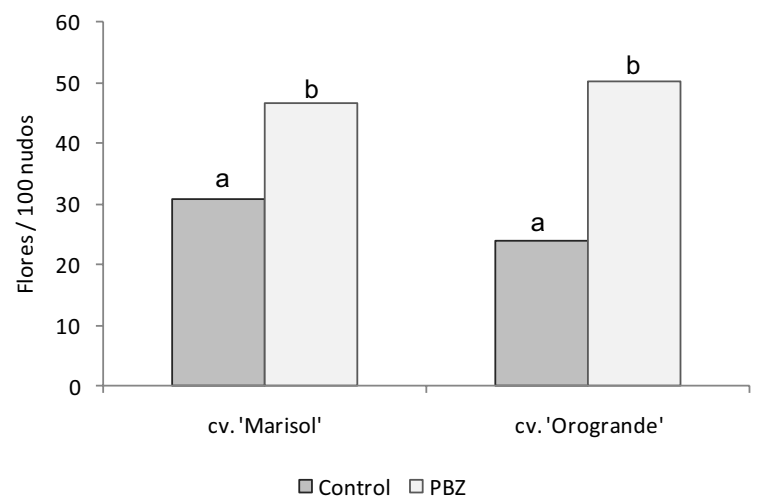

Figura 4.2. Efecto de la aplicación de PBZ (1 g.árbol-1) al suelo durante el reposo vegetativo sobre la floración del mandarino Clementino cvs. 'Marisol' y 'Orogrande'. Cada valor es la media de 8 árboles. Letras diferentes indican diferencias significativas $(P \leq 0.05)$. 
La respuesta sobre la distribución de los brotes, no fue, sin embargo, igual para las dos variedades. Mientras en el cv. 'Orogrande' el número de todos los brotes florales aumentó significativamente por efecto del tratamiento (Tabla 4.9), en el cv. 'Marisol' las diferencias no alcanzaron la significación estadística, siendo las flores solitarias las únicas estructuras florales que aumentaron significativamente (Tabla 4.9).

Tabla 4.9. Efecto de la aplicación de PBZ $\left(1 \mathrm{~g}\right.$ árbol $\left.{ }^{-1}\right)$ al suelo durante el reposo vegetativo sobre la distribución de los brotes de mandarino Clementino cvs. 'Orogrande' y 'Marisol'. Valores expresados en brotes por cien nudos. Cada valor es la media de 8 árboles. Letras diferentes en una misma columna indican diferencias significativas $(P \leq 0.05)$

\begin{tabular}{|cllllll|} 
& Tratamiento & FS & FC & BM & RF & BV \\
\hline \multirow{2}{*}{ cv. 'Orogrande' } & Control & $4.5 \mathrm{a}$ & $9.9 \mathrm{a}$ & $2.2 \mathrm{a}$ & $0.6 \mathrm{a}$ & 11.4 \\
\cline { 2 - 7 } & PBZ & $9 \mathrm{~b}$ & $14.4 \mathrm{~b}$ & $6.7 \mathrm{~b}$ & $1.7 \mathrm{~b}$ & 8.2 \\
\hline \multirow{2}{*}{ cv. 'Marisol' } & Control & $9.1 \mathrm{a}$ & 13.2 & 2.2 & 0.5 & 14.5 \\
\cline { 2 - 7 } & PBZ & $17.4 \mathrm{~b}$ & 19.3 & 2.8 & 0.8 & 21 \\
\hline
\end{tabular}

Debe destacarse que, al igual que al estudiar la influencia del número de frutos sobre las características de los brotes, expresadas como número medio de hojas y/o flores, éstas no fueron alteradas por las aplicaciones de PBZ en ninguno de estos tres experimentos (Tabla 4.10).

Tabla 4.10. Efecto de la aplicación de $\mathrm{PBZ}\left(1 \mathrm{~g}\right.$ árbol $\left.{ }^{-1}\right)$ al suelo durante el reposo vegetativo sobre las características de los brotes de mandarino Clementino cvs. 'Orogrande', 'Marisol' y 'Hernandina'. Valores de hojas y flores expresados por brote. Cada valor es la media de 8 árboles.

\begin{tabular}{|cllllll|}
\hline & Tratamiento & RF & FC & \multicolumn{2}{c|}{ BM } & BV \\
& & flores & hojas & flores & hojas & hojas \\
\hline \multirow{2}{*}{ cv. 'Orogrande' } & Control & 0.9 & 3.1 & 1.5 & 2.4 & 2.4 \\
\cline { 2 - 7 } & PBZ & 1.9 & 2.7 & 2.7 & 2.7 & 2.1 \\
\hline \multirow{2}{*}{ cv. 'Marisol' } & Control & 0.9 & 3.8 & 1.5 & 1.9 & 4.4 \\
\cline { 2 - 7 } & PBZ & 2.3 & 3.7 & 2.1 & 2.2 & 4.5 \\
\hline \multirow{2}{*}{ cv. 'Hernandina' } & Control & 2.7 & 2.5 & 3.4 & 2.4 & 2.1 \\
\cline { 2 - 7 } & PBZ & 2.8 & 1.8 & 3.1 & 1.9 & 1.1 \\
\hline
\end{tabular}


La adición de PBZ al suelo aumentó la brotación en los tres cultivares de mandarino Clementino estudiadas (Fig. 4.3). Así, en el cv. 'Orogrande' la brotación pasó de 29 brotes/100 nudos en los controles a 40 en los tratados con $1 \mathrm{~g}$ de PBZ por árbol, en el cv. 'Marisol' de 40 brotes/100 nudos a 61.3, respectivamente, y en los árboles sin fruto del mandarino Clementino cv. 'Hernandina' de 57 a 80 brotes/100 nudos, respectivamente (Fig. 4.3).

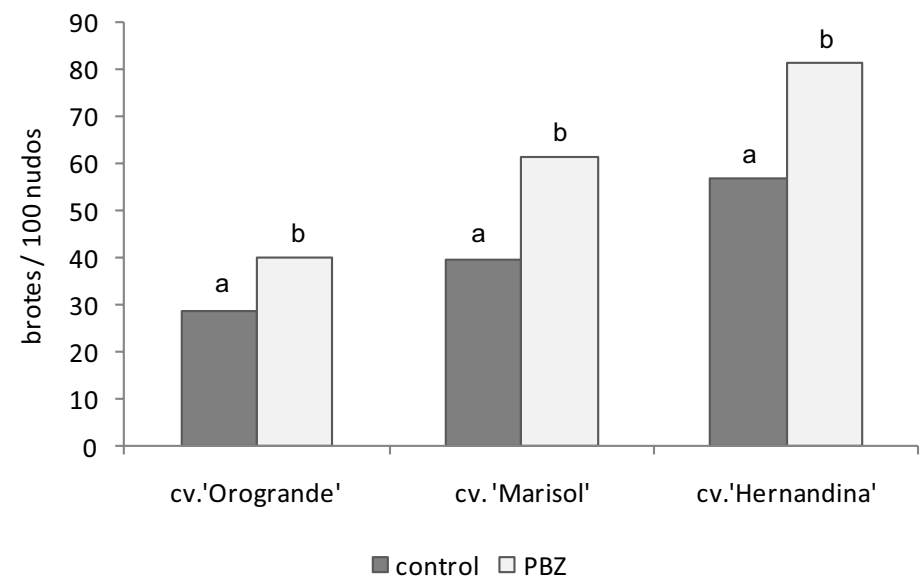

Figura 4. 3. Efecto de la aplicación de PBZ $\left(1\right.$ g.árbol $\left.^{-1}\right)$ al suelo durante el reposo vegetativo sobre la brotación del mandarino Clementino cvs. 'Orogrande', 'Marisol' y 'Hernandina'. Cada valor es la media de 8 árboles. Letras distintas en un mismo cultivar indican diferencias significativas $(P \leq 0.05)$.

En los árboles de mandarino Clementino cv. 'Hernandina' con elevada cosecha, la aplicación de PBZ al suelo no consiguió aumentar la floración; sin embargo, la brotación pasó de 20 brotes/100 nudos en los controles a 26 brotes/100 nudos en los tratados. 
Con el fin de conocer la acción directa del PBZ sobre las yemas, se aplicaron $2500 \mathrm{mg}^{-1} \mathrm{I}^{-1} \mathrm{de}$ PBZ localmente a las yemas, hojas o ramas completas de árboles off y on de mandarino Clementino cv. 'Hernandina' en la época de inducción floral (mediados de noviembre). En los primeros se logró un aumento de la brotación y de la floración similar para las tres aplicaciones (Tabla 4.11). La brotación se incrementó significativamente, pasando de un $32 \%$ de nudos brotados en las ramas control a un porcentaje cercano al 60\%. La intensidad de floración también aumentó significativamente, pasando de 59 flores/100 nudos en los árboles control sin tratar a 113 flores/100 nudos en el tratamiento a la yema, a 129 flores/100 nudos en el tratamiento a las hojas y a 122 flores/100 nudos en el tratamiento a la rama completa. En los árboles on el efecto del PBZ fue inexistente (Tabla 4.11).

Tabla 4.11. Efecto de la aplicación de PBZ (2500 mg l-1) localizada a la yema, hoja o rama sobre la brotación y floración del mandarino Clementino cv. 'Hernandina'. Influencia de la presencia del fruto. Cada valor es la media de 9 árboles. Letras diferentes en una misma columna indican diferencias significativas $(P \leq 0.05)$.

\begin{tabular}{|clrc|}
\hline \multirow{4}{*}{ Árboles off } & \multicolumn{1}{l}{ Tratamiento } & \% nudos brotados & Flores / 100 nudos \\
\cline { 2 - 4 } & Control & $31.6 \mathrm{a}$ & $59.5 \mathrm{a}$ \\
\cline { 2 - 4 } & PBZ yema & $59.4 \mathrm{~b}$ & $113.5 \mathrm{~b}$ \\
\cline { 2 - 4 } & PBZ hoja & $59.8 \mathrm{~b}$ & $129.5 \mathrm{~b}$ \\
\cline { 2 - 4 } & PBZ rama & $59.0 \mathrm{~b}$ & $122.4 \mathrm{~b}$ \\
\hline \multirow{3}{*}{ Árboles on } & Control & $22.4 \mathrm{a}$ & $7.8 \mathrm{a}$ \\
\cline { 2 - 4 } & PBZ yema & $22.8 \mathrm{a}$ & $7.6 \mathrm{a}$ \\
\cline { 2 - 4 } & PBZ hoja & $21.5 \mathrm{a}$ & $10.8 \mathrm{a}$ \\
\cline { 2 - 4 } & PBZ rama & - & - \\
\hline
\end{tabular}


La aplicación de prohexadione-Ca (PHD-Ca) también incrementó la floración. Una concentración de $200 \mathrm{mg} \mathrm{l}^{-1}$, aplicada vía foliar, aumentó la floración del naranjo dulce cv. 'Salustiana' en un año on (exp. I) con independencia de la fecha de aplicación (Tabla 4.12). Al igual que para el PBZ, un tratamiento cuando el fruto está próximo a alcanzar su tamaño final (septiembre) incrementó significativamente la floración en cuantía similar a la lograda en época de inducción floral (diciembre). La floración pasó de 8.6 flores /100 nudos en los controles sin tratar a 25.6 y 18.5 flores/100 nudos, respectivamente, sin que éstos últimos valores difirieran entre sí (Tabla 4.12). Todos los brotes florales incrementaron su número para el tratamiento de septiembre, mientras que para el de diciembre solo lo hicieron los BM y las FS, de modo que el incremento de FC y RF no alcanzó la significación estadística y el descenso en el número de brotes vegetativos tampoco se alteró significativamente (Tabla 4.12).

Tabla 4.12. Efecto de la aplicación de prohexadione-Ca $\left(200 \mathrm{mg} \mathrm{l}^{-1}\right)$ sobre la floración y brotación del naranjo dulce cv. 'Salustiana' en dos experimentos independientes. Influencia de la época de aplicación. Cada valor es la media de 8 árboles. Letras diferentes en la misma columna indican diferencias significativas entre tratamientos $(P<0.05)$.

\begin{tabular}{|c|c|c|c|c|c|c|c|c|c|c|}
\hline \multirow[t]{2}{*}{ Exp. } & \multirow[t]{2}{*}{ Época } & \multirow[t]{2}{*}{ PHD-Ca } & \multirow{2}{*}{$\begin{array}{l}\text { \%nudos } \\
\text { brotados }\end{array}$} & \multirow[t]{2}{*}{$\mathrm{B} \mathrm{NB}^{-1}$} & \multirow{2}{*}{$\begin{array}{l}\text { Flores / } 100 \\
\text { nudos }\end{array}$} & \multicolumn{5}{|c|}{ Brotes / 100 nudos } \\
\hline & & & & & & FS & FC & BM & RF & BV \\
\hline \multirow{3}{*}{ I } & - & 0 & $16 a$ & & $8.6 \mathrm{a}$ & $3.4 \mathrm{a}$ & $1.8 \mathrm{a}$ & $0.5 \mathrm{a}$ & $0.5 \mathrm{a}$ & 9.0 \\
\hline & Sept & 200 & $21 \mathrm{~b}$ & & $25.6 \mathrm{~b}$ & $9.4 \mathrm{~b}$ & $4.1 \mathrm{~b}$ & $2.0 \mathrm{~b}$ & $2.1 \mathrm{~b}$ & 5.6 \\
\hline & Dic & 200 & $23 \mathrm{~b}$ & & $18.5 \mathrm{~b}$ & $7.7 \mathrm{~b}$ & $2.7 \mathrm{ab}$ & $1.4 \mathrm{~b}$ & $1.4 \mathrm{ab}$ & 8.5 \\
\hline \multirow{2}{*}{ II } & - & 0 & $19 a$ & 1.07 & $22.9 \mathrm{a}$ & $5.8 \mathrm{a}$ & 3.1 & 2.5 & $1.9 \mathrm{a}$ & $3.8 \mathrm{~b}$ \\
\hline & Marz & 200 & $26 \mathrm{~b}$ & 1.09 & $43.6 \mathrm{~b}$ & $14.5 \mathrm{~b}$ & 3.6 & 3.8 & $4.1 \mathrm{~b}$ & $4.7 \mathrm{a}$ \\
\hline
\end{tabular}

Resulta relevante en este experimento que la aplicación de PHD-Ca cuando las yemas iniciaron su diferenciación (marzo) consiguiera, también aumentar la floración. Los árboles control, que en este caso se encontraban en año off, presentaron una intensidad floración de 22.9 flores/100 nudos y los tratados con PHD-Ca de 43.6 flores/100 nudos $(P \leq 0.05)$ (Tabla 4.12), aumentando el número de brotes florales sin hojas $(P \leq 0.05)$.

Un tratamiento a la misma concentración $\left(200 \mathrm{mg} \mathrm{l}^{-1}\right.$ ) y en el mismo ciclo productivo (off) también aumentó la floración en el Tangor 'Nadorcott', pasando de 82 a 94 flores/100 nudos $(P \leq 0.10)$. 
La comparación de los efectos del PBZ y PHD-Ca se llevó a cabo en el naranjo dulce cv. 'Salustiana'. La aplicación foliar al inicio de la diferenciación de las yemas (marzo) de una concentración de $2000 \mathrm{mg} \mathrm{l}^{-1}$ de PBZ o de $200 \mathrm{mg} \mathrm{l}^{-1}$ de PHD-Ca, incrementó la floración en cuantía similar, pasando de 22.9 flores/100 nudos en los árboles control a 46.4 y 43.6 flores/100 nudos, respectivamente $(P \leq 0.05)$ (Tabla 4.13). Ambas sustancias incrementaron significativamente el número de brotes florales sin hojas, pero el aumento del de los brotes con hojas no alcanzó la significación estadística. El número de brotes vegetativos por 100 nudos tampoco difirió estadísticamente del de los árboles control sin tratar (Tabla 4.13).

Tabla 4.13. Efecto de la aplicación foliar de PBZ (2000 $\left.\mathrm{mg} \mathrm{l}^{-1}\right)$ y PHD-Ca $\left(200 \mathrm{mg} \mathrm{I}^{-1}\right)$ al inicio de la diferenciación floral (marzo) sobre la floración y la distribución de los tipos de brotes en el naranjo dulce cv. 'Salustiana'. Valores expresados por cien nudos. Datos correspondientes al exp. II. Letras distintas en una misma fila indican diferencias significativas $(P \leq$ 0.05).

\begin{tabular}{|cccl|}
\hline & Control & PBZ & PHD-Ca \\
\hline Flores / 100 nudos & $22.9 \mathrm{a}$ & $46.4 \mathrm{~b}$ & $43.6 \mathrm{~b}$ \\
\hline \multicolumn{3}{|c|}{ Distribución (Brotes / } & $\mathbf{1 0 0}$ nudos) \\
\hline FS & $5.8 \mathrm{a}$ & $17.8 \mathrm{~b}$ & $12.7 \mathrm{~b}$ \\
\hline FC & 3.1 & 3.2 & 3.6 \\
\hline BV & 3.8 & 1.8 & 1.7 \\
\hline BM & 2.5 & 4.1 & 3.8 \\
\hline RF & 3.8 & 1.8 & 1.7 \\
\hline
\end{tabular}

Es de destacar que la aplicación de PBZ al inicio de la diferenciación floral resultó igual de eficaz que la de de PHD-Ca en el estímulo de la floración, ratificando dicho momento de sensibilidad al estímulo de la floración. 
Al inicio del periodo de inducción floral (8 de noviembre), las hojas de los árboles off habían acumulado mayor cantidad de sacarosa que las de los árboles on (Fig. 4.4 A). Algo similar ocurrió en las raíces, en las que el contenido en sacarosa de los árboles off era más de 2 veces superior al de los árboles on (Fig. 4.4 B). En las hojas, las diferencias se mantuvieron, aproximadamente, para los contenidos en hexosas. Así el contenido total de glucosa y fructosa era de $26.2 \mathrm{mg} \mathrm{g}^{-1}$ de peso seco en los árboles off y de 22.8 en los árboles on (Fig. 4.4 A). La relación sacarosa/hexosas era prácticamente la misma para ambos grupos de árboles ( 0.36 para los off y 0.27 para los on), lo que indica un contenido estable de carbohidratos en las hojas adaptado a la demanda. En las raíces, la concentración de glucosa y fructosa era prácticamente la misma para los dos tipos de árboles (Fig. $4.4 \mathrm{~B}$ ). Como en las hojas, el contenido en sacarosa, glucosa y fructosa de las ramas fue más elevado en los árboles off (Fig. 4.4 C).

Al final de este período, cuando el fotoperiodo inicia su crecimiento (enero), el contenido en las hojas de glucosa y fructosa era mayor que el de sacarosa, pero sin diferencias significativas entre los árboles on y off (Tabla 4.14). En las ramas, sin embargo, la sacarosa era el azúcar más abundante en ambos tipos de árboles, con mayor concentración en los árboles off $(P \leq 0.05)$; la glucosa y fructosa se encontraban en una concentración casi 4 veces inferior a la de sacarosa y sin diferencias significativas debidas a la presencia del fruto (Tabla 4.14). En las raíces, la concentración de sacarosa también era la más elevada, pero en este caso a favor de los árboles on; la glucosa y fructosa se encontraban en concentraciones mitad que la sacarosa en los árboles off y 5 veces inferiores en los árboles on (Tabla 4.14).

Tabla 4. 14. Contenido en carbohidratos de hojas, ramas y raíces de mandarino Clementino, cv.'Hernandina', en pleno reposo (4 de enero). Influencia de la presencia del fruto. Valores expresados en mg por gramo de peso seco. Cada valor es la media de 8 árboles \pm error estándar.

\begin{tabular}{|cllll|}
\hline & & Hojas & Raíces & Ramas \\
\hline \multirow{2}{*}{$\begin{array}{c}\text { Con frutos } \\
\text { on }\end{array}$} & sacarosa & $5.6 \pm 0.9$ & $11 \pm 0.02$ & $19.2 \pm 0.2$ \\
& glucosa & $9.9 \pm 1.1$ & $2.4 \pm 0.1$ & $4.8 \pm 0.3$ \\
& fructosa & $11 \pm 0.05$ & $2.5 \pm 0.2$ & $5.7 \pm 0.1$ \\
\hline \multirow{2}{*}{$\begin{array}{c}\text { Sin frutos } \\
\text { off }\end{array}$} & sacarosa & $5.6 \pm 1.5$ & $7.5 \pm 0.01$ & $23.3 \pm 1.1$ \\
& glucosa & $11.6 \pm 0.2$ & $3.2 \pm 0.2$ & $6.6 \pm 1.7$ \\
& fructosa & $11.9 \pm 0.3$ & $3 \pm 0.1$ & $5.7 \pm 0.4$ \\
\hline
\end{tabular}



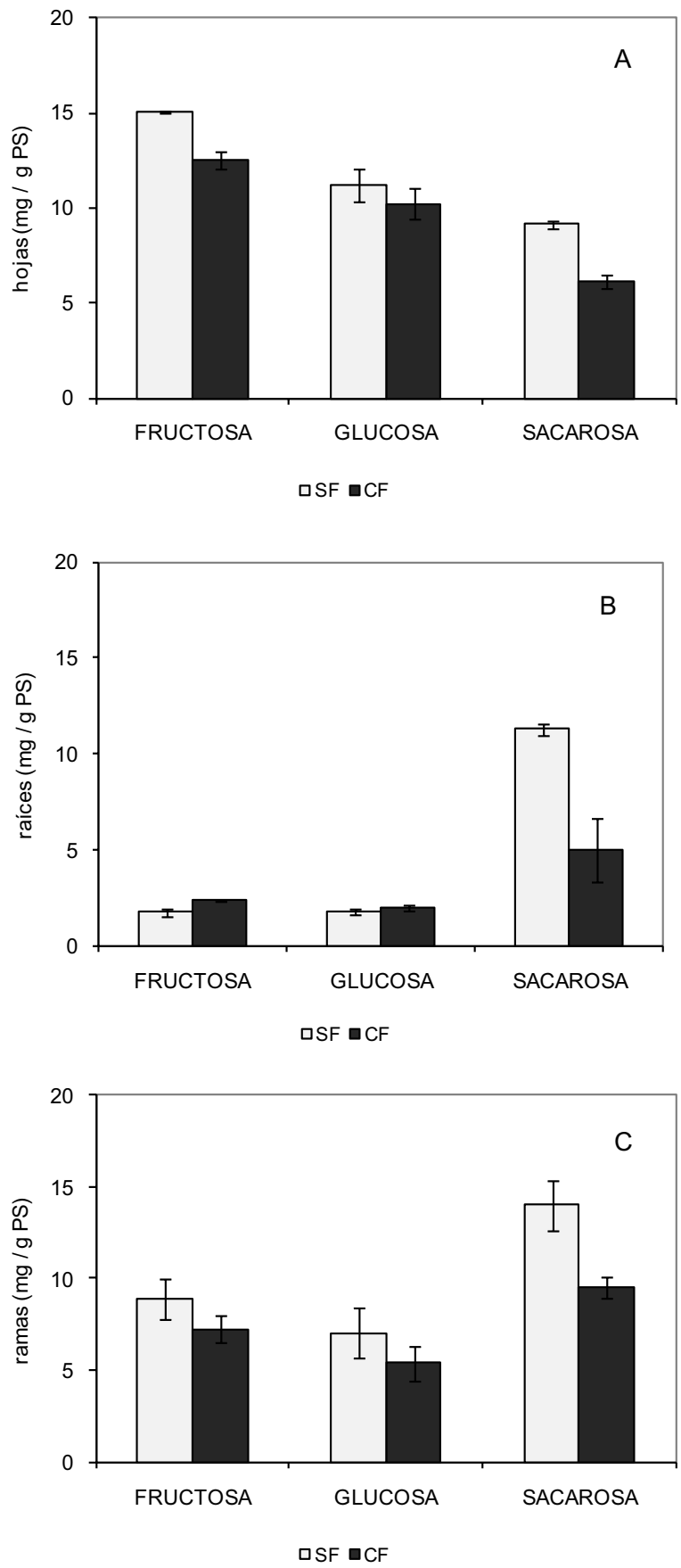

Figura 4.4. Contenido en carbohidratos de las hojas (A), raíces (B) y ramas (C) del mandarino Clementino cv. 'Hernandina' al inicio de la inducción floral (noviembre). Efecto de la presencia del fruto. Las barras verticales indican el error estándar. Cada valor es la media de 8 árboles. 
La evolución del contenido en azúcares en los órganos estudiados, desde el reposo invernal (época de inducción floral) hasta el momento de la brotación (marzo), no revela diferencias debidas a la presencia del fruto (Fig. 4.5). Solamente la concentración de sacarosa en las hojas en el momento de la brotación fue significativamente más elevada en los árboles off respecto de los on.

La aplicación de PBZ al suelo $\left(1 \mathrm{~g}_{\text {árbol }}{ }^{-1}\right.$ ) aumentó significativamente la concentración foliar de glucosa y fructosa de los árboles on en relación con los off cuando se aplica en la época de inducción floral (noviembre), pero disminuyó la de sacarosa (Fig. 4.6). Las mayores diferencias aparecieron en las etapas inmediatamente anteriores a la brotación (enero), permaneciendo prácticamente constantes hasta el final del experimento, es decir, cuando la brotación ya era evidente (marzo). En las ramas no se encontraron diferencias en la concentración de los tres azúcares (Fig. 4.6).

En las raíces, la concentración de glucosa y fructosa desde el momento de inducción floral (noviembre) apenas presentó diferencias debidas a la presencia del fruto, mientras que la sacarosa aumentó significativamente en los árboles on respecto de los off (Fig. 4.7). La aplicación de PBZ al suelo $\left(1 \mathrm{~g}_{\text {árbol }}{ }^{-1}\right)$ no alteró la concentración de monosacáridos en las raíces de ninguno de los dos tipos de árboles, on y off, pero sí el de sacarosa que aumentó significativamente en los árboles off (Fig. 4.7). En este último caso, sin embargo, en etapas próximas al inicio de la brotación (enero) las diferencias entre ambos tipos de árboles desaparecieron, iniciando la brotación con concentraciones iguales de sacarosa. 

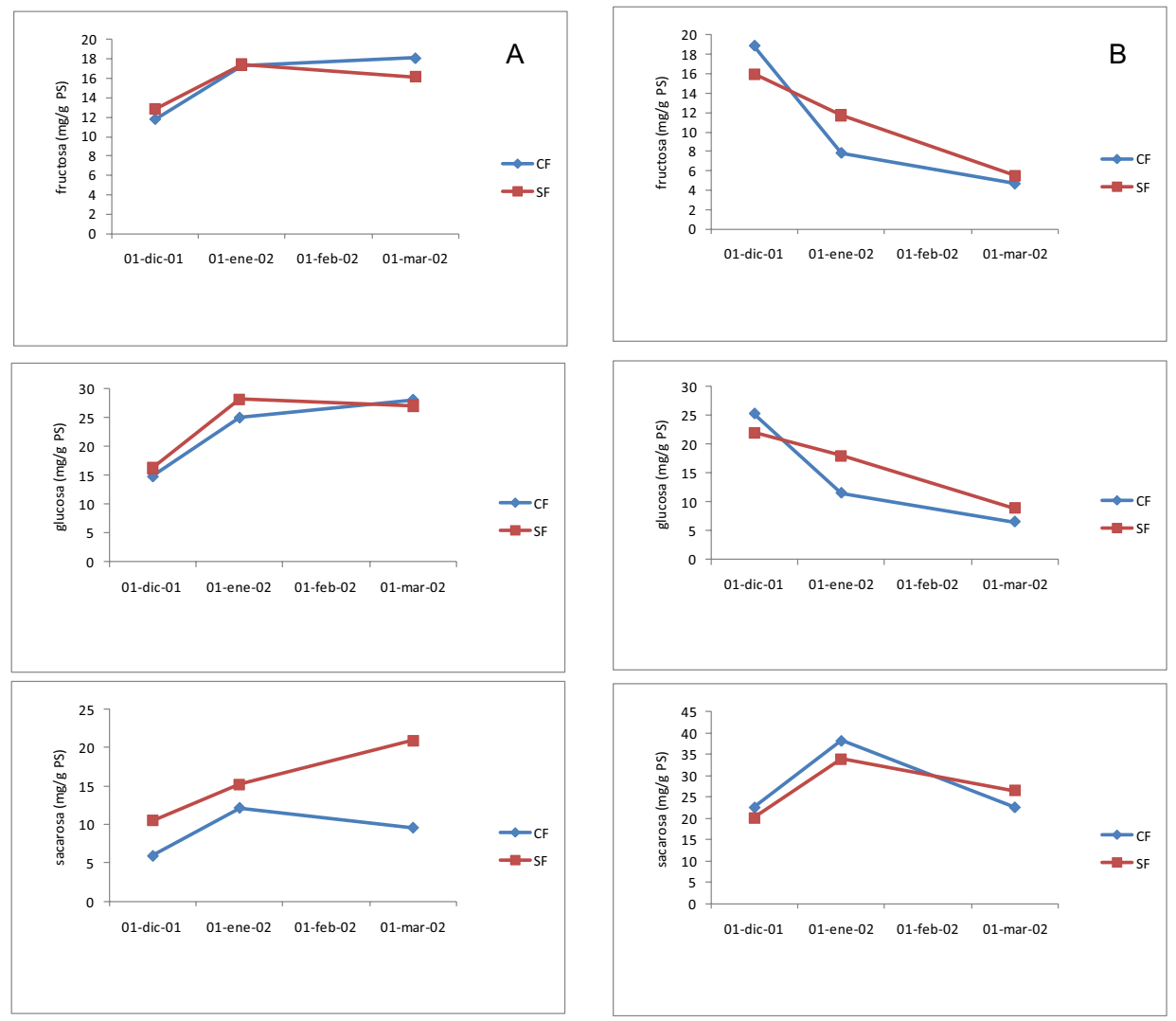

Figura 4.5. Evolución de la concentración de carbohidratos de las hojas (A) y ramas (B) del mandarino Clementino cv. 'Hernandina' desde la época de inducción floral hasta la brotación. Efecto de la presencia del fruto. Cada valor es la media de 8 árboles. 

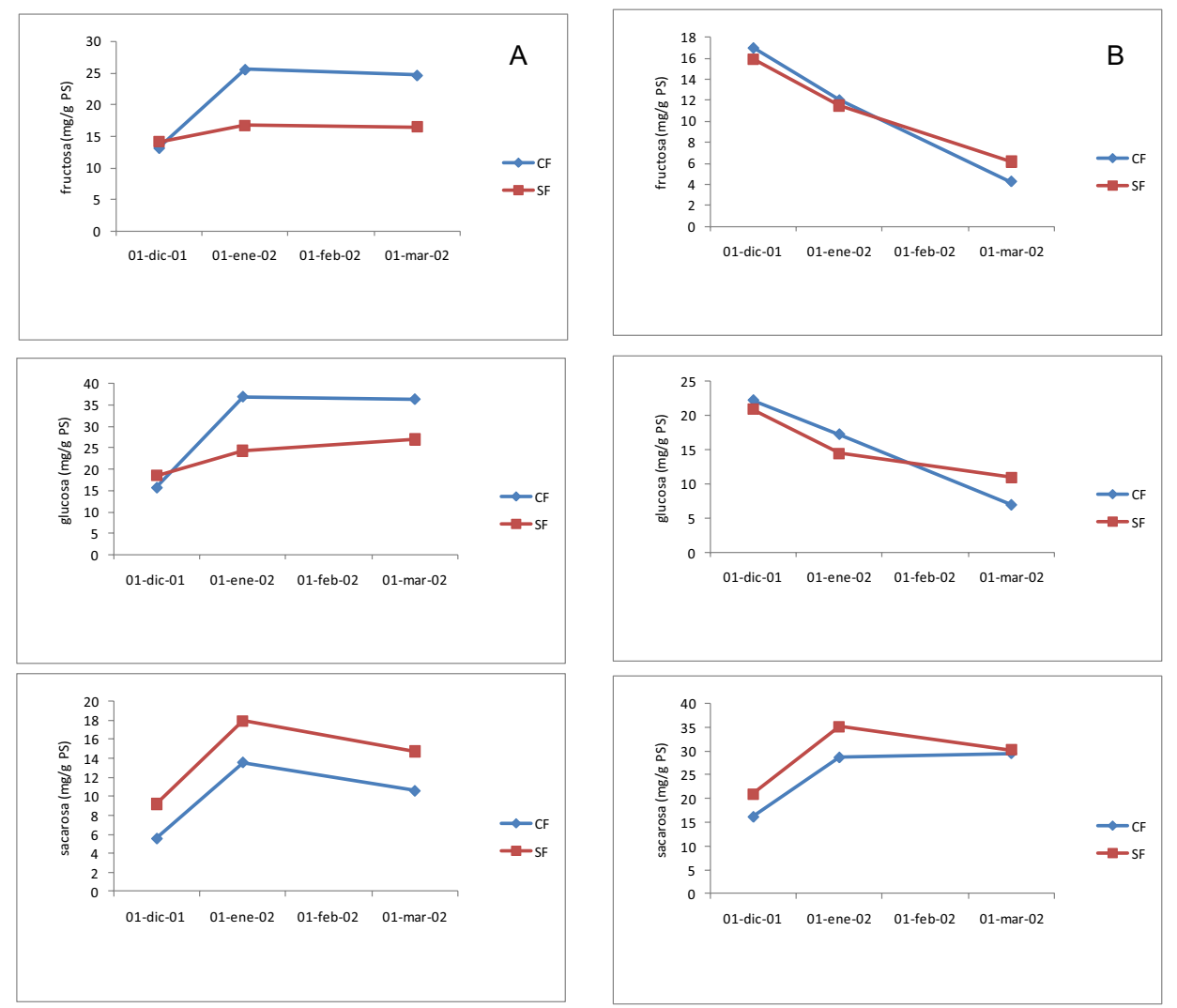

Figura 4.6. Efecto del PBZ (1 $\left.\mathrm{g}_{\text {árbol }}{ }^{-1}\right)$ aplicado al suelo en la época de inducción floral sobre la evolución de la concentración de carbohidratos de las hojas (A) y ramas (B) del mandarino Clementino cv. 'Hernandina' desde la época de inducción floral hasta la brotación. Efecto de la presencia del fruto. Cada valor es la media de 8 árboles. 

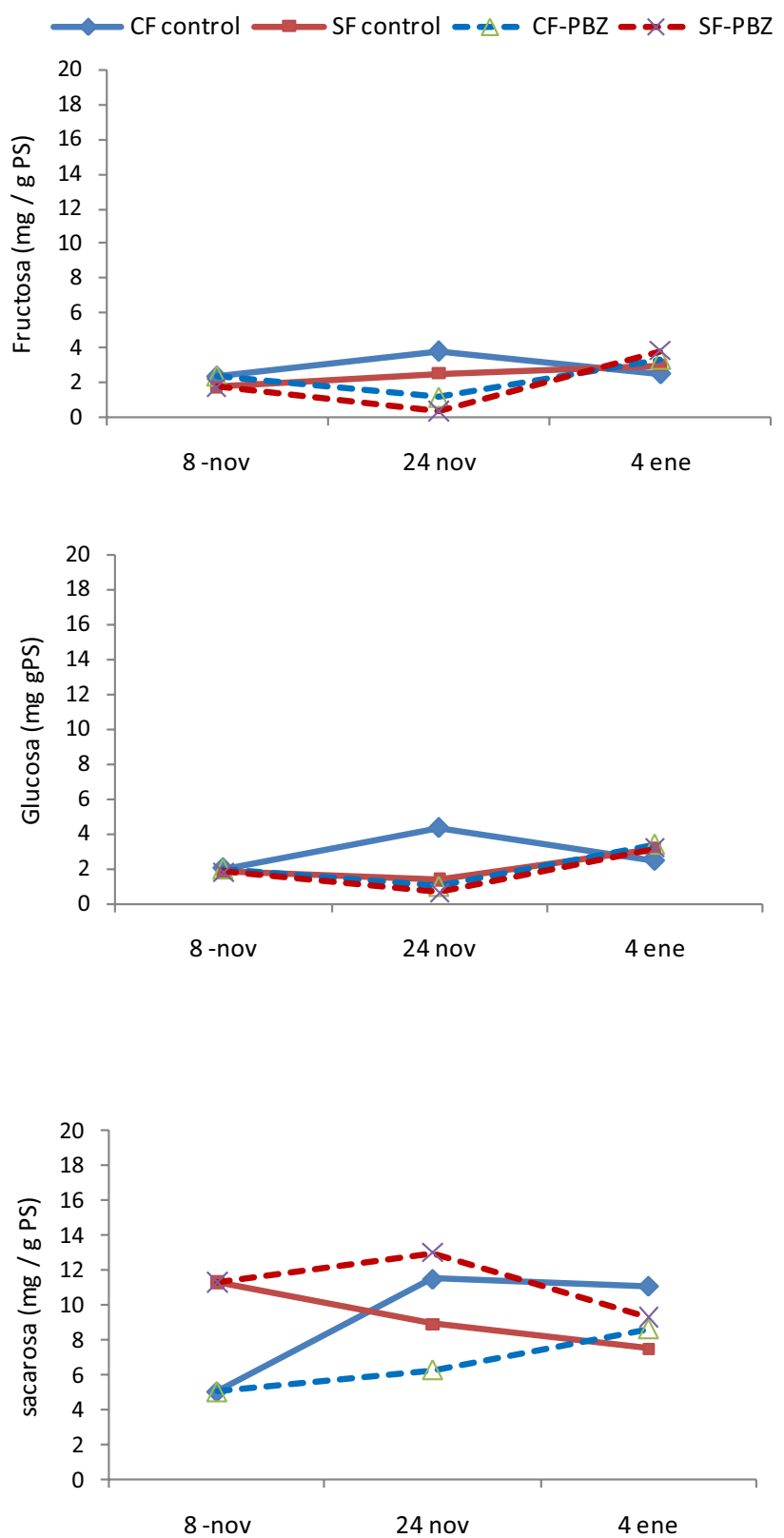

Figura 4.7. Evolución del contenido en carbohidratos de la raíz del mandarino Clementino cv. 'Hernandina' durante el reposo vegetativo. Efecto de la presencia del fruto y de la aplicación de PBZ $\left(1 \mathrm{~g}\right.$ árbol $\left.{ }^{-1}\right)$ al suelo. Cada valor es la media de 8 árboles. 
Discusión 

El efecto inhibidor del fruto sobre la floración se ha identificado en numerosas especies frutícolas leñosas, tanto perennifolias como caducifolias, tales como el manzano (Jonkers, 1979), el melocotonero (Reig et al., 2006) y los cítricos (Monselise y Goldschmidt, 1982), pero ninguno de estos estudios indican a partir de qué momento del desarrollo el fruto inicia su acción. Recientemente, Verreynne y Lovatt (2009) han mostrado evidencias de que la eliminación de todos los frutos de un árbol de mandarino 'Pixie' a principios del verano aumenta el número total de flores la primavera siguiente. Este efecto es indirecto a través de un incremento en el número de brotes de finales del verano-principios del otoño. El papel de esta brotación sobre la floración de la primavera siguiente ya había sido señalado para el naranjo dulce (Agustí y Almela, 1991).

Experimentos de defoliación, de aplicación de giberelinas y de rayado de ramas, llevados a cabo en diferentes épocas del año, han demostrado que el proceso de inducción floral tiene lugar a finales de otoño para el naranjo dulce y el pomelo (Furr y Armstrong, 1956; Ayalon y Monselise, 1960; Guardiola et al., 1982) y un mes más tarde para el mandarino Satsuma (Sánchez-Capuchino y Casanova, 1973; Iwahori, 1978; García Luis et al., 1986). No obstante, existen serias objeciones a este modo de detección de la época de inducción floral. El rayado de ramas durante el verano provoca, en nuestras condiciones climáticas, un estímulo de la floración mucho más notable que cuando se efectúa durante el reposo invernal (Agustí et al., 1992), y es posible encontrar épocas de gran sensibilidad a las aplicaciones de ácido giberélico para inhibir la floración muy alejadas de dicho periodo de reposo tanto en el naranjo dulce, como demuestran nuestros resultados, como en el mandarino Satsuma (García Luis et al., 1986).

Por otra parte, estaquillas defoliadas pueden ser inducidas a florecer sin más que someterlas a un estrés hídrico, lo que, por una parte, compromete al papel de las hojas como receptoras de un estímulo de inducción floral (Southwick y Davenport, 1986), y, por otra, abre la puerta al estudio de la floración como consecuencia de algún tipo de estrés, bien sea hídrico, térmico (Lovatt et al., 1988a) o inducido por la propia carga de frutos. Jones et al., (1976) observaron que las yemas de árboles de naranjo dulce cv. 'Valencia' que mantenían una alta fructificación durante el invierno, mostraban un período de latencia más largo y un menor crecimiento en primavera, comparadas con las yemas de árboles sin frutos o con pocos frutos. El ácido abscísico (ABA) ha mostrado su capacidad de restringir el desarrollo de las yemas en muchas especies, incluyendo los cítricos (Young y Cooper, 1969). Más tarde, Goldschmidt (1984) demostró que la concentración de ABA en hojas, ramas y yemas de mandarino 'Wilking' durante los años de elevada cosecha es superior a la encontrada en los años 
de cosecha reducida, reflejando el estrés impuesto por la elevada producción. Puesto que los frutos acumulan altos niveles de ABA durante su maduración, la acción de esta hormona restringiendo el crecimiento de las yemas axilares (Young y Cooper, 1969), estaría ligada a la capacidad de la yema para brotar y, por tanto, florecer, sobre todo después de una elevada cosecha.

Este efecto del estrés sobre la brotación/floración de las yemas también se ha relacionado con el metabolismo del nitrógeno. Lovatt et al. (1988a) sometiendo plantas de naranjo dulce 'Washington navel' a un estrés térmico y de limón 'Frost Lisbon'a un estrés hídrico demostraron una acumulación de iones amonio en las hojas que se correspondía con un aumento de la floración. Monselise et al. (1981) ya habían detectado una alteración del metabolismo del nitrógeno en hojas de árboles de mandarino 'Wilking' con elevada cosecha en comparación con árboles de escasa cosecha, y Reig et al. (2006) encontraron algo similar durante la latencia en el floema, próximo a la yema, de árboles de melocotonero que soportaron todos sus frutos hasta la maduración en comparación con aquellos a los que se les eliminaron todos los frutos en el momento de la lignificación del endocarpo. Esta alteración metabólica consiste en una tendencia opuesta de la concentración de $\mathrm{N}$ total y de $\mathrm{NO}_{3}{ }^{-}-\mathrm{N}$ según el número de frutos que soporta el árbol, de modo que la relación $\mathrm{NO}_{3}^{-}-\mathrm{N}$ para árboles off/on es inferior a 1 tanto en las hojas como en los brotes y las raíces. Nuestros resultados están de acuerdo con esta alteración del mecanismo de reducción de nitratos ya que a lo largo del periodo de maduración de los frutos la concentración de $\mathrm{NO}_{3}{ }^{-} \mathrm{N}$ en las hojas de las ramas que los mantuvieron hasta la brotación de las yemas no disminuyó, mientras que en las ramas sin frutos la concentración foliar de $\mathrm{NO}_{3}{ }^{-} \mathrm{N}$ disminuyó significativamente en etapas próximas a la brotación (estado 89 de la escala $\mathrm{BBCH}$ ), al mismo tiempo que la concentración foliar de la fracción $\mathrm{NH}_{4}{ }^{+}-\mathrm{N}$ en estas ramas aumentaba. De acuerdo con ello, en los cítricos, el mecanismo de reducción de nitratos en las hojas es alterado por la presencia del fruto. A pesar de ello, puesto que la concentración de $\mathrm{NO}_{3}{ }^{-} \mathrm{N}$ es una fracción pequeña del $\mathrm{N}$ total, entre el $0.4 \%$ y el $0.6 \%$ de acuerdo con nuestros resultados (ver Tabla 2.4), la relativa alta concentración en época de inducción floral de $\mathrm{NO}_{3}{ }^{-} \mathrm{N}$ en las hojas de las ramas a las que se les eliminó el fruto al inicio de su desarrollo (junio) podría ser más un reflejo metabólico que una acción nutricional directa (Monselise et al., 1981).

En el naranjo dulce 'Valencia, nuestros resultados demuestran que las ramas de árboles on de las que se eliminaron todos los frutos desde el estado 72 al 78 de la escala fenológica $\mathrm{BBCH}$ florecieron, la primavera siguiente, 8 veces más que las ramas de los mismos árboles a las que se les dejaron todos los frutos. De acuerdo con ello, el fruto ejerce su acción inhibidora de la floración desde el momento en que está 
próximo a adquirir su máximo peso, es decir, cuando alcanza el $90 \%$ de su tamaño final (noviembre), de un modo similar a como ha sido demostrado en el pomelo 'Marsh' bajo condiciones climáticas tropicales (Betancourt et al., 2008). Así, la presencia del fruto no ejerce ninguna acción inhibidora de la floración desde el estado 72 (43 flores por 100 nudos) hasta el estado 78 (42.8 flores/100 nudos), pero en el estado 79 de la escala fenológica $\mathrm{BBCH}$ (noviembre) reduce la floración en un 80\% (8.6 flores por 100 nudos). Esta época de sensibilidad es coincidente con la época de sensibilidad de la yema a las aplicaciones de ácido giberélico para inhibir exógenamente la floración (ElOtmani et al., 2000). Posteriormente, durante la maduración, es decir, desde el momento en que el fruto adquiere su máximo tamaño en adelante, no se observó ningún efecto adicional en la reducción de la floración hasta la brotación de la yema. García-Luis et al. (1986) sugieren, para el mandarino Satsuma 'Owari', que la inhibición de la floración por acción del fruto está más estrechamente relacionada con la coloración del flavedo que con el crecimiento del fruto, pero su estudio fue realizado solamente a lo largo del periodo de maduración del mismo. El fruto del naranjo dulce cv. 'Valencia' cambia de color 45 días después (en nuestro experimento) de haber alcanzado su máximo tamaño, mientras que el del mandarino Satsuma 'Owari' lo hace justo cuando deja de crecer (García-Luis et al., 1985). Por otra parte, este mandarino madura antes que el naranjo dulce 'Valencia' y su época de sensibilidad a las aplicaciones de ácido giberélico para inhibir la floración es un mes más tardía que la del naranjo dulce (Guardiola et al., 1982). Estas razones pueden explicar las diferencias encontradas entre especies.

A pesar de ello, nuestros experimentos con el naranjo dulce 'Washington navel' revelan un flujo de giberelinas desde el flavedo del fruto hacia el brote que lo sustenta al mismo tiempo que aquél cambia de color, de un modo similar a como lo habían sugerido García-Luis et al. (1986) y ha demostrado Gambetta (2009). Así, la concentración de $\mathrm{GA}_{1}$ y $\mathrm{GA}_{4}$ en el floema del pedúnculo de los frutos control (sin el pedúnculo rayado) aumentó con el transcurso del tiempo hacia etapas de sensibilidad a las aplicaciones exógenas de $\mathrm{GA}_{3}$ para inhibir la floración (ver tabla 3.4).

En un intento de demostrar que son las giberelinas exportadas desde el fruto hacia las yemas del brote que lo sustenta las responsables de su acción inhibidora de la floración, se rayó el pedúnculo de los frutos para interferir en el transporte. La respuesta, sin embargo, no fue la esperada y si bien la interrupción del transporte basípeto de las $\mathrm{GA}_{1}$ y $\mathrm{GA}_{4}$ desde el flavedo al brote consiguió su acumulación en la parte apical del rayado, no consiguió promover la floración. La razón fue una acumulación de giberelinas $\mathrm{GA}_{1}$ y $\mathrm{GA}_{4}$ también en la otra parte del rayado en la que se encuentran las yemas. De acuerdo con los conocimientos sobre el proceso de 
cicatrización de la herida producida por el rayado de ramas (Hamada et al., 2008), la propia herida debe ser la causa de que en la parte basal de ésta, es decir, en la zona del tallo en la que se encuentran las yemas, la concentración de giberelinas también aumentara en nuestro experimento y no difiriera de la encontrada en la zona apical, inhibiendo así la floración de dichas yemas haciendo inviable el rayado de pedúnculo como modelo de estudio de la acción inhibidora de la floración por el fruto.

La coincidencia del aumento de la exportación de giberelinas desde el fruto hacia las yemas de su brote con la época de mayor acción inhibidora del fruto y con la época de sensibilidad a la aplicación exógena de $\mathrm{GA}_{3}$ para inhibir la floración (septiembre-noviembre), fue la razón de la propuesta de utilización de inhibidores de la síntesis de giberelinas como técnica para estimular la floración en un intento de "inhibir al inhibidor" y demostrar, de este modo, que el proceso de la floración podría ser un fenómeno inhibitorio más que inductivo (Goldschmidt y Samach, 2004). Ello, a su vez, atribuiría a las giberelinas un papel decisivo en el control de la floración. Monselise y Havely (1964) encontraron que aplicaciones de diversos retardadores del crecimiento, durante el verano, incrementaban la floración y la producción en el limonero "Eureka". Aplicaciones de 2-cloroetiltrimetil amonio (CCC; Cycocel), a concentraciones de $1000 \mathrm{mg} \mathrm{l}^{-1}$, y de ácido $\mathrm{N}$-dimetilaminosuccinámico (Alar, B-Nine), a concentraciones de $2500 \mathrm{mg} \mathrm{l}^{-1}$, aumentaron la floración, sobre todo en las ramas jóvenes. Más eficaz que los dos anteriores fue el benzotiazol-2-oxiacetato (BTOA), pero en las ramas de mayor edad.

Aunque algunos de estos resultados fueron posteriormente confirmados (Monselise et al., 1966; Nir et al., 1972; Salomon, 1988; Lenz y Karnatz, 1975), si bien sin una explicación unificada de los mismos, y más tarde se demostró que el efecto estimulador del Alar sobre la inducción floral también se da en el naranjo dulce, pero de modo no consistente (Monselise y Goren, 1969), otros autores no pudieron reproducirlos (Moss, 1971). Es más, Davenport (1983) encontró un efecto inhibidor de la floración por parte del Alar cuando lo aplicó a una concentración de $2500 \mathrm{mg} \mathrm{l}^{-1}$ en verano a plantas de lima Tahiti y Agustí (1980) encontró que el CCC inhibe la floración cuando se aplica repetidamente a una concentración de $1000 \mathrm{mg} \mathrm{l}^{-1}$ durante el reposo vegetativo a árboles de naranjo dulce 'Washington navel'. Monselise (1979) razona esta respuesta errática proponiendo que los antagonistas de la síntesis de giberelinas pueden ser efectivos solamente antes de que éstas hayan sido sintetizadas y no cuando están presentes en cantidades elevadas, pero la inhibición encontrada en la lima Tahití y en el naranjo dulce no puede ser explicada así, quedando este tema todavía por resolver. 
Más recientemente se han conseguido buenos resultados con la aplicación de paclobutrazol. Esta sustancia inhibe la actividad kaureno-oxidasa y, consecuentemente, la biosíntesis de giberelinas (Henry, 1985), explicándose así su acción promotora de la floración. Delgado et al. (1986a; 1986b) con aportaciones al suelo entre 2,5 y $10 \mathrm{~g}$ árbol $^{-1}$ y Harty y Van Staden (1988a, 1988b) con tratamientos foliares a una concentración entre 25 y $100 \mathrm{mg} \mathrm{l}^{-1}$, aumentaron la floración en el naranjo dulce, el mandarino y el limonero, de un modo similar a lo conseguido en nuestros experimentos. No obstante, Iwahori y Tominaga (1986) trabajando con Kumquat (Fortunella crassifolia) encontraron que la aplicación foliar de $1000 \mathrm{mg} \mathrm{l}^{-1} \mathrm{de}$ paclobutrazol durante la época de inducción floral no modificaba la floración de la primera y segunda brotaciones, que incluso se redujeron ligeramente. El elevado número de frutos que produce esta especie en los años on puede ser la razón de ello, de un modo similar a lo que ocurrió en nuestros experimentos con el mandarino Clementino cv. 'Hernandina' en la que la presencia del fruto anuló la respuesta al paclobutrazol.

Los resultados con prohexadione-Ca fueron similares a los encontrados con el paclobutrazol. Esta sustancia actúa como mimético estructural del ácido 2-oxoglutárico inhibiendo de este modo la acción de las dioxigenasas que catalizan diferentes pasos de la biosíntesis de giberelinas (Rademacher, 2000). Su uso en manzanas (Evans et al., 1997; Owens y Stover, 1999) y otros frutales (Basak y Rademacher, 2000) para retardar el crecimiento vegetativo se halla en expansión por su carácter prácticamente inocuo y, sobre todo, por su eficacia, pero su uso como promotor de la floración, particularmente en los cítricos, es novedoso y no existen referencias al respecto. Pero también en este caso la presencia del fruto anula su respuesta. Esta acción del fruto impidiendo la promoción de la floración ya había sido detectada por Goldschmidt et al. (1985) en sus experimentos de rayado de ramas conducentes al estudio de la implicación de los carbohidratos en el proceso floración de los cítricos.

En nuestros experimentos, la eliminación de los frutos modificó el contenido foliar en azúcares solubles. En las ramas a las que se les eliminó el fruto, la concentración foliar de carbohidratos disminuyó inmediatamente dado que el principal sumidero de los mismo había desaparecido; posteriormente, se observó un incrementó de su contenido tanto en las ramas sin frutos como en las ramas con frutos, tal como habían señalado García-Luis y Guardiola (2000), seguido de un descenso en el momento de la maduración del fruto, como también ocurre en el melocotonero (Reig et al., 2006). Pero en el momento de la brotación no se observó ninguna diferencia significativa en la concentración foliar de carbohidratos por efecto de la presencia del fruto. Siendo que éste es el responsable de la inhibición de la floración, la acción de 
los carbohidratos sobre la floración resulta, por tanto, irrelevante, como se ha demostrado para otras especies y cultivares del género Citrus (García-Luis et al., 1988; Lovatt et al., 1988b) y para el melocotonero (Reig et al., 2006).

La acumulación de almidón durante el invierno ha sido registrada por diferentes autores (Davenport, 1990) y cuantificada por Yelenosky y Guy (1977), quienes relacionan su acumulación con las bajas temperaturas. Sin embargo, los trabajos de Goldschmidt et al. (1985) demuestran, para el tangelo 'Minneola', que la acumulación de almidón en hojas, tallos y raíces no tiene ninguna relación ni con el régimen térmico (día/noche) ni con la floración, pero ésta aumenta a medida que el régimen térmico disminuye. En nuestros experimentos, el contenido significativamente más bajo de almidón en las hojas de las ramas que mantuvieron todos sus frutos hasta la recolección aparece, también, como una buena razón para correlacionar su concentración con la intensidad de floración; sin embargo, las diferencias aparecen solamente en la época en que el fruto se muestra menos eficaz inhibiendo la floración. Es más, aunque una cierta concentración umbral de almidón debe ser necesaria para que una yema brote y se inicie la floración, la comparación de resultados de diferentes experimentos de sombreado, rayado de ramas, aclareo de frutos,..., en cítricos y otras especies, prueba que la existencia de otros factores oscurece una posible correlación entre la concentración de almidón en los tejidos y la floración, indicando que ésta permanece sin ser probada (García-Luis y Guardiola, 2000; García-Luis et al., 1988; Goldschmidt et al., 1985; Reig et al., 2006). La existencia del citado valor umbral también se desprende de nuestros resultados que muestran una reducción significativa de las concentraciones de sacarosa, glucosa y fructosa desde el cambio de color (estado 81 de la escala $\mathrm{BBCH}$ ) hasta la plena madurez del fruto y la brotación (estado $89 \mathrm{BBCH}$ ), independientemente de la cuantía de la cosecha.

El mantenimiento del fruto en el árbol hasta el estado 79 de la escala $\mathrm{BBCH}$ (o más tarde), reduce significativamente el número de brotes vegetativos de verano/otoño que se desarrollan, reduciendo de este modo el número de brotes en los que se desarrollan las inflorescencias la primavera siguiente, como se ha demostrado en los mandarinos 'Pixie' (Verreynne y Lovatt, 2009) y 'Nour' (El-Otmani et al., 2004)). Es más, el número de nudos de dichos brotes queda también alterado, lo que afecta, a su vez, el número de flores producidas (Verreynne y Lovatt, 2009; Agustí, 1980).

En nuestros experimentos, la reducción de la floración provocada por la presencia del fruto en el naranjo dulce 'Valencia' coincide, en parte, con un descenso del número de nudos brotados. Este efecto es similar al señalado para el mandarino Satsuma 'Owari' (García-Luis et al., 1986). En ambas especies, las yemas generativas son las más sensibles a la presencia del fruto, mientras que las yemas vegetativas 
aumentan su brotación en las ramas en las que el fruto se mantiene hasta que completa su tamaño. De un modo similar, Okuda et al. (2002a; 2002b) demostraron para el mandarino Satsuma que los árboles con un mayor número de frutos dieron lugar, la primavera siguiente, a un menor número de brotes florales, con hojas o sin hojas, y un mayor número de brotes vegetativos, en comparación con los que tenían una reducida cosecha. Asimismo, el rayado de ramas en verano incrementa la floración del naranjo dulce cv. 'Salustiana' y del mandarino Satsuma 'Owari' porque estimula la brotación de la yema en primavera (Agustí et al., 1992).

Es importante destacar que las características de los brotes, es decir, el número de flores y/o hojas, no fue alterado por el tiempo de permanencia del fruto en el árbol. Ello indica un efecto directo de fruto sobre la yema impidiéndole brotar. Solamente las yemas que consiguen eludir este efecto pueden brotar y, en su caso, desarrollar flores (Lang, 1965), manteniendo el promedio de número de hojas y flores. Por tanto, aparentemente el fruto no altera el número de flores por yema brotada, sino el número de yemas que brotan.

En conclusión, en el naranjo dulce 'Valencia', el fruto inhibe la floración a partir del momento en que alcanza su máximo tamaño a través de un proceso de reducción del número de nudos que brotan y del número de yemas brotadas por nudo, particularmente florales, sin afectar el número de flores por brote desarrollado. Ni la concentración foliar de azúcares solubles ni la de almidón provocada por la eliminación de frutos, presentan relación con la intensidad de floración, y solamente un desajuste en el metabolismo del nitrógeno se ha relacionado con ello. La similitud temporal y de acción de la época a partir de la cual la presencia del fruto reduce la floración siguiente, de la presencia de elevadas concentraciones de giberelinas endógenas en el floema próximo a las yemas que no desarrollan flores, y de la aplicación exógena de $\mathrm{GA}_{3}$ para reducir la floración, demuestra la participación de estos fitorreguladores en la acción inhibidora del fruto sobre la floración. 

Conclusiones 

1. En el naranjo dulce la intensidad de floración se halla inversamente relacionada con la fructificación precedente según una curva exponencial. Los límites $X$ e $Y$ de esta curva son variables con los años y dependen, por tanto, del porcentaje de cuajado.

2. El fruto inhibe la floración siguiente a partir de etapas próximas a completar su tamaño. La reducción en el número de flores es, aproximadamente, paralela a la reducción de la brotación sin que el número de hojas y/o flores por brote sea alterado, lo que indica que el fruto no altera el número de flores por yema brotada sino el número de yemas que brotan.

3. El transporte de las giberelinas $G_{1}$ y $G_{4}$ desde el fruto, medido por la concentración en el floema de su pedúnculo, aumenta a medida que avanza el crecimiento del fruto, lo que podría explicar la acción inhibidora de éste sobre la brotación/floración de las yemas situadas en el mismo brote que lo sustenta.

4. La aplicación de los inhibidores de la síntesis de giberelinas, paclobutrazol y prohexadione-Ca, entre mediados de septiembre y mediados de noviembre, aumenta significativamente la intensidad de floración. Su acción, sin embargo, queda anulada por la presencia del fruto. Este tipo de respuesta se ha mostrado general en todas las especies y cultivares de cítricos ensayados.

5. No se ha encontrado ninguna relación entre la variación en la intensidad de floración provocada por el tiempo de permanencia del fruto en el árbol o por la aplicación de inhibidores de la síntesis de giberelinas y la concentración foliar de carbohidratos. Solamente un desajuste en el metabolismo del $\mathrm{N}$ se ha relacionado con ello. 

Referencias bibliográficas 

Agustí M.1980. Biología y control de la floración en el género Citrus. PhD Thesis. Universidad Politécnica de Valencia. España.

Agustí, M. 2003. Citricultura. Ediciones Mundiprensa. 2da. Edición. España.

Agustí M and Almela V. 1984. Mejora de la calidad del fruto de la mandarina 'Satsuma'. Bco. de Santander, ISBN: 84-394-1798-3.

Agustí M and Almela V. 1991. Aplicación de fitorreguladores en Citricultura. Ed. AEDOS, p. 261.

Agustí M, Almela V and Pons J. 1992. Effects of girdling on alternate bearing in Citrus. Journal of Horticultural Science, 67: 203-210.

Agustí M, Zaragoza S, Bleiholder H, Buhr L, Hack H, Klose R and Stauss R. 1997. Adaptation of the BBCH scale for the description of Citrus fruits' phenological stages. Fruits, Paris 52(5): 287-295.

Albrigo L G and Saúco V G. 2004. Flower bud induction, flowering and fruit-set of some tropical and subtropical fruit tree crops with special reference to citrus. Acta Horticulturae 632, ISHS: 81-90.

Ali A G and Lovatt C J. 1995. Relationship of polyamines to low-temperature stress-induced flowering of the 'Washington' navel orange (Citrus sinensis L. Osbeck). Journal of Horticultural Science 70 (3): 491-498.

Amasino R M. 2005. Vernalization and flowering time. Current Opinion in Biotechnology, 16: 154-158.

Arias M. 1999. Cuantificación y evolución de poliaminas en los cítricos. Comparación de especies con diferente comportamiento reproductivo. Tesis Doctoral. Universidad Politécnica, España.

Ayalon S and Monselise S P. 1960. Flower bud induction and differentiation in the Shamouti orange. Proceedings of the American Society of Horticultural Science, 75: 216-221.

Badr S A and Hartman H T. 1972. Flowering response of the olive (Olea europaea L.) to certain growth regulators applied under inductive and non inductive environments. Botanical Gazette 133 (4): 387-392.

Basak A and Rademacher W. 2000. Growth regulation of pome and stone fruit trees by use of prohexadione-Ca. Acta Horticulturae. 514: 41-50.

Becerra S and Guardiola J L. 1984. Inter-relationship between flowering and fruiting in sweet orange, cultivar Navelina. $5^{\text {th }}$ Proc. Int. Citrus Congr.: Paulo, Brazil, 1: 190-194.

Ben-Tal Y and Lavee S. 1984. Girdling olive trees, a partial solution to biennial bearing. Influence of consecutive mechanical girdling on flowering and yield. Riv. Ortoflorofruttic. It. 68: 441-451.

Ben-Tal Y and Lavee S. 1985. Girdling olive trees, a partial solution to biennial bearing. Chemical girdling: its influence on flowering and yield. Riv. Ortoflorofruttic. It. 69: 1-11.

Ben-Yaakov A, Zilberstaine M and Sela I. 1991. A plan for narional fruit and nut germoplasm repositories in avocado. HortScience 12: 298-300. 
Betancourt M, Martínez-Fuentes A, García M.E, Mesejo C, Sánchez CD, Nuñez M Reig C and Agustí M. 2008. The influence of fruit load on flowering intensity of grapefruit (Citrus paradisi Macf.) under tropical climatic conditions. 2008 ISC Congress, Abstract P249.

Bhandwalkar S M and Desai U T. 1995. Pollination and fruit set studies in mango cv. Kesar. Recent Horticulturae 2 (2): 1-3.

Buban T and Faust M. 1982. Internal control and differentation of flower bud induction in Apple tres. P 174203. J Janick (Ed.). Horticultural reviews, vol. 4. AVI Publishing, Westport, Conn.

Callejas R and Bangerth F. 1997. Is auxin export in apple fruit an alternative signal for inhibition of flower bud induction?. Acta Horticulturae. 463:271-277.

Cassin J, Bourdeaut J, Fougue A, Furon V, Gaillard JP, LesBourdelles J, Montagut and Moureil C. 1969. The influence of climate upon blooming of citrus in tropical areas. Proc. $1^{\text {st }}$ Intl. Citrus Symp.1: 315-323.

Cohen A. 1981. Recent developments in girdling of citrus trees. Proc. Int. Soc. Citriculture, 1: 196-199.

Couranjou J. 1970. Recherches sur les causes génétiques de l'alternance du prunier domestique (Prunus domestica L.) I. Mise en evidence de deux charactères de productivité comme facteurs d'alternance. Plantes 20: 297-318.

Couranjou J. 1978. Recherches sur les causes génétiques de l'alternace du prunier domestique (Prunus domestica L.) II. Effect de la charge en fruits d'une partie d l'arbre sur l'induction florale dans le reste de l'arbre dépourvu de fruits; niveau d'autonomie entre les deux parties selon les cultivars. Physiologie végétale 16: $505-520$.

Crane J C, Al-Shalan I and Carlson R M. 1973. Abscission of pistachio inflorescence buds as affected by leaf area and number of nuts. Journal of the American Society for Horticultural Science. 98: 591-592.

Crane J C, Catlin P B and Al-Shalan I. 1976. Carbohydrates levels in the pistachio as related to alternate bearing. Journal of the American Society for Horticultural Science. 101: 371-374.

Crane J C and Forde H I. 1976. Effects of four rootstocks on yield and quality of pistachio nuts. HortScience 6: 489-490.

Crane JC and Nelson M M. 1971. The unusual mechanism of alternate bearing in pistachio. HortScience 6: 489-490.

Cutting J G M and Lyne M C. 1993. Girdling and the reduction in shoot xylem sap concentrations of cytokinins and gibberellins in peach. Journal of Horticultural Science, 68: 619-626.

Chan B C and Cain J C. 1967. The effect of seed formation on subsequent flowering in apple. Proc American Society for Horticultural Science. 91: 63-67. 
Chandler W H. 1950. Evergreen orchards. Henry kimpton, London.

Chiwocha S D S, Abrams S R, Ambrose S J, Cutler A J, Loewen M, Ross A R S and Kermode A R. 2003. A method for profiling classes for plant hormones and their metabolites using liquid chromatographyelectrospray ionization tandem mass spectrometry: and analysis of hormones regulation of thermodormancy of lettuce (Lactuca sativa L.) seeds. The Plant Journal, 35: 405-417.

Dann I R, Jerie P H and Chalmers D J. 1985. Short-term changes in cambial growth and endogenous IAA concentrations in relation to phloem girdling of peach Prunus persica. Australian Journal of Plant Physiology, $12: 395-402$

Davenport T L. 1983. Daminozide and gibberellins effects on floral induction of Citrus latifolia. HortScience 18: 947-949.

Davenport T L. 1990. Citrus flowering. Horticultural Review, 12: 349-408.

Davies L D. 1957. Flowering and alternate bearing. Proceedings of the American Society of Horticultural Science, 70: 545-556.

Davies FS and Albrigo LG. 1994. Citrus. CAB Intl., UK.

Davis J T and Sparks D. 1974. Assimilation and translocation patterns of carbon 14 in the shoot of fruiting pecan trees Carya illinoensis Koch. Journal of the American Society for Horticultural Science. 99: 468-480.

Deidda P and Agabbio M. 1978. Some factors influencing flowering and fruit-set of clementine mandarin. Studi sassaresi. Sezione III 1977 (pub. 1978). v. 25 (pt.3) 25

Delgado P, Casamayor R, Rodriguez J O, Cruz P y Fajardo R. 1986a. Paclobutrazol effects on oranges under tropical conditions. Acta Horticulturae 179: 537-544.

Delgado P, Casamayor R, Rodriguez J O, Cruz P y Fajardo R. 1986b. Paclobutrazol effects on mandarin under tropical conditions. Acta Horticulturae 179: 545-548.

Dennis F G Jr, and J C Nielsen. 1999. Physiological factors affecting biennial bearing in tree fruit: The role of seeds in apple. HortTechnology 9(3):317-322.

Eaton G N. 1978. Floral induction and biennial bearing in the cranberry. Fruit Varieties Journal 32: 58-60.

Ebert A and Bangerth F. 1981. Relations between the concentration of diffusible behavior in apple as affected by chemical fruit thinning. Scientia Horticulturae. 15: 45-52.

El-Otmani M, Coggins C H W, Agusti M and Lovatt CG, 2000. Plant Growth Regulators in Citriculture. World Current Uses. Critical Reviews in Plant Sciences 19: 395-447. 
El-Otmani M, Goumari M, Srairi I, Lbrek A, Charif L and Lovatt C J. 2004. Heavy fruit load and late harvest inhibit flowering of the 'Nour' Clementine mandarin. Proceedings of the International Society of Citriculture 2: 525-527.

El-Otmani M, Lovatt C J, Coggins C W Jr and Agustí M. 1995. Plant growth regulators in citriculture: Factors regulators endogenous levels in citrus tissues. Critical Reviews in Plant Sciences. 14: 367-412.

El-Zeftawi B. M. and Lorton L. R. 1975. Effects of rootstocks and fruit stripping on alternate bearing of Valencia oranges trees. The journal of Horticultural Science. 50: 219-226.

Endo T, Shimada T, Fujii H, Kobayashi Y, Araki T, Omura M. 2005. Ectopic expression of an FT homolog from Citrus confers an early flowering phenotype on trifoliate orange (Poncirus trifoliate L. Raf). Transgenic Research, 14: 703-712.

Epstein E. 1981. Concentration of free and bound indole-3-acetic acid in leaves of fruiting and barren olives and mandarins. Plant Physiology supplement 67: 18.

Erner Y. 1988. Effects of girdling on the differentiation of inflorescence types and fruit set in 'Shamouti' orange trees. Israel Journal of Botany 37: 173-80.

Erner Y, Goren R and Monselise S P. 1976. The rough fruit condition of the 'Shamouti'orange-connections with the endogenous hormonal balance. Journal of Horticultural Science 51: 367-374.

Evans R R, Evans J R and Rademacher W. 1997. Prohexadione calcium for suppression of vegetative growth in eastern apples. Acta Horticulturae., 451: 663-666.

Fatta del Bosco. 1961. Indagini sull'epoca di differenziazione delle gemme nel nespolo del giappone. Rivista dell'Ortofrutticoltura Italiana vol. XLV (2): 104-118.

Fisher D V. 1951. Time of blossom bud induction in apricots. Proccedings of the American Society for Horticultural Science 58: 19-22.

Fucik J. F. 1977. Hedging and topping in Texas grapefruits orchards. Proccedings of the International Society of Citriculture 1: 171-176.

Furr and Armstrong 1956. Flower induction in Marsh grapefruit in the Coachella Valley. California. Proccedings of the American Society for Horticultural Science 67: 176-182.

Galliani S, Monselise S P and Goren R. 1975. Improving fruit size and breaking alternate bearing in Wilking mandarins by ethephon and other agents. Hortscience 10 (1) 1, p. 68-69

Gambetta G. 2009. Control endógeno y exógeno de la maduración externa de los frutos cítricos. PhD Thesis. Universidad Politécnica de Valencia. 
García-Luís A, Almela V, Monerri C, Agustí M and Guardiola J L. 1986. Inhibition of flowering in vivo by existing fruits and applied growth regulators in Citrus unshiu. Physiologia Plantarum 66: 515-520.

García-Luis A, Agustí M, Almela V, Romero E and Guardiola J L. 1985. Effect of gibberellic acid on ripening and peel puffing in 'Satsuma' mandarin. Scientia Horticulturae 27:75-86.

García-Luís A, Fornes F, Sanz A and Guardiola J L. 1988. The regulation of flowering and fruit set in Citrus: relationship with carbohydrate levels. Israel Journal of Botany 37: 189-201.

García-Luís A, Fornes F, Sanz A and Guardiola J L. 1995. Leaf carbohydrates and flower formation in Citrus. Journal of the American Society for Horticultural Science 120(2): 222-227.

García-Luís A and Guardiola J L. 2000. Influence of citrus internal factors and climatic effects on flowering. Proccedings of the International Society of Citriculture IX Congr. 2000: 292-295.

Gardner V T. 1966. Principles of horticultural production. Michigan State Univ. Press, East Lansing.

Goldschmidt E E . 1984. Endogenous abscisic acid and 2-trans abscisic acid in alternate bearing "Wilking" mandarin trees. Plant Growth Regulation $2: 9-13$

Goldschmidt E E. 1999. Carbohydrate supply as a critical factor for citrus fruit development and productivity. HortScience, v.34(6): 1020-1024.

Goldschmidt E E. 2005. Regulazione dell'alternanza di produzione negli alberi da fruto. Italus Hortus 12(1): $11-17$.

Goldschmidt E E and Golomb A. 1982. The carbohydrate balance of alternate-bearing citrus trees and the significance of reserves for flowering and fruiting. Journal of the American Society for Horticultural Science 107(2): 206-208.

Goldschmidt E E and Monselise S P. 1970. Hormonal control of flowering in citrus and some other woody perennials. International Conference of Plant Growth Substances (7th: 1970: Canberra) Plant Growth Substances, 1970. Berlin, Springer Verlag: 758-766.

Goldschmidt E E. and Monselise S P. 1972. Hormonal control of flowering in citrus and some other woody perenials. In: Carr, D. J. (ed.) Plant growth Substances 1970, Springer-Verdag, New York, pp. 758-766.

Goldschmidt E E, Aschkenazi N, Herzano Y, Schaffer A A and Monselise S P. 1985. A role for carbohydrate levels in the control of flowering in citrus. Scientia Horticulturae 26: 159-166.

Goldschmidt E E, Chun-Yao Li and Weiss D. 2003. Girdling affects carbohydrate-related gene expression in leaves, bark and roots of alternate-bearing citrus trees. Annals of Botany 92: 219-221.

Goldschmidt E E and Samach A. 2004. Aspects of flowering in fruit trees. Acta Horticulturae 653: 23-27. 
Goldschmidt E E, Tamim M and Goren R. 1997. Gibberellins and flowering in citrus and other fruit trees: A critical analysis. Acta Horticulturae, 463: 201-208.

Golomb A and Goldschmid E E. 1981. Mineral balance of alternate bearing 'Wilking' mandarins . Alon Hanotea, 35: 639-647.

Gonzalez-Rossia D, Juan M, Reig C and Agusti M. 2006. The inhibition of flowering by means of gibberellic acid application reduces the cost of hand thinning in Japanese plums (Prunus salicina Lindl.). Scientia Horticulturae 110(4): 319-323.

Gonzalez-Rossia D, Reig C, Juan M and Agusti M. 2007. Horticultural factors regulating effectiveness of GA3 inhibiting flowering in peaches and nectarines (Prunus persica L. Batsch). Scientia Horticulturae 111(4):352-357.

Gonzalez-Rossia D, Reig C, Dovis V, Gariglio N and Agusti M. 2008. Changes on carbohydrates and nitrogen content in the bark tissues induced by artificial chilling and its relationship with dormancy bud break in Prunus sp. Scientia Horticulturae 118 (4): 275-281.

Goren R and Goldschmidt E E. 1970. Regulative system in the developing citrus fruit. I. The hormonal balance in orange fruit tissues. Physiologia Plantarum 23: 937-947.

Goren R and Monselise S P. 1969. Promotion of flower formation and fruit set in citrus by antimetabolites of nucleic-acid and protein synthesis. Planta 88(4): 364

Goren R and Monselise S P. 1971. Effects of ringing on yields of low-bearing orange trees (Citrus sinensis (L.) Osbeck). The hournal of Horticultural Science Oct 1971, 46 (4) 4, p. 435-441.

Gravina A. 1999. Ciclo fenológico-reproductivo en Citrus. Bases fisiológicas y manejo. Universidad de la República. Facultad de Agronomía. 55 p.

Grochowska M J.1964. Identification of the growth inhibitor connected with flower bud formation in apple. Bulletin de l'Academie Polonaise desd Sciences, Biologie 12: 379-383.

Grochowska M J. 1968. Translocation of indole-acetic acid-2 $-{ }^{14} \mathrm{C}$ injected into seeds of five week old apple fruits. Bulletin de l'Academie Polonaise desd Sciences, Biologie 16: 577-580.

Guardiola J L, Agustí M and García-Marí F. 1977. Gibberellic acid and flower bud development in sweet orange. Proccedings of the International Society of Citriculture, 2: 696-699.

Guardiola J L, Monerri C and Agustí M. 1982. The inhibitory effect of gibberellic acid on flowering in citrus. Physiologie Plantarum 55: 136-142.

Gur A. 1976. Responses of apple-trees to various kinds of root stress. Israel Journal of Botany 25 (1-2): 100. 
Gur A, Samish R M and Zamet D. 1969. A comparison of different planting distances for apple trees. Israel Journal of Agricultural Research 19: 79-86.

Hackett W P and Hartmann H T. 1964. Infloresce formation in olive as influenced by low temperature, photoperiod, and leaf area. Botanical Gazette. 125: 65-72.

Hamada K, Ogata T, Fujiwara S y Hasegawa K. 2009. Healing process of the wounds of the branches of the Japanese persimmon that were caused by girdling, scoring and stangulation. Scientia Horticulturae 120 : 276-281

Harley C P, Masure M P and Magness J R. 1932. Effect of leaf area, nitrate of soda and soil moisture on fruit bud formation in the 'Delicious'apple. Proccedings of the American Society of Horticultural Science 29: 193-198.

Harris M J and Dugger W M. 1986. Levels of free and conjugated abscisic acid in developing floral organs of te navel orange (Citrus sinensis (L.) Osbeck cv. Washington). Plant Physiology 82(4): 1164 -1166.

Harty A R and van Staden J. 1988a. The use of growth retardants in citriculture. Israel Journal of Botany 37 : $155-164$.

Harty A R and van Staden J. 1988b. Paclobutrazol and temperature effects on lemon. Proccedings. $6^{\text {th }}$ Int. Citrus Congress 1: 343-353.

Henderson I R and Dean C. 2004. Control of Arabidopsis flowering: the chill before the bloom. Development, 131: 3829-3838.

Henry M J. 1985 Plant growth regulating activity of sterol and gibberellin biosynthesis inhibitors. Bull Plant Growth Regut Soc Am 13:9-11

Hield H Z. 1969. Orange fruit removal. Agrichem West 12 (7):5-8.

Hoad G V. 1978. The role of seed derived hormones in the control of flowering in apple. Acta Horticulturae. 80: 93-103.

Huet J. 1972. Etude des effects des feuilles et des fruits sur l'induction florale des brachyblastes du Poirier. Physiologie Vegetale 10:529-545.

Iwahori S. 1978. Use of growth regulators in the control of cropping of mandarin varieties. Proccedings of the International Society of Citriculture: 263-270.

Iwahori S. 1986. Increase in first-flush flowering of 'Meiwa' kumquat, Fortunella crassifolia Swingle, trees by paclobutrazol. Scientia horticulturae. May 1986. v. 28 (4) p. 347-353. 
Iwahori S and Oohata J T. 1981. Control of flowering of satsuma mandarins (Citrus unshiu Marc.) with Gibberellin. Proceedings of the International Society of Citriculture / [International Citrus Congress, November 9-12, 1981, Tokyo, Japan ; K. Matsumoto, editor] p. 247-249. ill.

Iwahori S y Tominaga S. 1986. Increase in first-flush flowering if 'Meiwa' kumquat, Fortunella carssifolia Swingle, trees by Paclobutrazol. Scientia Horticulturae vol 86: 347-353.

Iwasaki T, Shichijo T and Iba Y. 1962. Studies on the control of altérnate bearing in citrus. VI. An investigation on thinning materials for 'Satsuma' orange. Journal Japan Society Horticultural Science 31: 1-12.

Jones W W, Coggins C W and Embleton T W. 1976. Endogenous abscisic acid in relation to bud growth in alternate bearing 'Valencia' orange. Plant Physiology 58(5):681-682.

Jones W W, Embleton T W and Coggins C W. 1975. Starch content of roots of 'Kinnow' mandarin trees bearing fruits in alternate years. Hortscience 10: 514.

Jonkers H. 1979. Biennial bearing in apple and pear: a literature survey. Science Horticulturae-Amsterdam 11: 303-317.

Kachru R B, Singh R N and Chako E K. 1971. Inhibition of flowering in mango (Magnifera indica L.) by gibberellic acid. HortScience 6: 140-141.

Kessler B, Bak R and Cohen A. 1959. Flowering in fruit trees and annual plants as affected by purines, pyrimidines and triiodobenzoic acid. Plant Physiology 34: 605-608.

Koornneef M, Hanhart C J. and Van der Veen J H. 1991. A genetic and physiological analysis of late flowering mutants in Arabidopsis thaliana. Molecular and General Genetics, 229: 57-66

Koshita Y, Takahara T, Ogata T and Goto A. 1999. Involvement of endogenous plant hormones (IAA, ABA, GAs) in leaves and flower bud formation of 'Satsuma' mandarin (Citrus unshiu Marc.) Science Horticulturae 79:185-194.

Krajewski A J and Rabe E. 1995. Citrus flowering: a critical evaluation. Journal of Horticultural Science 70(3): 357-74.

Lahav E B, Gefen B and Zamet D. 1971. The effect of girdling on the productivity of the avocado. Journal American Society for Horticultural Science 96: 396-398.

Lang A. 1965. Physiology of flower initiation, in Handbunch der pflanzenphysiologie XV/1 ed. Ruhland W Sprieger Verlag, Berlin Germany, pp. 1380-1586.

Lavee S. 1996. Biology and Physiology of the olive In: World Olive Encyclopaedia. Plaza and Janes Editores. Barcelona: 61-105.

Lavee S, Haskal A and Ben-Tal Y. 1983. Girdling olive trees, a partial solution to biennial bearing. Methods, timing and direct tree response. Journal Horticultural Science 58: 209-218. 
Lavee S, Melamud H Ziv M and Bernstein Z. 1981. Necrosis in grapevine buds (Vitis vinifera cv. Queen of Vineyard). Relation to vegetative vigor. Vitis 20: 8-14.

Lenz F and Karnatz A. 1975. The effect of $\mathrm{GA}_{3}$, Alar and CCC on citrus cuttings. Acta-Horticlturae July, 49: 147-155.

Looney N E, Pharis R P and Noma M. 1985. Promotion of flowering in apple trees with Gibberellin and C-3 epi-gibberellin A4. Planta 165: 292-294.

Lovatt C J, Zheng Y and Hake K D. 1988a. Demonstration of a Change in Nitrogen Metabolism Influencing Flower Initiation in Citrus. Israel Journal of Botany 37: 181-188.

Lovatt C J, Zheng Y and Hake KD. 1988b. A new look at the Kraus-Kraybill hypothesis and flowering in Citrus. Proceedings of the 6th International Citrus Congress 1: 475-483.

Luckwill L C. 1957. Studies of fruit development in relation to plant hormones. IV Acidic auxins and growth inhibitors in leaves and fruits of the apple. Journal of Horticultural Science 32: 18-33.

Luckwill L C. 1970. The control of growth and fruitfulness of apple trees. P. 237-254. In L. C. Luckwill and C. V. Cuttings (eds.). The Physiology of Tree Crops. Academic Press, New York.

Luckwill L C. 1974. A new look at the process of fruit bud formation in apple. XIX Intern. Hort. Cong., Warsaw 3: 237-245.

Martínez-Fuentes A, Mesejo C, Juan M, Almela V and Agustí M. 2004. Restrictions on the exogenous control of flowering in citrus. Acta Horticulturae (ISHS) 632: 91-98.

Maquieira A, Climent M D, Puchades R and Primo-Yúfera E. 1984. Fertilization of orange trees with sulfurcoated urea. Nitrogen levels in leaves and fruits. Plant and Soil, 80: 247-254.

Mehouachi J, Serna D, Zaragoza S, Agustí M, Talón M and Primo-Millo, E. 1995. Defoliation Increases fruit abscision and reduces carbohydrate levels in developing fruits and woody tissues of Citrus unshiu. Plant Science 107: 189-197.

Michaels S D, Himelblau E, Kim S Y, Schomburg F M. and Amasino R M. 2005. Integration of flowering signals in winter-annual Arabidopsis. Plant Physiology 137: 149-156

Monselise S P. 1979. The use of growth regulators in citriculture, a review. Scientia Horticulturae 11: 151162.

Monselise S P, Goren R and Halevy A H. 1966. Effects of B Nine, cycocel and benzothiazole oxycetate on flower bud induction of lemon trees. Proccedings of the American Society of Horticultural Science 89:195200.

Monselise S P and Goldshmindt E E. 1982. Alternating bearing in fruit trees. Horticultural reviews, 4, 12873. 
Monselise S P, Goldschmidt E E and Golomb A. 1981. Alternate bearing in citrus and ways of control. Proc. Int. Soc. Citriculture, 1: 232-242.

Monselise S P and Goren R. 1969. Flowering and fruiting interactions of exogenous and internal factors. Proccedings 1st. Interantional Citrus Symp. 3: 1105-1112.

Monselise S P and Goren R. 1984. Control of citrus tree size by growth regulators- Past attemps and recent breakthrogh. Proccedings Interantional Society Citriculture. 1: 271-275.

Monselise S P, Goren R and Halevy A H. 1966. Effects of B-nine, cycocel and benzothiazole oxyacetate on lower bud induction of lemon tres. Proccedings of the American Society Horticulture 89: 195-200.

Monselise S P and Halevy A H. 1964. Chemical inhibition and promotion of citrus flower bud induction. Proccedings of the American Society Horticulture Sci 84: 141-146.

Morettini A 1950. Olivicultura. Edit. Agricoltori, Roma.

Moss G I. 1969. Influence of temperature and photoperiod on flower induction and inflorescence development in sweet orange [Citrus sinensis (L.) Osbeck]. Journal of Horticultural Science 44: 311-320.

Moss G I. 1970. Chemical control of flower development in sweet orange (Citrus sinensis L. Osbeck) Journal of Horticultural Science 44: 311-320.

Moss G I. 1971.The effect of fruit on flowering in relation to biennal bearing in sweet orange

(Citrus sinensis). Journal of Horticultural Science 46: 177-184.

Moss G I. 1974. Influence of temperature during flower development on subsequent fruit-set of seet orange (Citrus sinensis). Horticultural Research 13 (2): 65-73.

Moss G I and Bellamy J. 1973. The use of gibberellic acid to control flowering of sweet orange. Acta Horticulturae 34(1): 207-212.

Moss G I, Bevington K B, Gallasch P T, El-Zeftawi B M. 1981. Alternate croping of Valencia oranges. Scientia Bulletin-New South Wales. Sept 88: 27.

Moss G I, Bevington K B, Gallasch P T, El-Zeftawi B M, Thornton I R, Bacon P and Freeman B. 1977. Methods to control alternate cropping of 'Valencia' orange trees in Australia. International Citrus Congress, Florida USA, 2: 704-708.

Mullins M G. 1980. Plantlets from cultured anthers of VItis species and hybrids. Proceeding of the Third International Symposium on Grape Breeding, p: 111-119.

Mullins M G and Rajasekaran K. 1981. Fruiting cuttings: revised method for producing test plants of grapevine cultivars. American Journal of Enology and Viticulture 32(1): 35-40. 
Nielsen J C and Dennis F G Jr. 1998. Effects of seed number, fruit removal, bourse shoot length and crop density on flowering in 'Spencer Seedless' apple. Acta Horticulturae. 527: 137-146.

Nir I, Goren R and Leshem B. 1972. Effects of water stress, gibberellic acid, and 2chloroethyltrimethylammoniumchloride (CCC) of flower differentiation in 'Eureka' lemon trees. Journal American Society Horticultural Science 97: 774-778.

Nishikawa F, Endo T, Shimada T, Fujii H, Shimizu T, Omura M, Ikoma Y. 2007. Increased CiFT abundance in the stem correlates with floral induction by low temperature in Satsuma mandarin (Citrus unshiu Marc.). Journal of Experimental Botany, 246: 1-13.

Normand F and Habib R. 2001. Phenology of strawberry guava (Psidium cattleianum) in Réunio Island. The journal of Horticultural Science and Biotechnology 76 (5): 541-545.

Ojima M. 1985. Alternate bearing in persimmon cv 'Pomelo'. Bragantia 44(1): 481-486.

Okuda H. 2000. A comparison of IAA and ABA levels in leaves and roots of two citrus cultivars with different degrees of alternate bearing. Journal of Horticultural Science and Biotechnology 75(3): 355-359.

Okuda H, Kihara T, Noda K and Hirabayashi T. 2002a Systemized alternate bearing method for mature Satsuma mandarin trees. Bull Natl Inst Fruit Tree Sci 1: 61-69.

Okuda H, Noda K, Kihara T and Hirabayashi T. 2002b. Fine root volume, flowering, sprouting and carbohydrate content in the leaves and roots of bearing and non-bearing Satsuma mandarin trees in a systemized alternate-bearing orchard. J Jpn Soc Hortic Sci 71: 588-590.

Olszack R. 1986. Current status of Lychees and Longans in South Florida. Proc. Flo. State Hort. Soc. 99: 219-221.

Owens C L. y E. Stover. 1999. Vegetative growth and flowering of young apple trees in response to prohexadione-calcium. HortScience, 34: 1194-1196

Peña L, Martin-Trillo M, Juarez J, Pina J.A, Navarro L, Martinez-Zapater J M. 2001. Constitutive expression of Arabidopsis LEAFY or APETALA 1 genes in Citrus reduces their generation time. Nature Biotechnology 19: 263-267

Pharis R D and King R W. 1985. Gibberellins and reproductive development in seed plants. Ann. Rev. Plant Physiol. 36:517-568

Pillary A E, Willians J R, El Mardi M O, Hassan S M and AL-Hamdi A. 2005. Boron and the alternate bearing phenomenon in the date palm (Phoenix dactylifera). Journal of arid environments 62: 199-207.

Pilliteri L J, Lovatt C J, Walling L L. 2004. Isolation and characterization of TERMINAL FLOWER homolog and its correlation with juvenility in Citrus. Plant Physiology., 135: 1540-1551. 
Plummer J A, Mullins M G and Vine J J. 1989. The role of endogenous hormones in shoot emergence and abscission in alternate bearing Valencia oranges trees. Acta Horticulturae 239: 341-344.

Poerwanto R and Inoue H. 1990. Effects of air and soil temperatures on flower development and morphology of satsuma mandarin. Journal Horticultural Science 65: 739-745.

Potter G F, Sitton B J and McCann L P. 1947. The effect of different rates of application of nitrogen in biennial bearing in tung. Proccedings of the American Society Horticultural Science 50: 125-130.

Rademacher W. 2000. Growth retardants: effects on gibberellin biosynthesis and other metabolic pathways. Annu. Rev. Plant Physiol. Plant Mol. Biol., 51: 501-531.

Raigón M D, Pérez-García M, Maquieira A and Puchades R.1992. Determination of available nitrogen (nitric and ammoniacal) in soils by flow injection analysis. Analisis, 20: 483-487.

Reece P C, Furr J R and Cooper W C. 1949. Further studies of floral induction in the 'Haden'mango (Magnifera indica L.) American Journal of Botany 36: 734-740.

Reig C, Gonzalez-Rossia D, Juan M and Agusti M. 2006. Effects of fruit load on flower bud initiation and development in peach. Journal of horticultural science \& biotechnology 81, no. 6 p. 1079-1085.

Reuther W. 1973. Climate and citrus behavior. En: The citrus industry, Vol. III, W. Reuther (Ed.), Univ. California, Div. Agricultural Science, Berkeley, USA, pp 280-337.

Reuther W, Nuer E M and Summers L. 1973. Effects of seasonal temperature of regimes on development and maturation of citrus fruits. Proccedings of the International Society of Citriculture 3: 63-71.

Rivas F, Fraschini C, Lanfraco M, Borges A, Espino M and Gravina A. 2004. Characterization and improvement of potential productivity of 'Nova' mandarin in Uruguay. Proccedings of the International Society of Citriculture. X Congr. In press.

Rivas F, Gravina A, Agusti M. 2007. Girdling effects on fruit set and quantum yield efficiency of PSII in two Citrus cultivars. Tree Physiology 27:527-535.

Rosecrance RC, Weinbaum S A and Brown P H. 1998. Alternate bearing affects nitrogen, phosphorus, potassium and starch storage pools in mature pistachio trees. Annals of Botany 82:463-470.

Sagee O and Lovatt C J. 1991. Putrescine content parallels ammonia and arginine metabolism in developing flowers of 'Washington' navel orange. Journal American Society of Horticultural Science 116: 280-285.

Saidha T., Goldschmidt E. E. and Monselise S. P. 1983. Endogeneous growth regulators in tracheal sap of citrus. HortScience 18: 231-232.

Salomon E. 1988. Effect of paclobutrazol and gibberellic acid (GA3) on the root growth and biomass partitioning of citrus leaf cuttings. Israel journal of botany v. 37 (2/4) 37, 2/4, p. 165-172. ill. 
Sanchez-Capuchino J A, Casanova R., 1973. Induccion floral en mandarinos Clementina sin hueso y Satsuma. First International Congress Citriculture 2, 223-225.

Singh R N. 1971. Biennial bearing in fruit tres- accent on apple and mango. Ind. Counc. Agr. Res. Bul. 30.

Singh L and Khan A A. 1940. Forcing mango to bear regulary. Indian Farming 1: 380-383.

Southwick S M and Davenport T L. 1986. Characterization of water stress and low temperature effects on flower induction in citrus. Plant Physiology 81(1): 26-29.

Sparks D. 1975. The alternate fruit bearing problem in pecans. $65^{\text {th }}$ Annu. Proc. Nortern Nut Growers Assoc. p: $145-158$.

Spiegel-Roy R P and Goldschmidt E E. 1996. Biology of citrus. Biology of horticultural crops. Cambridge; New York. Cambridge University Press.

Stewart I, Wheaton T A and Reese R L. 1968. 'Murcott' collapse due to nutritional deficiencies. Proc. Fla. State Hort. Soc. 81: 15-18.

Stutte C W and Martin G C. 1986. Effect of light intensity and carbohydrate reserves on flowering in olive. Journal of the American Society for Horticultural Science 111: 27-31.

Talon M, Mehouachi J, Iglesias DJ, Tadeo FR, Agusti M and Primo-Millo E . 2000. The role of leaves in citrus fruitlet abscission: Effects on endogenous gibberellin levels and carbohydrate content. Journal of Horticultural Science and Biotechnology 75 (1): 79-85.

Tamim M, Altman A, Goren R and Goldschmindt E E. 1996. Modification of the time and intensity of flowering in Citrus cultivars by water stress, light, low temperatures and growth regulators. Proccedings International Society of Citriculture 2: 945-948.

Tanaka Y, Yamao M. and Kato H. 2004. Annual changes in concentrations of abscisic acid-glucosyl ester in Citrus fruits and leaves. Plant Cell and Physiology 45: 77.

Thompson T E and Baker J F. 1993. Heritability and phenotypic correlations of six pecan nut characteristics. Journal American Society Horticultural Science 118: 415-418.

Valiente J L and Albrigo L G. 2000. Modeling flowering date of sweet orange [Citrus sinensis (L.) Osbeck] trees in Central Florida based on historical weather records. Proccedings of the International Society Citriculture IX Congr., 1: 186-190.

Valiente $\mathbf{J}$ L and Albrigo L G. 2004. Flower bud induction of sweet orange tres (Citrus sinensis (L.) Osbeck): effect of low temperatures, crop load, and bud age. Journal American Society Horticultural Science 129(2): 158-164.

Verreynne JS and Lovatt C J. 2009 The effect of crop load on budbreak influences return bloom in alternate bearing 'Pixie' mandarin. Journal American Society Horticultural Science 134: 299-307. 
Wallerstein I, Goren R and Monselise S P. 1973. Seasonal changes in giberellin-like substances of shamouti orange (Citrus sinensis (L.) Osbeck) trees in relation to ringing. Journal of Horticultural Science 48:75-82.

Wallerstein I, Goren R and Monselise S P. 1974. The effect of girdling on starch accumulation in sour orange seedings. Canadian Journal of Botany, 52: 935-937.

Wallerstein I, Goren R and Monselise S P. 1978. Rapid and slow traslocation of $14 \mathrm{C}$ assimilates in Citrus and Phaseolus with specials references to ringing effect. Journal of Horticultural Science, 53: 203-208.

West E S and Barnard C. 1935. The alternation of heavy and light crops in the 'Valencia' late orange. J. Counc. Sci. Ind. Res. Australia 10: 215-224.

Westwood M N. 1978. Temperate-zone pomology. W. H. Freeman \& Co., San Francisco.

Willians M W and Edgerton L J. 1974. Biennial bearing of apple trees. Proc. XIX Intern. Hort. Congr., Warsaw 3: 343-352.

Worley R E. 1971. Effects of defoliation date on yield, quality, nutlet set and foliage regrowth of pecan. HortScience 6: 446-447.

Yelenosky G and Guy Cl. 1977. Carbohydrate accumulation in leaves and stems of 'Valencia' orange at progressively colder temperatures. Botanical Gazette 138: 13-17.

Young R and Cooper W C . 1969. Effect of cycocel and abscicic acid on bud growth of Red Blush grapefruit . Journal American Society Horticultural Science 94 : 8-10

Yuan L and Xu D Q. 2001. Stimulation effect of gibberellic acid short-term treatment on leaf photosynthesis related to the increase in Rubisco content in broad bean and soybean. Photosynthesis Research vol 68(1): $39-47$.

Zeevart J A D. 1978. Phytohormones and flower formation. In: Phytohormones and Related Compounds: A Comprehensive Treatise, Vol. 2, D. S. Letham, P. B. Goodwin and T. J. V. Higgins (eds.) Elsevier/NorthHolland Biomedical Press, Amsterdam: 291-327. 

